\title{
Models for Reducing Deadheading through Carrier and Shipper Collaboration
}

\author{
Erin D. Bailey \\ West Virginia University
}

Follow this and additional works at: https://researchrepository.wvu.edu/etd

\section{Recommended Citation}

Bailey, Erin D., "Models for Reducing Deadheading through Carrier and Shipper Collaboration" (2011). Graduate Theses, Dissertations, and Problem Reports. 2239.

https://researchrepository.wvu.edu/etd/2239

This Thesis is protected by copyright and/or related rights. It has been brought to you by the The Research Repository @ WVU with permission from the rights-holder(s). You are free to use this Thesis in any way that is permitted by the copyright and related rights legislation that applies to your use. For other uses you must obtain permission from the rights-holder(s) directly, unless additional rights are indicated by a Creative Commons license in the record and/ or on the work itself. This Thesis has been accepted for inclusion in WVU Graduate Theses, Dissertations, and Problem Reports collection by an authorized administrator of The Research Repository @ WVU. For more information, please contact researchrepository@mail.wvu.edu. 


\title{
Models for Reducing Deadheading through Carrier and Shipper Collaboration
}

\author{
By \\ Erin D. Bailey \\ Thesis submitted to the \\ College of Engineering and Mineral Resources \\ at West Virginia University \\ in partial fulfillment of the requirements \\ for the degree of \\ Master of Science \\ in \\ Civil Engineering \\ Avinash Unnikrishnan, Ph.D., Chair \\ David R. Martinelli, Ph.D. \\ Ronald Eck, Ph.D. \\ Department of Civil and Environmental Engineering \\ Morgantown, WV \\ 2011
}

Keywords: Freight collaboration; integer programming; mixed integer programming; truck deadheading; cost allocation; cooperative game theory; tabu search 


\section{ABSTRACT \\ Models for Reducing Deadheading through Shipper and Carrier Collaboration Erin D. Bailey}

The competitive nature in the trucking industry has forced trucking firms to develop innovative solutions to improve their operational efficiency and decrease marginal costs. There is also a great need to reduce deadheading miles of heavy trucks to help reduce the amount of air pollutants they emit. One way carriers and shippers are attempting to accomplish these goals is through various collaborative operational strategies. This work focuses on developing multiple collaboration frameworks and formulating optimization models for each framework that demonstrates the operations and reveals the potential cost savings of each framework.

The first collaboration framework focuses on how a medium level shipper or carrier can introduce collaboration in their operations by fulfilling a collaborative carrier's or shipper's delivery requests on its backhaul route. Two optimization models are developed to route the carrier of interest's backhaul routes and select collaborative shipments to fulfill; one is formulated as an integer program and the other is formulated as a mixed integer program. Two solution methodologies, a greedy heuristic and tabu search, are used to solve the two problems, and numerical analysis is performed with a real world freight network. Numerical analysis on a real world freight network reveals that the percentage of cost savings for backhaul routes can be as high as $27 \%$.

The second collaboration framework focuses on a group of shippers that collaborate their operations and form cycles between their long-haul shipping lanes. If the shippers provide the bundled lanes, as loops, to a common carrier they can realize cost savings from the carrier. The problem is formulated as a mixed integer program and forms least cost loops between the shipping lanes. A tabu search heuristic is used to solve the second collaboration framework and 
results using a real freight network reveal collaborative network costs savings between $7 \%$ to $12 \%$. Three cost allocation mechanisms are proposed for the problem to distribute the costs to the shippers involved in the collaboration and computational results are provided for each of the allocation mechanisms. 


\section{ACKNOWLEDGEMENTS}

I would like to start by sincerely thanking my graduate advisor Dr. Avinash Unnikrishnan for all of the guidance, teaching, support and encouragement you have provided me throughout my graduate studies at WVU. I know you have gone above and beyond what is required of an advisor to help strengthen my knowledge and experience in transportation engineering and lead me to develop a solid foundation for a successful career. I sincerely appreciate everything you have taught me and provided me in my graduate education. I would also like to thank my other thesis committee members, Dr. David Martinelli and Dr. Ronald Eck. Thank you for the insightful comments and edits in producing this thesis.

I extend my gratitude to Dr. Dung-Ying Lin, at the National Cheng Kung University in Tainan City, Taiwan for the help provided in programming the tabu search heuristics.

I would like to thank Varunraj Valsaraj and other logistic engineers of ArrowStream Logistics for helping me obtain data and providing me guidance through discussions about the topic and the implications of the various assumptions made in the models of this thesis.

I would like to acknowledge the Federal Highway Administration's Eisenhower Graduate Fellowship program for providing funding for my graduate studies and the research to produce the thesis.

Finally, I would like to thank my family, friends, and Adam for their constant support, patience, love and encouragement, not only through my graduate studies but all of my life endeavors. 


\section{TABLE OF CONTENTS}

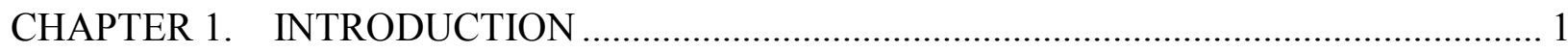

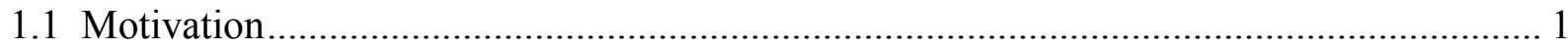

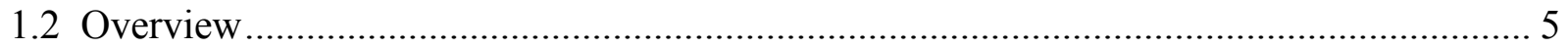

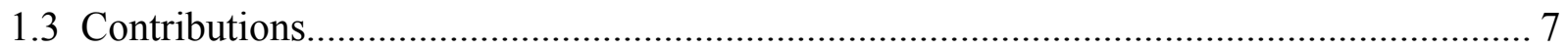

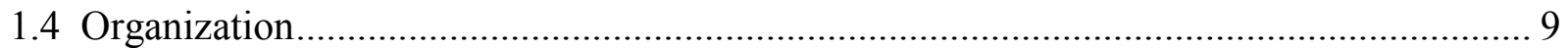

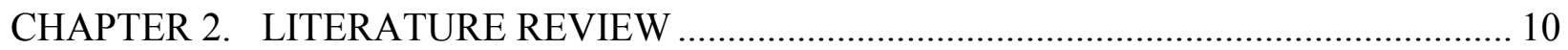

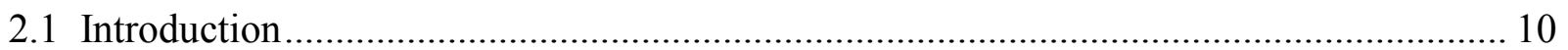

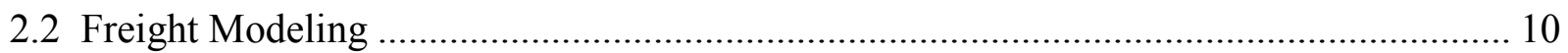

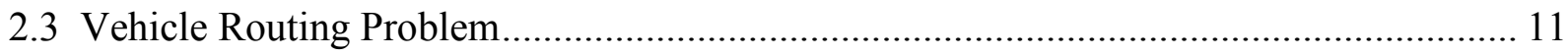

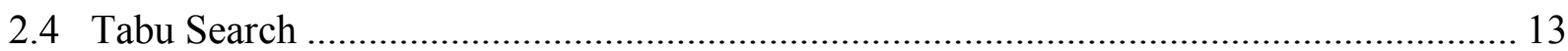

2.5 Collaborative Modeling in Truck Transportation ............................................................ 13

CHAPTER 3. PROBLEM A MODEL FORMULATIONS …..................................................... 19

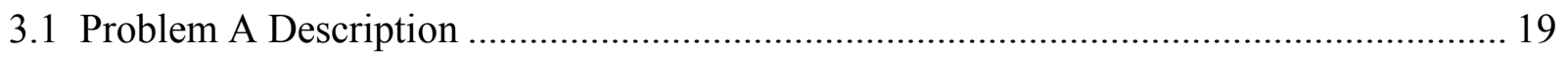

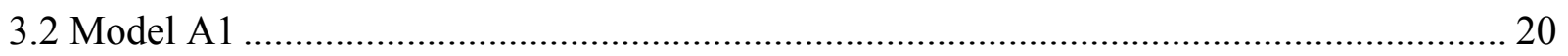

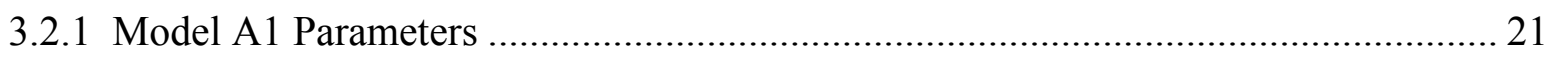

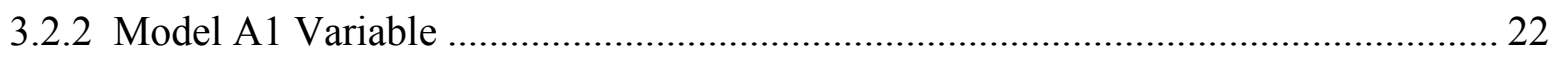

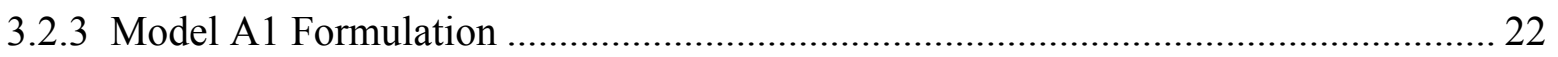

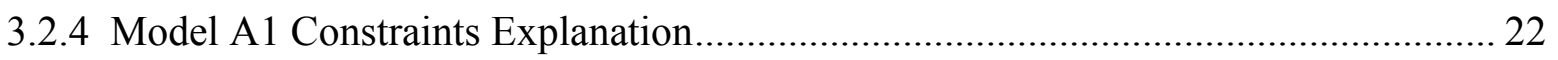

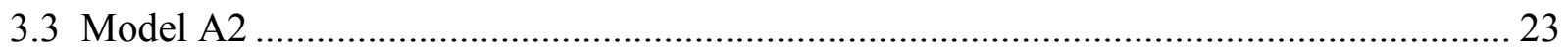

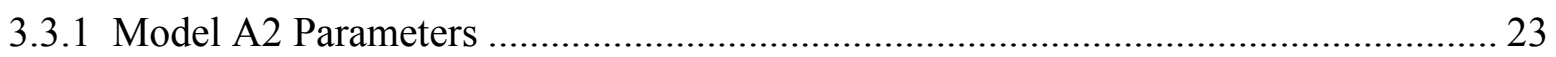

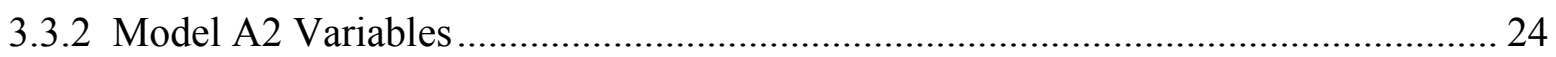

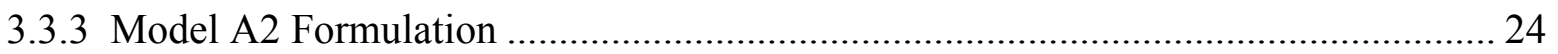

3.3.4 Model A2 Constraints Descriptions ...................................................................... 25

CHAPTER 4. PROBLEM A SOLUTION METHODS AND NUMERICAL RESULTS ........ 27

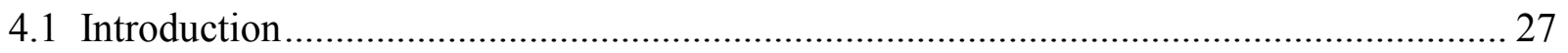

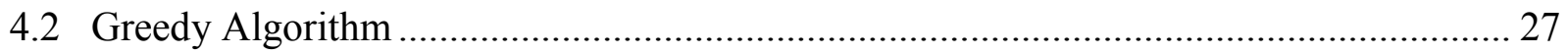

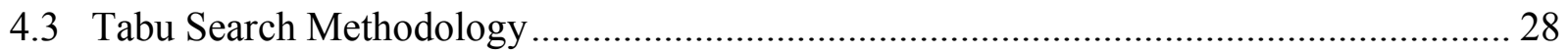

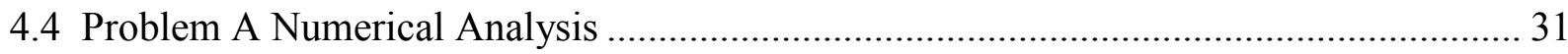

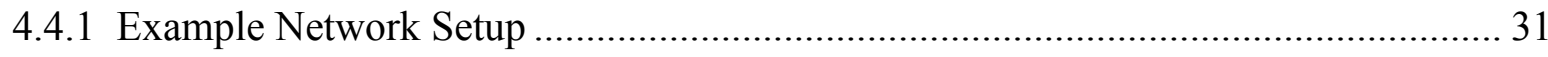

4.4.2 Model A1 - Analysis of Results........................................................................... 33

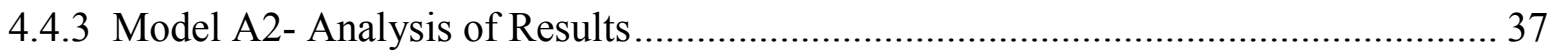

CHAPTER 5. PROBLEM B MODEL FORMULATION ………………………................... 41 


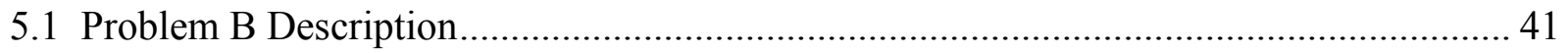

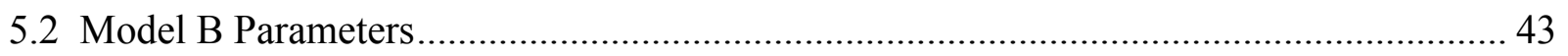

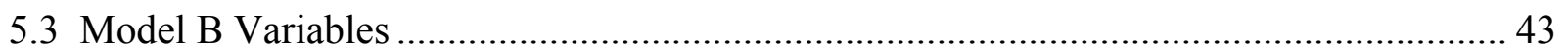

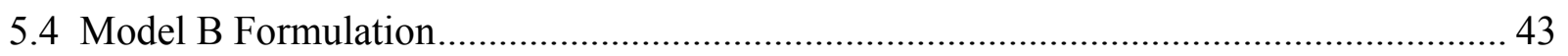

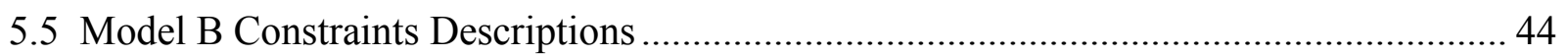

CHAPTER 6. PROBLEM B SOLUTION METHODOLOGY AND NUMERICAL RESULTS

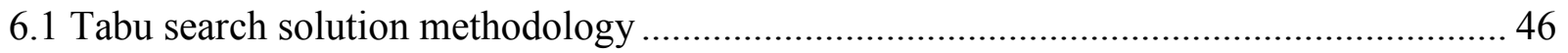

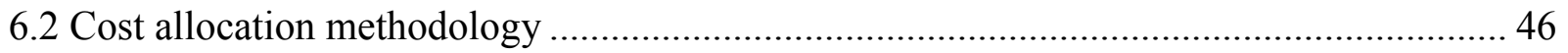

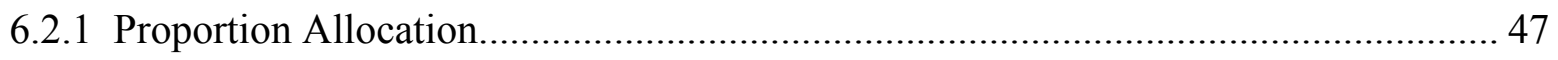

6.2.2 Proportion Allocation by Loop ………………................................................... 47

6.2.3 Marginal Contribution Allocation............................................................................ 48

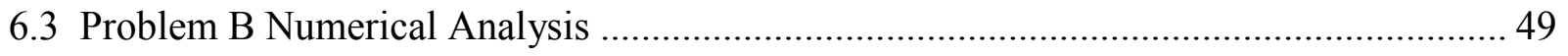

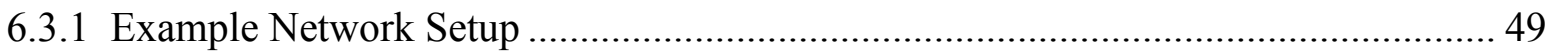

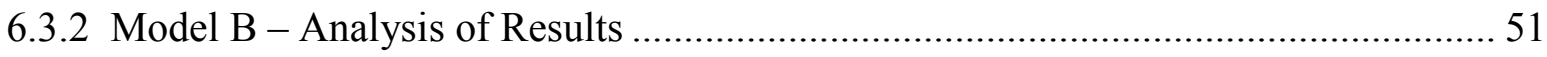

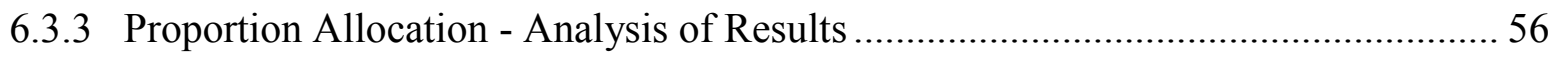

6.3.4 Proportion Allocation by Loop - Analysis of Results ................................................. 59

6.3.5 Marginal Contribution Allocation - Analysis of Results ............................................... 62

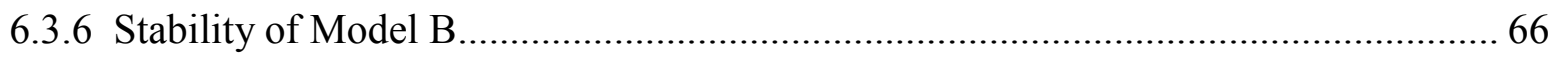

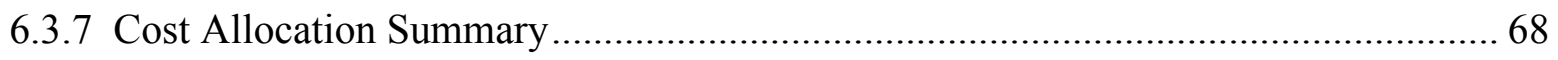

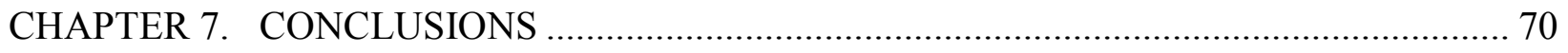

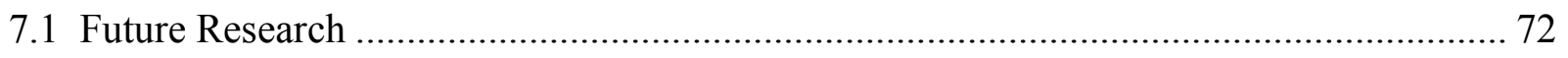

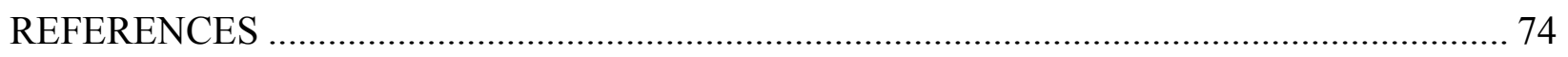

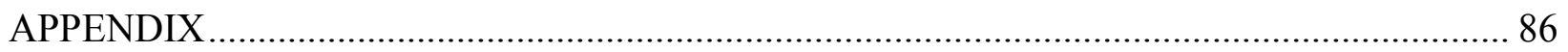




\section{LIST OF TABLES AND FIGURES}

FIGURE 1 Simple Example for Model A1 and Model A2 .............................. 20

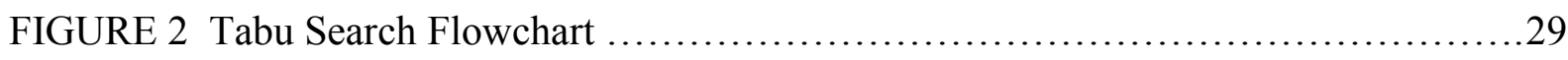

TABLE 1 Collaborator Nodes for Models A1 and A2 ................................ 32

TABLE 2 Model A1 Results with Variations in Transportation Cost and Percent Revenue

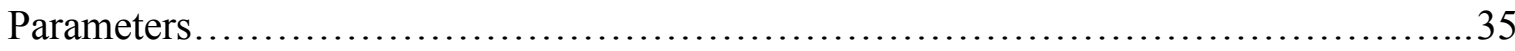

TABLE 3 Model A1 Results with Variations in Unloading and Loading Times ..............36

TABLE 4 Model A1 Results with Reduction of the Maximum Backhaul Time Parameter... 37

TABLE 5 Model A2 Results with Variations in Transportation Cost and Percent Revenue

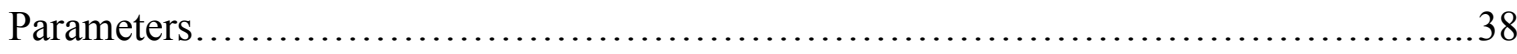

TABLE 6 Model 2 Results for Number of Collaborators Serviced on Each Route............ 39

TABLE 7 Model A2 Results with Variations in Unloading and Loading Times..............39

TABLE 8 Model A2 Results with Reduction of the Maximum Backhaul Time Parameter... 40

FIGURE 3 Simple Example for Model B.......................................... 41

TABLE 9 Shipping Lanes in Model B Dataset...................................... 51

TABLE 10 Results of Model B Analysis with Variations in Cost Per Mile...................5 52

TABLE 11 Results of Model B Analysis with Variations in the Maximum Arcs per Loop...53

TABLE 12 Results of Model B Analysis with Variations in Capacity........................54

TABLE 13 Case 1 Results of Model B with Variations in Cost per Mile.....................55

TABLE 14 Case 1 Results of Model B with Variations in the Maximum Arcs Per Loop....55

TABLE 15 Case 2 Results of Model B with Variations in Cost per Mile.....................55

TABLE 16 Case 2 Results of Model B with Variations in the Maximum Arcs per Loop.... 56

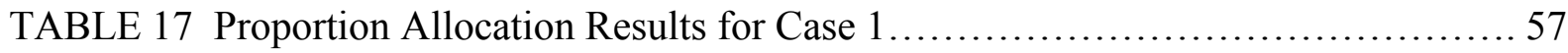

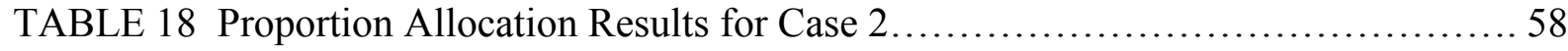

TABLE 19 Proportion Allocation Results for Case 3 ................................... 59

TABLE 20 - Results of Proportion Allocation by Loop for Case 1 .......................60

TABLE 21 - Results of Proportion Allocation by Loop for Case $2 \ldots \ldots \ldots \ldots \ldots \ldots \ldots \ldots \ldots . \ldots 1$

TABLE 22 - Results of Proportion Allocation by Loop for Case 3 .......................66

TABLE 23 Results of Marginal Contribution Allocation for Case 1......................6 64

TABLE 24 Results of Marginal Contribution Allocation for Case $2 \ldots \ldots \ldots \ldots \ldots \ldots \ldots \ldots . \ldots 6$ 
TABLE 25 Results of Marginal Contribution Allocation for Case 3...................66 66

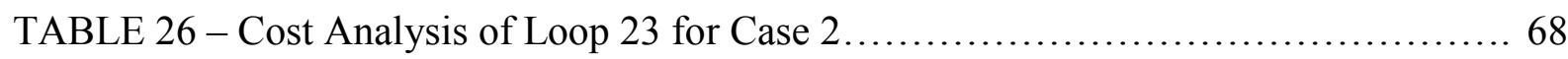

TABLE 27 Summary of Cost Allocations..................................... 69

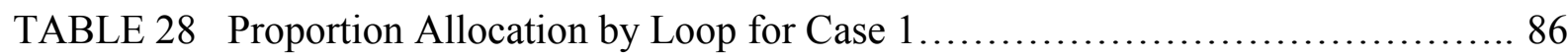

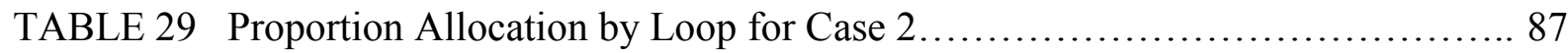

TABLE 30 Proportion Allocation by Loop for Case 3 (Part 1),,,,,................... 88

TABLE 31 Proportion Allocation by Loop for Case 3 (Part 2)........................ 89

TABLE 32 Marginal Contribution Cost Allocation Results for Case 1 ....................90

TABLE 33 Marginal Contribution Cost Allocation Results for Case 2 ...................91

TABLE 34 Marginal Contribution Cost Allocation Results for Case 3 ....................92 


\section{CHAPTER 1. INTRODUCTION}

\subsection{Motivation}

The U.S. economic strength and growth depends significantly on the flow of commodities and goods and particularly the trucking industry for its ground movement. In 2009, the U.S. transportation system moved about 44 million tons of freight each day, with the trucking industry transporting about 30 million tons of freight each day (FHWA, 2010). Heavy duty trucks consumed nearly 40 billion gallons of fuel costing approximately US \$114 billion (ATA, 2010). This number is expected to increase as freight tonnage is expected to grow over the next several decades, increasing at an average rate of $1.6 \%$ per year (US DOT, 2010). The increased freight traffic will require a more efficient freight transportation system. Businesses are requiring more timely and reliable service of their goods, which also demands more efficient freight operations.

Since the deregulation of the trucking industry in the 1980s, the trucking industry has become more competitive and dynamic. The deregulation allowed carriers to set their prices independently and removed restrictions on geographical locations they could serve. Entry barriers into the industry were eliminated and many new firms joined the transportation industry. By November 2009, there were approximately 517,100 for-hire motor carriers and private fleets registered with the U.S. Department of Transportation. Nearly $88 \%$ of these trucking companies operated less than six trucks (ATA, 2010). Due to the highly competitive nature of the industry, trucking firms have had to improve their operations and lower their marginal costs through innovative solutions. The U.S. trucking industry has a wide range of truck company size and capability and it is essential for small- and medium-sized firms to decrease their operation costs to compete with the larger ones. Many technologies have emerged to improve operations and 
allow the exchange of information. Trucking companies have used communication technologies to develop more sophisticated scheduling and routing tools. New technologies assist carriers and shippers in information exchange and transactions. Shippers, sometimes along with third-party logistics providers, are using new procurement methods to find carriers at low prices. For example, various online auction mechanisms have been developed to help match capacity and loads (Song et al., 2004). There is significant scope for the trucking companies in the United States to exploit the synergies in their operations to control costs and increase competitiveness.

In addition, environmental and health concerns due to emissions from the transportation sector is receiving increasing attention. Heavy freight trucks are a major source of pollutants into the atmosphere. In the U.S., considering only mobile source emissions, heavy trucks account for $20 \%$ of greenhouse gases (GHG), $47 \%$ of nitrogen oxides (NOx), $75 \%$ of particulate matter (PM), 7\% of carbon monoxide (CO), and 4\% of hydrocarbons (HC) (EPA 2007, EPA 2011). In a study conducted by the South Coast Air Quality Management District in California, 71\% of cancer risk from air pollutants comes from diesel exhaust (SCAQMD, 2000). These air pollutants have negative affects to the environment and people's health and it is one of the nation's top objectives to reduce and regulate emissions. The EPA set standards to reduce emissions from heavy truck diesel engines through a three stage process, which was implemented through 2010. Some of the strategies included manufacturing diesel particulate filters, cooled exhaust gas recirculation, and selective catalytic reduction (Thompson et al., 2010). In October 2010, the EPA and NHTSA created the heavy-duty national program to set rules on reducing fuel consumption and GHG emissions from highway sources. The EPA proposed emission standards for $\mathrm{CO}_{2}, \mathrm{CH}_{4}$ and $\mathrm{N}_{2} \mathrm{O}$ (GHGs that contribute to global warming) and the NHTSA proposed fuel consumption standards for each of the categories: combination 
tractors; heavy-duty pickup trucks and vans; and vocational vehicles (EPA, 2010). In addition to the technological advancement made in truck engines and fuels, environmental concerns and emissions can be further reduced by decreasing the number of truck trips through efficient truck operations. Nearly $30 \%$ of the total miles traveled by trucks operated by small trucking companies in the United States in February of 2008 had zero loads (ATA, 2008). Reducing these zero-load trips and truck miles on highways in general can help accomplish the goals of reducing fuel consumption and emissions.

With expected increase in freight movement, a competitive trucking environment, and businesses' demand for timely delivery of products, there is a great need for more innovative solutions to improve efficiency and lower operation costs in truck transportation. Transportation cost has a significant effect on the cost of goods and can commonly comprise $10 \%$ of a product's cost (Rodrigue et. al., 2009). Reducing empty truck miles can help in reducing final product costs to consumers.

Collaboration among trucking firms can help the trucking industry to help accomplish these goals. Freight demand is often geographically widespread, creating empty backhauls after shipment delivery, called deadheading. Deadheading results in significant costs to carriers and shippers and ultimately increases costs to consumers. When carriers or shippers form alliances they can collaborate their truck operations and change non-profitable empty hauls into profitable backhauls. Other benefits of collaboration include increased asset utilization, decreased lead times, improved service levels to customers, and improved highway safety due to reduced truck traffic.

Freight collaboration has become increasingly popular due to its great potential to increase profitability. It has been practiced in the sea cargo and airline industry, and more 
recently in the trucking industry. Starting in 1990, Sea-Land and Maersk have collaborated through sharing ship capacities (Argawal et al., 2010). Collaborations in the sea cargo industry have become more common since then: The New World Alliance is a collaboration between Hyundai Merchant Marine, APL, and MOL; the Australia and China Express consists of OOCL and China Shipping (Agarwal et al., 2005). Recently, alliance formation has become very common in the passenger airline industry. The practice of code sharing is used to fill passenger capacity and improve operational efficiency. It is an agreement between two airline carriers where a carrier can market and sell the seats on some of its partner's flights. (Ito et al., 2007). Alliances have formed in the air passenger and in the air cargo industries. In passenger airlines, code sharing has been used for many years for international flights, but more recently code sharing agreements have become very common on U.S. domestic flights. Three major passenger airline alliances are Star Alliance, SkyTeam and Oneworld, linking U.S. airline carriers to airlines in other countries (Brueckner, 2003). In cargo airlines, some of the largest alliances are the WOW alliance and SkyTeam Cargo (Zhang et al., 2007). The alliances allow the airlines to extend their networks and offer new destinations to their costumers and provide lower costs to costumers and passengers.

In the last 20 years, collaboration has occurred between the various freight companies involved in the (full) truckload industry, and more recently in the less-than-truckload (LTL) industry. Two common types of collaboration in truckload transportation are shipper collaboration and carrier collaboration. Truckload shipper collaboration involves multiple shippers coordinating with one or more carriers and matching their loads so that optimal routing can be found at a minimum cost. In truckload carrier collaboration, multiple carriers reduce operating costs by pooling delivery tasks and vehicle capacities in common to find efficient ways 
of fulfilling all shipping requests. Collaboration among agents involved in the less-thantruckload (LTL) industry has only been recently studied and primarily focuses on the collaboration among carriers in the LTL industry. LTL transportation involves shipping smaller freight, typically from many shippers and has shorter planning periods than truckload transportation. Because many LTL carriers have overlapping networks and use distribution centers, depots or warehouses, it provides the opportunity for carriers to easily exchange freight and utilize one another's capacities (Hernandez et al., 2010).

\subsection{Overview}

In this thesis multiple collaboration frameworks are developed to demonstrate how truck carriers and shippers can integrate their operations and realize significant cost savings. The trucking industry is fragmented in the US, with a wide variety of trucking company size and capability. The same collaboration frameworks and model cannot be applied to every firm. In order to produce the best outcome, it is imperative that models incorporate a collaborative framework that considers the type of companies involved, their operations and their constraints. It is for this reason that multiple models are presented in this thesis.

The first collaboration framework, presented in detail in Chapter 3, demonstrates how small- to medium-sized truckload carriers can reduce empty backhauls to a depot or distribution center location by adding pickup and delivery tasks of collaborative shippers or carriers to their backhaul. A carrier of interest can increase their profit margins by fulfilling a shipping request of another firm during its backhaul route. Reducing the empty and often long hauls to the depot will greatly increase the carrier's profitability. This collaboration framework is called Problem A and two mathematical models are developed to route backhaul shipments for the carrier of 
interest's fleet of trucks. The first model, Model A1, allows at most one collaborative shipping request be fulfilled for each truck and is formulated as an integer program. Model A2 is more complicated, allows multiple pick-up and delivery tasks for each truck and is formulated as a mixed integer program. Model A1 is solved using a greedy heuristic and a tabu search heuristic is provided for solving Model A2. If it is feasible for the carrier of interest to fulfill another carrier's or shipper's request during its backhaul route, the routing is as follows: from a truck's last delivery location, the empty truck would pick up a collaborative shipper's or carrier's shipment, deliver the shipment to its destination, then return back to the depot. Model A1 is a simpler model that is easier to solve while Model A2 provides more collaborative options and is more difficult to solve. One advantage of Problem A's approach over a full collaboration is that the carrier of interest would not have to alter its existing line haul routes, and only slightly change its backhaul routes. This type of collaboration can be a good transition into full collaboration later, where all delivery tasks and vehicle capacities are in common and optimal routing is found for the collaborative network. Note that the models are flexible with respect to whom the carrier of interest collaborates. Collaboration can occur with other TL shippers that have origin-destination shipping locations close to the carrier of interest's backhaul routes. Collaboration with carriers is also possible if a carrier does not have available capacity to service all of their requests. The models described in further sections refer to the collaborative shipper or carrier as the "collaborator" or "collaborative freight company" to not exclude a type of collaborator.

The second collaboration framework is presented in detail in Chapter 5 and demonstrates how shippers can collaborate their truck movements to attain lower rates from a common carrier. This problem, named Problem B, is particularly applicable to long haul truckload shipments that 
have very long, costly empty trips to return to their depot or origin. These deadhead miles cause increase in rates that carriers offer to shippers. If shippers coordinate their shipping lanes and form loops between their lanes, the empty repositioning miles are significantly less. The shippers can then provide bundled lanes to a common carrier and realize much lower rates. For this collaboration framework, one model is developed and is formulated as a mixed integer program. Differing from Problem A, this problem is a "full" collaboration between shippers where all truck capacities and demand are taken in common to fulfill all requests.

\subsection{Contributions}

The thesis has the following contributions:

- Two collaboration frameworks are examined. Framework A is for small or medium sized carriers or shippers and collaboration only occurs on the carrier/shipper's backhaul routes. The other framework B is for multiple large shipping companies and involves full collaboration of all shippers' lanes and truck capacities.

- Under framework A, two modes named A1 and A2 are formulated to match backhauls with potential collaborators. An integer programming formulation is developed for Model A1 which is similar to a constrained capacitated matching problem. The model can be solved efficiently on larger sized networks but limits trucks' backhauls to be matched with at most one collaborator. A mixed integer programming formulation is developed for Model A2. It is more computationally difficult to solve on large sized networks, but allows a truck's backhaul to be matched with more than one collaborator. 
- $\quad$ Solution methodologies are developed for Model A1 and Model A2, which provide accurate solutions with a reasonable amount of computation time. A greedy heuristic is used for solving Model A1 and a tabu search heuristic is used to solve Model A2. The models consider realistic carrier and shipper constraints, such as vehicle driver hour restrictions and vehicle capacity constraints.

- A real freight network, obtained from a third party logistics company, is used to implement Models A1 and A2. Making assumptions where necessary, the network is modified to be suitable for each model. Model A1 and A2 results reveal cost savings as high as $27 \%$ for the carrier of interest's backhauls. The models show how a small or medium sized freight company can introduce collaboration into their operations without significant modifications of their schedule.

- For the second collaboration framework, a mathematical formulation is developed, called Model B. Realistic freight shipping constraints are considered in Model B, such as capacity constraints and maximum length of each vehicle's cycle. The problem is shown to be NP-Hard. A tabu search heuristic is developed to solve Model B to provide good solutions with reasonable computation time.

- A real world network, obtained from a third party logistics company, is used to implement Model B with appropriate assumptions made where needed. Model B results show collaborative network cost savings of up to $12 \%$.

- Various cost allocation mechanisms are investigated to allocate the worth of a collaborative network in Problem B. Two proportion allocation methods and a 
marginal contribution allocation method are implemented on the real world network to demonstrate cost sharing among collaborators.

\subsection{Organization}

The remainder of the report is organized as follows. Chapter 2 provides a literature review of general freight modeling, the vehicle routing problem, tabu search heuristics, and a detailed review of collaborative trucking logistics. The two formulations of Problem A are provided in Chapter 3. Chapter 4 provides Problem A's solution methodologies and numerical analysis using a real world freight network with modified parameters. The model formulation of Problem B is presented in Chapter 5. Chapter 6 provides the solution methodology, cost allocation methodology and numerical analysis of Problem B using a real world truckload freight network. Finally, Chapter 7 provides conclusions and directions for future research. 


\section{CHAPTER 2. LITERATURE REVIEW}

\subsection{Introduction}

The literature review of this report first covers the various optimization models used in freight modeling. An overview of the vehicle routing problem (VRP) is then provided because Models A2 and B in the thesis are variants of the VRP. A literature review of the Tabu search heuristic commonly used to solve VRP problems is then provided. The Tabu search heuristic is used in this thesis to solve Model A2 and Model B. Finally, the collaborative logistics literature of the trucking industry is reviewed.

\subsection{Freight Modeling}

After the deregulation of the trucking industry in the 1980s, trucking firms were driven to develop more efficient operations to be profitable in a competitive environment. This initiated an interest in improving planning and routing of freight through new mathematical models that incorporate the economical structure of the freight industry. These models can be classified into two general categories: predictive models and design models. The objective of the predictive models is to predict the flow on a network, given values for the network parameters. The objective of the design models is to determine the optimal design of the network parameters to maximize the use of the owner's resources.

The predictive models can be classified into three categories: spatial equilibrium models, freight network equilibrium models, and integrated network equilibrium models. Spatial equilibrium models involve the interaction between producer, consumer and shipper. The models

have been used to calculate interregional freight flows (Friesz. et al.,1983a; Florian et al., 1982). In freight network equilibrium models, the interaction between the shipper and carrier is 
considered. Two subclasses are sequential models and simultaneous models. The sequential models have a two step process to determine the flow through a carrier's network, while the simultaneous model takes the shipper and carrier's decisions at the same time to attain an equilibrium flow (Gottfried, 1983; Friesz et al., 1983b). The third classification of predictive models is the integrated network equilibrium model. It considers the interaction between the producer, consumer, shipper and carrier (Harker et al., 1986; Friesz et al., 1986).

The second main category of freight models is design models, where network parameters are designed in order to maximize the owner's profit. Design models can be divided into carrier design models and shipper design models, since they are independent decision makers. Under each type, there are various decisions that the models make, depending on the planning horizon: strategic decisions (long term); tactical decisions (medium term); and operational decisions (short term). Within carrier design models, the literature is basically divided into carrier network design models (Crainic, 2000; Unnikrishnan et al., 2009) and tariff setting models (Brotcorne et al., 2000), depending on the model objective. Shipper design models optimize the planning decisions of the shipper, particularly the routing of goods and inventory levels at each time step (Baita et al., 1998). They can be separated into three categories: frequency models, frequency models with terminal inventory, and dynamic flow models. The next section provides an overview of vehicle routing problem (VRP).

\subsection{Vehicle Routing Problem}

The formulations of Model A2 and B in future sections of this thesis are rooted in the vehicle routing problem, or VRP. The following is a brief overview of the VRP, some variations to the VRP and some common solution methods. The VRP was first introduced by Dantzig and 
Ramser (1959) and is a generalization of the Traveling Salesman Problem (TSP). In the TSP, the goal is to find a minimum cost tour that reaches all nodes, or costumers, in the network. The VRP is a TSP with multiple vehicles that must reach all costumers in the network. When the VRP includes vehicle capacity constraints, it is a Capacitated Vehicle Routing Problem (CVRP). When each customer is associated with a time window, say a delivery needs to be made at a certain time, the problem becomes the VRP with time windows (VRPTW) (Toth and Vigo, 2001).

Two VRP variants are relevant to the work done in the thesis - VRP with backhauls (VRPB) and VRP with pickup and delivery (VRPPD). In the VRPB, the customers are divided into two subsets. One subset includes the line haul costumers, who require deliveries. The other subset is the backhaul costumers, requiring pickups. VRPB includes precedence constraints so that on any particular vehicle route, the line haul costumers are visited before the backhaul costumers (Toth and Vigo, 1997; Mingozzi et al., 1999; Toth and Vigo, 2001). In the VRP with pickup and delivery (VRPPD), goods need to be moved from specific pickup locations to dropoff locations. (Dumas et al., 1991; Nagy et al., 2005; Montane et al., 2006).

To solve VRPs, there exist exact solution methods and heuristic methods. Some exact solution methods include Bender's decomposition (Fisher et al., 1981), branch-and-bound schemes (Christofides et al., 1981; Fisher 1994a, 1994b; Laporte et al., 1986), column generation (Balinski et al., 1964; Lysgaard et al., 2004; Baldacci et al., 2008), and dynamic programming approaches (Eilon et al., 1974). Popular heuristics for solving CVRPs include the Clarke and Wright Savings Algorithm (Clark et al., 1964; Laporte et al., 2002), the Cluster-First RouteSecond (Fisher et al., 1981), and the Sweep heuristic (Wren et al., 1972). Tabu search metaheuristic has been found to be extremely effective in solving VRP's and its variants. Tabu search 
was first applied to VRP by Willard (1989) and has been updated and applied to various VRP problems since then (Gendreau et al., 1991, Osman, 1993; Semet et al., 1993; Cordeau et al., 1998; Barbarosoglu et al., 1999).

\subsection{Tabu Search}

Tabu search is an iterative meta-heuristic which has been found to be extremely effective in solving combinatorial optimization problems such as VRP (Glover, 1977; Gendreau et al., 1991, Osman, 1993; Semet et al., 1993; Cordeau et al., 1998; Barbarosoglu et al., 1999). Given a current solution, tabu search applies a local search procedure to iteratively find a new solution in the neighborhood of the current solution. To avoid convergence to local optima, the neighborhood search space is modified continuously for each solution. This ensures that the entire feasible region is covered. The search procedure also maintains a tabu list $-\mathrm{a}$ list which contains the most recent solutions visited in the neighborhood of the current solution. The tabu list prevents the algorithm to move to points which have already been evaluated recently. Tabu search was chosen to solve Models A2 and B because of their VRP structure.

\subsection{Collaborative Modeling in Truck Transportation}

The literature in sections 2.2, 2.3, and 2.4 includes modeling from a regional perspective or from one carrier's perspective. The focus of this thesis is on modeling collaborations between carriers and shippers. This section includes a review of literature for collaborative logistics, particularly in truck transportation.

One group of carrier collaborative literature studies truckload transportation procurement, where least cost methods of obtaining additional capacity for a carrier of interest or shipper of 
interest are investigated (Chu, 2005; Ball et al., 1983; Song et al., 2004; Figliozzi, 2006). Although not distinctively collaboration, Chu (2005) and Ball et. al. (1983) studied how a shipper with limited capacity could execute all of its delivery tasks by utilizing an outside carrier to meet the demand it could not self fulfill. Song et. al. (2004) and Figliozzi (2006) studied an auction-based carrier collaboration mechanism among TL carriers. Song et al. (2004) developed a framework for a collaborative carrier network that is exclusively designed for small and medium sized TL carriers. An auction occurs in a post-market exchange, where non-profitable lanes are bid on by other carriers in the collaboration. The model uses global optimization and an auction so that efficient solutions are found for every carrier. Compared to the static model presented in Song et. al. (2004), Figliozzi (2006) examined a dynamic mechanism. Simulations of a truckload pick-up and delivery problem are run to examine the dynamic auction-based collaboration mechanism. Results reveal up to $50 \%$ reduction in deadheading trips when existing capacities of carriers are used. Hernández et al. (2010) studied LTL carrier collaboration and developed the single carrier collaboration problem (SCCP) to gain insights on the potential for a carrier with excess demand to collaborate with other carriers to service that demand. Their static model is formulated from the perspective of a carrier of interest with the objective of minimizing its cost to fulfill all shipments. Under a collaborative scenario, the results reveal savings up to $59 \%$ for the carrier of interest when compared to a leasing option to obtain additional capacity. Hernandez et. al. also developed models for carrier collaboration with time-dependent aspects (2011a) and with dynamic capacities (2011b).

Another set of literature addresses LTL collaboration from the perspective of optimizing the operations of the whole collaborative freight network (Dai et al., 2009; Berger et al., 2010). Dai and Chen (2009) developed an optimization model for LTL collaboration that can be applied 
to a set of shippers and/or carriers, in which all delivery tasks are shared and all vehicle capacities are known. Their model allows for pick up and/or delivery at every node in the network. The mathematical model determines the number of times each transportation lane in the network needs to be covered to carry out all delivery requests. Then a Lagrangian relaxation methodology is used to construct a set of feasible vehicle tours from the model's solution. Berger and Bierwirth (2010) developed a model in a post-market environment, where LTL carriers can exchange non-profitable delivery requests. The model optimizes the operations of all carriers while ensuring that no carrier loses profit under the collaboration. A cash flow model, called the Collaborative Carrier Routing Problem, reassigns requests to a carrier in which the profit of the collaborative network is maximized. They developed two solution approaches to perform analysis on their model, involving decentralized control and an auction based exchange mechanism.

Shipper collaboration is limited in literature and was first introduced by Ergun, Kuyzu and Savelsbergh (2007b). They studied how truckload shippers can collaborate to minimize asset repositioning, thereby reducing deadhead trips. They translated their problem into the Lane Covering Problem (LCP), where a minimum cost set of constrained cycles is found to cover a subset of arcs (delivery lanes) in a directed Euclidean graph. They presented algorithms to solve this problem, which were found to be solved in polynomial time. Özener and Ergun (2008) developed cost-allocation schemes in similar shipper alliances after determining the optimal collaborative routing. They apply several types of the cost allocation mechanisms where the goal in all of them is to ensure the stability of the collaboration. Using the basis of the Lane Covering Problem, Ergun, Kuyzu and Savelsbergh (2007a) developed optimization technology to assist in identifying collaborative shippers' repeatable, dedicated truckload continuous move 
tours in order to reduce the need for carriers to reposition empty trucks. The intention is that this technology can help shippers identify potential collaboration partners. Ergun et. al. (Agarwal et al., 2010; Agarwal et al., 2008; Houghtalen et al., 2010) have addressed carrier collaboration in the air cargo and sea cargo industries and have developed models and allocation mechanisms for these types of collaborations.

Other literature focuses on minimizing empty truckloads for a single company's operations without collaboration. Arcelus et. al. (1998) formulated a dynamic model for reducing empty hauls within a company's hub-and-spoke structured network. Using data from a Canadian trucking company, they performed sensitivity analysis on whether or not it was beneficial to obtain more freight requests for specific origin-destination pairs. Jordan (1987) examined deadheading trip reduction for a single company's operations with more than two terminals. After delivering shipments, trucks would carry out a backhaul shipment before returning to their respective originating terminals, thereby reducing the number of empty truck-miles within the company's network. Jordan developed a backhaul model that can be solved as a matching problem, but is only appropriate for solving small networks. To solve the problem for larger, more realistic networks, he developed a Lagrangian Relaxation method (Jordan, 1987).

Another set of literature focuses on the allocation of profit or costs when freight operators enter into alliances with each other. The authors of these papers use the concepts of cooperative game theory to develop mechanisms that split the collaborative profit among the members. Since every member in the collaboration contributes differently and every member needs an incentive to participate in the collaboration, it is important that a profit allocation mechanism distributes the profits in a fair manner and is desirable to everyone in the collaboration. A good cost or profit allocation mechanism ensures stability of the collaboration. Xu et al. (2009) developed a 
profit allocation mechanism, called the weighted relative savings model, to allocate profit in a less-than-truckload carrier alliance. The model provides a stable allocation to their problem by minimizing the maximum difference between the relative savings among the alliance members. They performed computational analysis on collaborations in groups of 1,2 and 3 members. Krajewska et al. (2008) and Voruganti et al. (2011) used the popular Shapley value scheme to allocate profit in the context of their carrier collaboration problem. Özener and Ergun (2008) investigated multiple cost allocation mechanisms to apply to their shipper collaboration problem, and each mechanism used different desirable properties of a cost allocation. Outside of the realm of collaborative freight literature, much literature exists on allocating costs or profits among members that share those costs/profits (Engevall et al., 1998; Castro et al., 2008; Fatima et al., 2008; Castro et al., 2009)

The models presented in this paper for the first problem, called Problem A, differentiate themselves from past works as they focus on optimizing the backhaul route of a specific carrier of interest through collaboration with other shippers and/or carriers. Another distinction is that the models ensure that the new modified backhauls are not significantly longer than the existing backhauls so that the carrier of interests can satisfy the new requests without significantly modifying their driver schedule. Carriers can use the backhaul models presented in this report to evaluate the savings obtained by optimizing the backhauls in their entire network or part of their network.

The second type of problem, Problem B, investigated in this report is similar to the Lane Covering Problem (LCP), presented by Ergun et al. (2007b), but uses a much different formulation than used in this report. One distinction of Model B over the LCP is that truck 
capacities are taken into consideration and multiple loops may cover a lane to fulfill the demand on that lane.

The two formulations for the backhaul models, Models A1 and A2, are described next. 


\section{CHAPTER 3. PROBLEM A MODEL FORMULATIONS}

\subsection{Problem A Description}

The problem of interest is to reroute the empty backhaul trucks of a carrier to fulfill other collaborative carriers' or shippers' requests. Given a set of locations for the trucks' last deliveries (described heretofore as origin locations), the models decide if a collaborative freight operator's request can be fulfilled by one of the trucks. If not, the truck will keep its original empty backhaul route. The two models presented in this section route the backhauls such that the cost to the carrier of interest is minimized. Both models consider truck capacity constraints and vehicle driver hour constraints. The backhaul trip length cannot exceed an upper time limit, which is explained in more detail in the numerical analysis section of Problem A.

The first model, called Model A1, is an integer programming model that pairs each origin node with a collaborator node or the depot node. If an origin is paired with a collaborator, then it will fulfill that shipping request before returning to the depot. This model will allow at most one collaborative shipping request to be fulfilled for each truck. Model A1 is similar to a constrained matching problem. The second model, Model A2, is a mixed integer programming problem and a more complicated model than Model A1. Model A2 is similar to a capacitated vehicle routing problem with pickup and delivery (Goetschalckx et al., 1989; Dumas et al., 1991; Toth et al., 1999; Nagy et al., 2005; Montane et al., 2006) with the vehicles not returning to the originating depot. Note that in the above mentioned works both the line haul and backhaul deliveries are optimized whereas in this work the focus is on the backhaul variation. This model also has the advantage of allowing multiple pick-up and deliveries in one truck's backhaul. Similar problems involving pick-up and deliveries have been studied in the literature by Dumas et. al. (1991) and Nagy et. al. (2005). Model A2 is different as there are constraints on the route length 
corresponding to driver hour restrictions and there is the option of not picking up goods if it is not profitable for the carrier of interest. The model also ensures that an O-D shipment is not split up in its delivery.

A simple example is provided in Figure 1 to demonstrate the routing of Model A1 and Model A2 for a very small network. Figure 1 displays how two backhaul routes would be rerouted for a collaboration using Model A1 and a collaboration using Model A2. Notice that Model A2 provides multiple pickup and delivery tasks along a backhaul route.
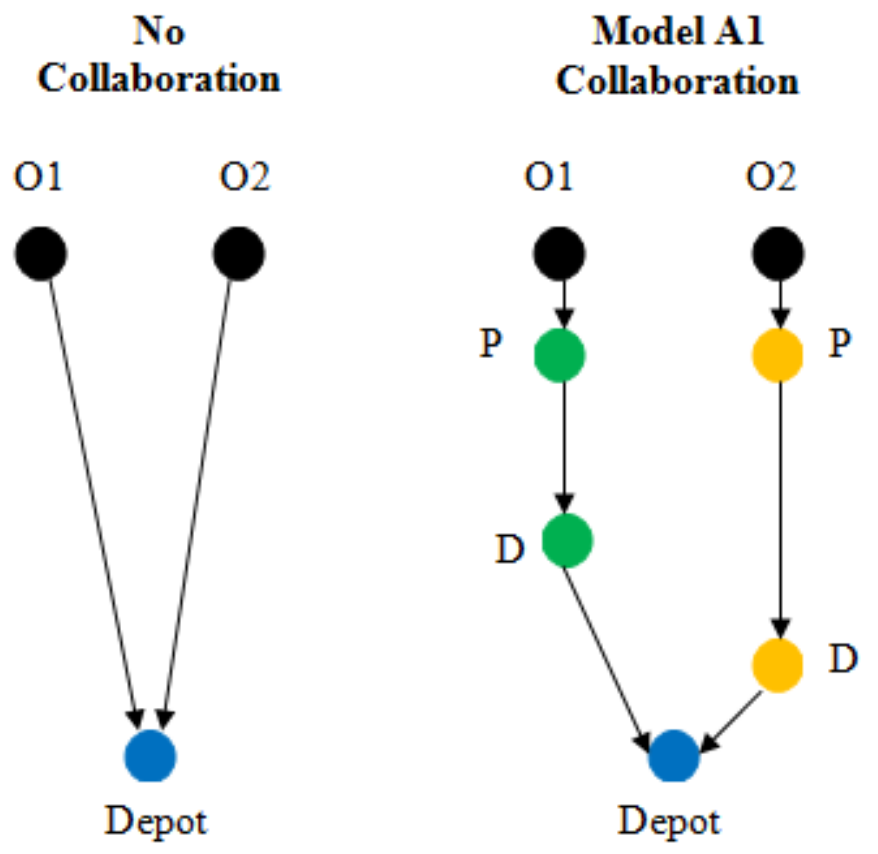

$\mathrm{O} 1, \mathrm{O} 2$ - origin nodes $\mathrm{P}$ - pick up nodes $\mathrm{D}$ - delivery nodes

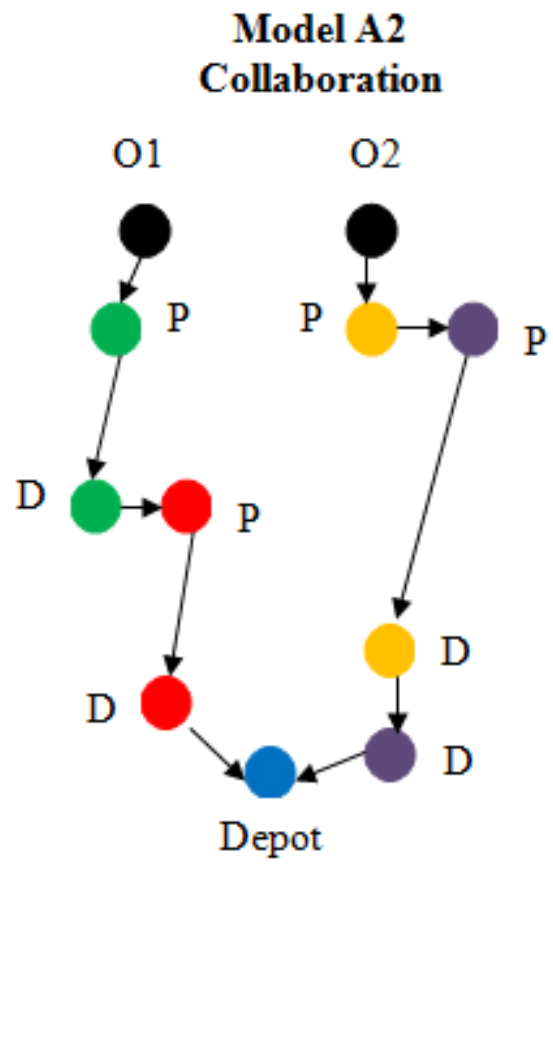

FIGURE 1. Simple Example for Model A1 and Model A2

\subsection{Model A1}

Model A1 maximizes the collaborative savings, $s_{i j}$, of the carrier of interest. Some explanation of the collaborative savings computation is needed before the model formulation can 
be presented. The original transportation cost, $c_{i d}$, is the cost for the truck to go from a backhaul origin node $i$ to the depot node $d$ and $c_{i p}$, is the cost for the truck to leave its origin node, carry out the shipping request of collaborator $p$ and return to the depot. If a collaborator's request is fulfilled, then that collaborator will provide compensation to the carrier of interest, resulting in a revenue $r_{p}$ for that request. The backhaul savings, as shown in equation (1), is computed by subtracting the collaborative transportation cost from the original transportation cost. Equation (2) explains that the backhaul savings is zero for a truck returning to the depot instead of making a backhaul delivery.

$$
\begin{array}{ll}
s_{i p}=c_{i d}-\left(c_{i p}-r_{p}\right) & \forall p \in P, \forall i \in O \\
s_{i d}=c_{i d}-c_{i d}=0 & \forall i \in O
\end{array}
$$

The model parameters and the variables used in the Model A1 formulation are described below.

\subsubsection{Model A1 Parameters}

$O$ set of all origin nodes $i$

$P \quad$ set of all collaborators $p$

$J \quad$ set of all collaborator nodes $p$ and the depot node $d$, indexed by $j$

$u_{j}$ product demand of node $j$

$C$ capacity of trucks

$t_{i j}$ total trip length, in time, to travel from the origin node, pick up and deliver request $p$, and return to depot

$T_{i}$ upper limit of the total backhaul trip length, in time, for origin node $i$ 


\subsubsection{Model A1 Variable}

$x_{i j}$

$=\left\{\begin{array}{cc}1 \text { if truck at origin i carries out the request of collaborator } \mathrm{p} \text { or goes directly to depot } \mathrm{d} \\ 0 & \text { otherwise }\end{array}\right.$

\subsubsection{Model A1 Formulation}

Maximize $\quad \sum_{i \in O} \sum_{j \in J} s_{i j} x_{i j}$

Subject to:

$$
\begin{array}{ll}
\sum_{j \in J} x_{i j}=1 & \forall i \in O \\
\sum_{i \in O} x_{i j} \leq 1 & \forall j \in P \\
\sum_{j \in J} x_{i j} u_{j} \leq C & \\
\sum_{j \in J} x_{i j} t_{i j} \leq T_{i} & \forall i \in O \\
x_{i j} \in\{0,1\} & \forall i \in O, j \in J
\end{array}
$$

\subsubsection{Model A1 Constraints Explanation}

The objective function of Model A1, equation (3), maximizes the collaborative savings of the carrier of interest. Equation (3) sums the collaborative savings of all of the backhaul routes. Constraint (4) ensures that each origin truck node is paired with exactly one of the collaborators $p$ or the depot $d$. An origin node cannot be paired up with both a collaborator node and a depot node because being matched up with the depot node means that the backhaul route will go directly from the origin node to the depot node. Constraint (5) ensures that each collaborator is paired with no more than one origin node. A collaborator can either be unmatched or it can be matched with one origin node. Constraint (6) is a capacity constraint, ensuring that the demand 
on any arc of a backhaul route does not exceed the carrier of interest's truck capacity. The demand at the origin and depot nodes are zero, so this constraint actually ensures that any collaborator with demand exceeding capacity will not be matched to any of the backhaul routes. The capacity is considered homogenous for all trucks leaving the origin nodes. Constraint (7) ensures that the total backhaul trip length does not exceed the maximum trip length for a truck at node $i$ so that the carrier of interest can meet the collaborative freight operator's shipping request without significantly altering the driver schedule. Constraint (8) identifies the variable $x_{i j}$ as an integer variable, taking the values of 0 or 1 . The formulation of Model A2 is explained next.

\subsection{Model A2}

The parameters and decision variables for Model A2 are described, followed by the mixed integer programming formulation.

\subsubsection{Model A2 Parameters}

$N$ set of all nodes $i$

$A \quad$ set of all $\operatorname{arcs}(i, j)$

$P \quad$ set of all collaborators' pick-up nodes

$B$ set of all collaborators' delivery nodes

$O$ set of all origin nodes for empty trucks

$D$ depot node

$M$ set of all collaborator's origin-destination shipment pairs $m$

$c_{i j}$ transportation cost to travel on arc $(i, j)$

$r_{i} \quad$ carrier of interest's revenue for fulfilling a collaborator's shipment from pick-up node $i$ 
$u_{i}^{m}$ collaborator's product demand of O-D shipment $m$ at node $i$

$t_{i j}$ length of time to travel on arc $(i, j)$

$T_{o}$ upper limit on length of backhaul trip, in time, of truck originating from node $o$

$C$ capacity of trucks

\subsubsection{Model A2 Variables}

$x_{i j o}=\left\{\begin{array}{ccc}1 & \text { if truck originating from node o travels on } \operatorname{arc}(i, j) \\ 0 & \text { otherwise }\end{array}\right.$

$y_{\mathrm{ijo}}{ }^{\mathrm{m}} \quad$ quantity of product $m$ shipped on arc $(i, j)$ by truck originating from node o

$z_{i}=\left\{\begin{array}{cc}1 & \text { if shipment from pick }- \text { up node } \mathrm{i} \text { is fulfilled } \\ 0 & \text { otherwise }\end{array}\right.$

\subsubsection{Model A2 Formulation}

Minimize $\sum_{(i, j) \epsilon A} \sum_{o \in O} c_{i j} x_{i j o}-\sum_{i \in P} r_{i} z_{i}$

Subject to:

$$
\begin{array}{ll}
\sum_{j \in N} x_{i j o}=\sum_{j \in N} x_{j i o} & \forall i \in P, \forall i \in B, \forall o \in O \\
\sum_{j \in N} \sum_{o \in O} x_{i j o}=z_{i} & \forall i \in P \\
\sum_{j \in N} x_{j o o}=0 & \forall o \in O \\
\sum_{j \in N} x_{o j o}=1 & \forall o \in O \\
\sum_{j \in N} x_{j D o}=1 & \forall o \in O
\end{array}
$$




$$
\begin{array}{ll}
\sum_{j \in N} x_{D j o}=0 & \forall \mathrm{o} \in O \\
\sum_{j \in N} y_{i j o}^{m}-\sum_{j \in N} y_{j i o}^{m}=\mathrm{u}_{\mathrm{i}}^{\mathrm{m}} \sum_{j \in N} x_{i j o} & \forall o \in O, \forall m \in M, \forall i \in N \\
\sum_{(i, j) \epsilon A} t_{i j} x_{i j o} \leq T_{o} & \forall o \in O \\
\sum_{m \in M} y_{i j o}^{m} \leq C \cdot x_{i j o} & \forall(i, j) \in A, \forall o \in O \\
\sum_{i \in S} \sum_{j \in S} x_{i j o} \leq|S|-1 & \forall S \subseteq(P \cup B), \text { where }|S| \geq 2, \forall o \in O \\
x_{i j o} \in\{0,1\} & \forall(i, j) \in A, \forall o \in O \\
y_{i j o}^{m} \geq 0 & \forall(i, j) \in A, \forall o \in O, \forall m \in M \\
z_{i} \in\{0,1\} & \forall i \in P
\end{array}
$$

\subsubsection{Model A2 Constraints Descriptions}

The objective function for Model A2, equation (9), subtracts the total revenue earned from collaborative shipments from the total transportation cost. Therefore, the objective function minimizes the overall cost of the carrier of interest's backhaul trips. Constraints (10) and (11) are truck flow conservation constraints for the collaborators' pick-up and delivery nodes. Constraint (11) ensures that at most one truck visits each pick-up node, thereby ensuring that an O-D shipment is not split. Constraint (10) ensures that the number of trucks leaving and arriving at a collaborator's node is equal. Therefore, constraints (10) and (11) ensure that the number of trucks arriving and leaving a collaborator's node is either zero or one. It also ensures that the collaborator's shipments will get from its origin to its destination. Constraints (12) and (13) are truck flow constraints for the empty trucks at the origin nodes, ensuring that exactly one trip leaves each origin node and no trips arrive at the origin nodes. Constraints (14) and (15) are truck flow constraints for the depot node, ensuring that each trip returns to the depot node and no trips 
leave it. Constraint (16) ensures that the product demand at all of the nodes is met; the demand at the collaborator nodes is only met if the nodes are visited. The demand for the origin and depot nodes is zero. It also ensures that each collaborator's shipment is delivered to its corresponding delivery node because the demand parameter has an O-D shipment type specification. Constraint (17) ensures that a backhaul route's total trip length does not exceed the maximum allowable trip length. This places a restriction on trucks to not fulfill those collaborator's shipments that will extend the backhaul trip beyond the maximum allowable driver hours. Constraint (18) ensures that the capacity of a truck is not exceeded; all trucks have equal capacity in this model. Because this model allows a truck to do multiple pick-ups followed by multiple deliveries, constraint (18) ensures that the sum of all shipments on a truck on each arc does not exceed the capacity. Constraint (19) must be included to eliminate any subtours in the solution and is the well-known generalized subtour elimination constraint (Toth et al., 2001). Without constraint (19), subtours could form between the collaborator nodes, which would go against the purpose of the model. Constraints (20) through (22) define the variables of Model A2: the variables $x_{i j o}$ and $z_{i}$ are integer variables taking the values of 0 or 1 ; the product flow variable $y_{i j o}{ }^{m}$ takes the value of zero or a positive real number. The next chapter describes the heuristics to solve Models A1 and A2 and the numerical analysis for these models. 


\section{CHAPTER 4. PROBLEM A SOLUTION METHODS AND NUMERICAL RESULTS}

\subsection{Introduction}

Model A1 is similar to a constrained matching problem and Model A2 is similar to a constrained vehicle routing problem with pickup and delivery (VRPPD). We present a greedy heuristic to solve Model A1 and a tabu search based heuristic to solve Model A2. Models A1 and A2 have integer variables and are difficult to solve for larger sized problems. Also Model A2 has the subtour elimination constraints which explode for any decent sized network. The greedy algorithm to solve Model A1 is described in the next subsection followed by the tabu search heuristic. Then the example network setup is described and the numerical analysis of Model A1 and Model A2 is provided.

\subsection{Greedy Algorithm}

Greedy algorithms can be used to solve many optimization problems. It does not always result in an optimal solution, but for many types of problems it does. In a greedy algorithm, a locally optimal solution is found in hopes that it will eventually find a globally optimal solution. In other words, the algorithm is a sequence of choices that seem best at the moment. Many weighted matching problems can be solved using a "greedy" heuristic methodology to obtain good solutions in a reasonable amount of time (Jordan, 1987). It provides a simple and efficient solution methodology. Therefore, we use a greedy matching algorithm to solve Model A1. This greedy method differs from Jordan's (1987) algorithm in that this method checks for capacity and time limitations. Let $A=\{(i \in O, j \in J)\}$ denote the set of arcs, where $O$ is the set of all origin nodes and $J$ is the set of all collaborator nodes and the depot node. The algorithm is as follows:

(1) Set all $x_{i j}=0$ for all $\operatorname{arcs}(i, j)$. 
(2) Delete any $(i, j)$ from list $A$ where the demand at $j$ exceeds the vehicle capacity, $C$.

(3) Select the arc $(i, j)$ from list $A$ which has the maximum value of arc savings, $s_{i j}$. $\left(s_{i j}\right.$ must be greater than or equal to zero). Remove the selected $(i, j)$ from list $A$.

(4) For the selected (i,j) in step (3), if $x_{i j} t_{i j} \leq T_{i}$ (the total trip length does not exceed the maximum trip length from origin $i)$, then set $x_{i j}=1$, remove any $\operatorname{arc}(i, j)$ from list $A$ that contains either the selected $i$ or selected $j$, except where the selected $j$ is the depot node $D$. If $x_{i j} t_{i j}>T_{i}$, go back to step (3).

(5) Repeat steps (3) and (4) until number of matched pairs $\left(x_{i j}=1\right)$ equals the number of origins, $O$.

The greedy algorithm might not produce optimal solutions to Model A1, but it provides good solutions for examining numerical results of the model. The tabu search methodology for solving Model A2 is described next.

\subsection{Tabu Search Methodology}

A brief overview of the Tabu search methodology used for solving Model A2 is provided in Figure 2. Tabu search was chosen among other meta-heuristics as it was found to be extremely efficient and thus popular for solving vehicle routing problems (Gendreau et al., 1991; Taillard et al., 1997; Cordeau et al., 1998). While the focus of the current paper is on a new problem definition and formulation, the design of the Tabu search heuristics follows the common principles (Glover, 1990). 


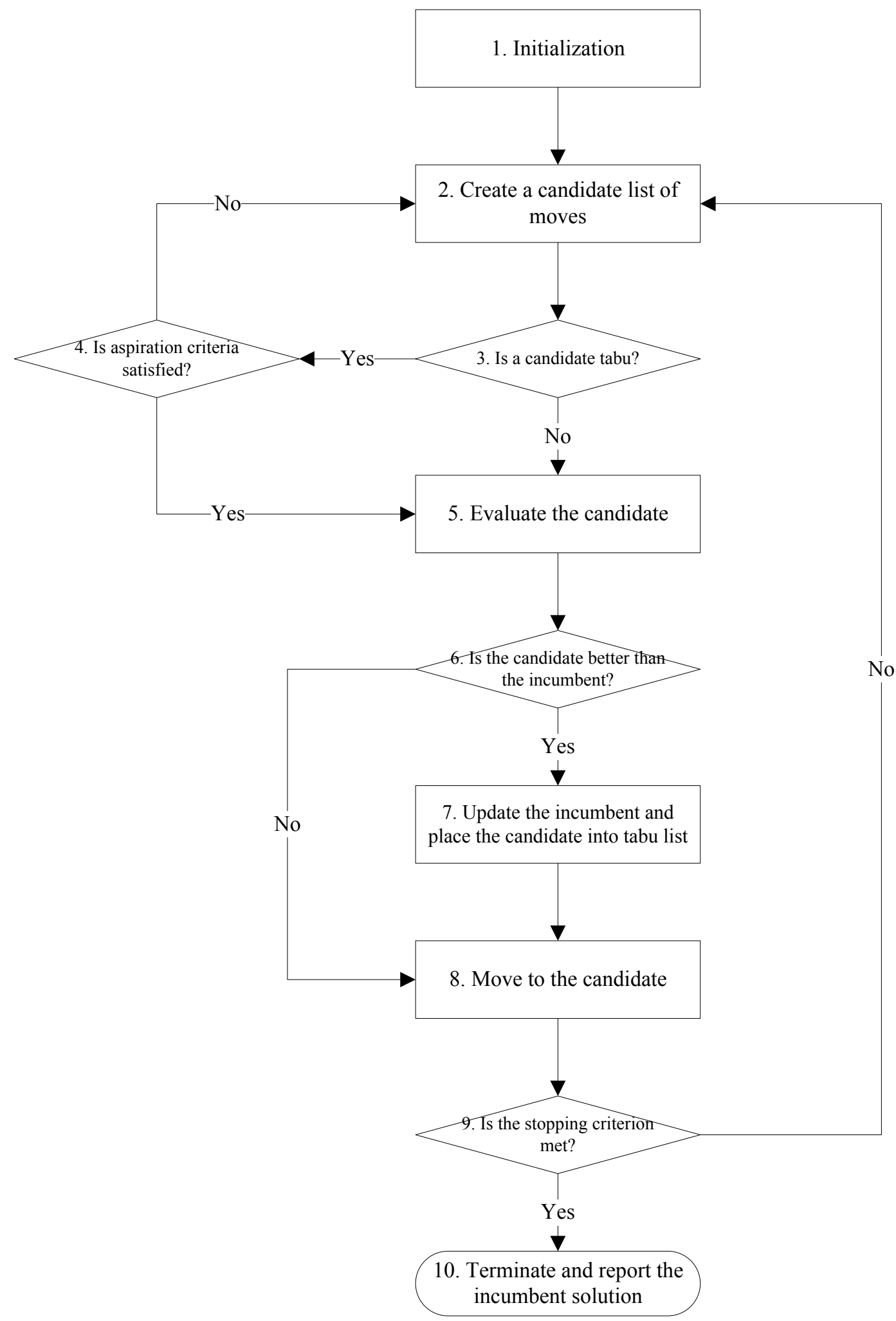

FIGURE 2 Tabu Search Flowchart 
Step 1 initializes the tabu search procedure by assuming that no collaborator's request is fulfilled. Further, initial parameters (the size of tabu list, maximum number of iteration, memory size and incumbent solution) are also assigned in that step. Step 2 creates a candidate list of moves where each move corresponds to a new solution generated from the current solution. Details of the neighborhood search and the edge-swapping procedure for generating candidate lists are available in Glover (1990). Step 3 selects a candidate move from the candidate list and checks if the selected candidate is tabu. If a candidate is tabu, go to Step 4. Otherwise, the procedure evaluates the performance of the move based on the objective function (Equation (9)) in Step 5. In Step 4, if a candidate satisfies aspiration criteria (yields better objective value than the incumbent solution), the procedure goes to Step 5. Otherwise, the procedure goes back to Step 2 and Step 3 to choose another candidate move. If the candidate move evaluated in Step 5 yields better objective value, the procedure goes to Step 7 to update the incumbent solution and places the move into the tabu list such that the move will not be admissible in the following few iterations. The procedure then moves to the candidate in Step 8 and checks the stopping criteria in Step 9. Two stopping criteria are employed in this research. The first one is the iteration limit which constrains the maximum number of iterations that can be performed. However, if the incumbent solution fails to improve over the pre-defined number of iterations, the procedure is terminated, which forms the second stopping criterion. If any of the stopping criteria is met, the procedure stops and the incumbent solution is reported. Otherwise, the procedure goes back to Step 2 and starts the procedure over again. 


\subsection{Problem A Numerical Analysis}

Computational runs are conducted to analyze the variation in model savings obtained through collaboration using Model A1 and Model A2. The example network used to analyze theses models is first described followed by the results from the computation runs.

\subsubsection{Example Network Setup}

An example network was used to implement Model A1 and Model A2 and to analyze the models' performance and potential cost savings for the carrier of interest. Real network data from a third-party logistics firm was used to establish the carrier of interest's inputs into the model. This data set includes 15 backhaul origin nodes and one depot node location. The depot node location is York, PA and the origin node locations are the following: Orlando, FL; Crofton, MD locations; Clementon, NJ; Glassboro, NJ; Robinsville, NJ; Olean, NY; Oneonta, NY; Miamisburg, OH; Troy, OH; Allentown, PA; Bensalem, PA; Hazleton, PA; Palmyra, PA; and Norfolk, VA. The maximum backhaul trip length, $T_{i}$ in Model 1 and $T_{o}$ in Model 2, was determined by considering the Federal Motor Carrier Safety Administration hours-of-service regulations for truck drivers (FMCSA, 2010). When fulfilling collaborator's shipping requests, the carrier of interest's backhaul trip should not be lengthened such that any driver's hours would exceed limits set by FMCSA regulations. The time constraints used for this model in hours for the origins are: $22.5,13,6.75,6.75,5.5,9.75,4.75,9.25,20,6,7,8.75,6,7.75,10.25$

respectively. To obtain potential collaborator pick-up and delivery locations and their O-D demand, we used shipping lanes from a real shipping network. We chose 45 of the O-D pairs as potential collaborators due to their geographic proximity to the carrier of interest's backhaul route network. Table 1 provides the list of potential collaborator nodes with the demand units. Due to privacy constraints, the trucking company did not reveal the nature of the goods and 
modified the demands. The truck fleet is considered homogenous for our example with capacities of 1000 demand units.

TABLE 1 Collaborator Nodes for Models A1 and A2

\begin{tabular}{|c|c|c|c|c|c|}
\hline Pick-up City & Delivery City & $\begin{array}{c}\text { Product } \\
\text { Demand } \\
\text { Units }\end{array}$ & Pick-up City & Delivery City & $\begin{array}{c}\text { Product } \\
\text { Demand } \\
\text { Units }\end{array}$ \\
\hline Jacksonville, FL & Charlotte, NC & 672 & Columbus, $\mathrm{OH}$ & Harrisburg, PA & 360 \\
\hline Jacksonville, FL & Rocky Mount, NC & 328 & Sidney, $\mathrm{OH}$ & Harrisburg, PA & 1083 \\
\hline Haines City, FL & Rocky Mount, NC & 1142 & Sidney, OH & Eighty Four, PA & 745 \\
\hline Lake Wales, FL & Charlotte, NC & 323 & Columbus, $\mathrm{OH}$ & Harrisburg, PA & 341 \\
\hline Lake Wales, FL & Baltimore, MD & 292 & Springfield, $\mathrm{OH}$ & Harrisburg, PA & 901 \\
\hline Savannah, GA & Charlotte, NC & 157 & York, PA & Harrisburg, PA & 429 \\
\hline Owings Mills, MD & Harrisburg, PA & 443 & Quakertown, PA & Harrisburg, PA & 155 \\
\hline Baltimore, MD & Harrisburg, PA & 375 & Coatesville, PA & Harrisburg, PA & 243 \\
\hline Gaithersburg, MD & Harrisburg, PA & 1270 & Hermitage, PA & York, PA & 234 \\
\hline Hampstead, MD & York, PA & 221 & Hershey, PA & Harrisburg, PA & 374 \\
\hline Mount Olive, NC & York, PA & 235 & York, PA & Harrisburg, PA & 126 \\
\hline Cherry Hill, NJ & Philadelphia, PA & 388 & York, PA & Manayunk, PA & 758 \\
\hline Cranbury, NJ & Philadelphia, PA & 400 & Leola, PA & York, PA & 155 \\
\hline Trenton, NJ & Philadelphia, PA & 303 & Manheim, PA & Philadelphia, PA & 4290 \\
\hline South Brunswick, NJ & Pennsauken, NJ & 576 & Bethlehem, PA & Manayunk, PA & 225 \\
\hline Edison, $\mathrm{NJ}$ & Philadelphia, PA & 224 & Breinigsville, PA & Philadelphia, PA & 299 \\
\hline North Brunswick, NJ & Pennsauken, NJ & 672 & Hazleton, PA & Philadelphia, PA & 262 \\
\hline North Brunswick, NJ & Philadelphia, PA & 229 & Plains, PA & Harrisburg, PA & 591 \\
\hline Totowa, NY & Harrisburg, PA & 192 & Philadelphia, PA & Harrisburg, PA & 378 \\
\hline Canandaigua, NY & Conklin, NY & 1656 & King of Prussia, PA & York, PA & 315 \\
\hline Canandaigua, NY & Harrisburg, PA & 823 & Leesport, PA & York, PA & 342 \\
\hline Silver Springs, NY & Kirkwood, NY & 199 & Richmond, VA & Harrisburg, PA & 239 \\
\hline Middletown, NY & York, PA & 667 & & & \\
\hline
\end{tabular}

The data set structure for the transportation costs, revenue, travel time, and product demand varies from Model A1 to Model A2. For the Model A2 parameter, $t_{i j}$, the travel time between every node in the network was determined and 1 hour for loading time and 1 hour for unloading time was added to arcs containing pick-up or delivery nodes, respectively. The Model A2 data set for transportation costs required finding the distance between each node in the network, and applying a unit cost per mile. The base cost per mile used for both models' networks was $\$ 1.60$ per mile and is based on typical industry values. Additional data sets were 
established using variations to the cost and the results are shown in the next section. The revenue parameter, $r_{i}$, in Model A2 represents the collaborator's compensation for satisfying a shipment request from node $i$. Each $r_{i}$ was taken as a percentage of the transportation cost, $c_{i j}$, from its pick-up node to its delivery node. This revenue percentage was varied from $30 \%$ to $50 \%$ during the numerical analysis of the models. The product demand input for Model A2 consisted of identifying product demand for each O-D pair $m$, in which there was zero demand at every origin node and the depot node, positive demand at each pick-up node and negative demand at each delivery node. Most of Model A1's data set can be taken from Model A2's data set. The transportation time, $t_{i j}$, is not needed between every node as in Model A2, but only from each origin node to each pick-up node, each pick-up node to its corresponding delivery node, and from each delivery node to the depot node. The loading and unloading time was added to the transportation time in Model A1 as discussed earlier for Model A2. The collaborative savings, $s_{i j}$, data input of Model A1 is computed from transportation costs and collaborative revenues as previously described in equations (1) and (2). The transportation costs for the backhaul routes and revenue of each collaborator's shipment were found in the same manner as they were for Model A2. The input for product demand of collaborator's shipments is the same as in Model A2 but simplified in that there's only one positive demand value for each collaborator.

\subsubsection{Model A1 - Analysis of Results}

Table 2 summarizes the percent cost savings obtained from Model A1 and A2 with variations to the transportation arc cost and the revenue percentage parameter. The fourth column, the total cost of backhauls without collaboration, is the cost of all backhaul routes to travel from the origin node to the depot node. The fifth column shows the total cost savings with collaboration and for Model A1 this is the objective value solution. Computation times of 
running the models are also provided in Table 2 . The $\$ 1.60 /$ mile transportation cost is considered our "typical" cost and additional results are shown for transportation costs ranging from $\$ 1.20 /$ mile to $\$ 2.00 /$ mile. The results of Model A1 show that varying the transportation cost does not affect the number of matched backhauls to collaborators. The percent cost savings also does not vary with transportation costs. For example, a $\$ 1.20 /$ mile transportation cost at the $30 \%$ revenue level results in 10 matched pairs and a collaborative cost savings of $13.17 \%$; a $\$ 2.00 /$ mile transportation cost at the $30 \%$ revenue level produces these results. The savings dollar amount increases with transportation cost increase because the transportation cost is built into the computation of revenue and savings.

Variations to the percent revenue show that more backhaul routes are paired with collaborators at a higher percent revenue than at a lower percent revenue. As shown in Table 2, when the percent revenue is set at $30 \%$ and $40 \%$ of the transportation cost, 10 out of the 15 carrier of interest's backhaul routes are matched with a collaborator's shipment. When the percent revenue is $50 \%$, an additional 3 backhaul routes are matched with collaborator's shipments. The cost savings experienced for the backhaul routes are found to range from about $13 \%$ to $27 \%$ for the three revenue levels. More of the longer mileage backhaul routes match up with collaborators at the $30 \%$ revenue level than the shorter mileage routes. Results show that backhaul routes match up with collaborator O-D pairs that are very close geographically to the backhaul route, which is as expected. Collaborator O-D shipments that consist of longer hauls are more likely to be matched with a backhaul route than those with shorter hauls. This is because the revenue, $r_{i}$, that the carrier of interest receives is greater for the longer O-D hauls. It should be noted that the assumption is made that all collaborators are willing to pay the compensation price to the carrier of interest, be it $30 \%, 40 \%$ or $50 \%$ of the carrier of interest's 
shipping costs. Typically this price would be appealing to a collaborative shipper, but not appealing for all collaborative carriers. Further research could explore the development of a profit sharing mechanism incorporated with the models presented in this paper. The greedy heuristic for Model A1 takes on an average $20 \%$ of the time needed to solve the tabu search heuristic for Model A2 on a Dell Latitude Laptop with Core 2 Duo $2.53 \mathrm{GHz}$ processor with 3 GB Ram.

TABLE 2 Model A1 Results with Variations in Transportation Cost and Percent Revenue Parameters

\begin{tabular}{|c|c|c|c|c|c|c|}
\hline $\begin{array}{c}\text { Transportation } \\
\text { arc cost } \\
\text { parameter }\end{array}$ & $\begin{array}{c}\text { Percentage } \\
\text { revenue } \\
\text { parameter }\end{array}$ & $\begin{array}{c}\text { Number of } \\
\text { backhaul } \\
\text { routes matched } \\
\text { to } \\
\text { collaborators }\end{array}$ & $\begin{array}{c}\text { Total cost of } \\
\text { backhauls } \\
\text { without } \\
\text { collaboration }\end{array}$ & $\begin{array}{c}\text { Total cost } \\
\text { savings with } \\
\text { collaboration }\end{array}$ & $\begin{array}{c}\text { Percent cost } \\
\text { savings of } \\
\text { ackhauls with } \\
\text { collaboration }\end{array}$ & $\begin{array}{c}\text { Computation } \\
\text { time (sec) }\end{array}$ \\
\hline \multirow{2}{*}{$\begin{array}{c}\$ 1.20 / \\
\text { mile }\end{array}$} & $30 \%$ & 10 & $\$ 4,279.20$ & $\$ 563.52$ & $13.17 \%$ & 0.047 \\
\cline { 2 - 7 } & $40 \%$ & 10 & $\$ 4,279.20$ & $\$ 848.16$ & $19.82 \%$ & 0.032 \\
\hline \multirow{2}{*}{$\begin{array}{c}\$ 1.40 / \\
\text { mile }\end{array}$} & $30 \%$ & 13 & $\$ 4,279.20$ & $\$ 1,156.80$ & $27.03 \%$ & 0.031 \\
\cline { 2 - 7 } & $40 \%$ & 10 & $\$ 4,992.40$ & $\$ 657.44$ & $13.17 \%$ & 0.047 \\
\hline \multirow{2}{*}{$\begin{array}{c}\$ 1.60 / \\
\text { mile }\end{array}$} & $30 \%$ & 13 & $\$ 4,992.40$ & $\$ 989.52$ & $19.82 \%$ & 0.047 \\
\cline { 2 - 7 } & $40 \%$ & 10 & $\$ 5,705.60$ & $\$ 751.36$ & $13.17 \%$ & 0.031 \\
\hline \multirow{2}{*}{$\begin{array}{c}\$ 1.80 / \\
\text { mile }\end{array}$} & $30 \%$ & 13 & $\$ 5,705.60$ & $\$ 1,130.88$ & $19.82 \%$ & 0.047 \\
\cline { 2 - 7 } & $40 \%$ & 10 & $\$ 5,705.60$ & $\$ 1,542.40$ & $27.03 \%$ & 0.031 \\
\hline \multirow{2}{*}{$\begin{array}{c}\$ 2.00 / \\
\text { mile }\end{array}$} & $30 \%$ & 13 & $\$ 6,418.80$ & $\$ 845.28$ & $13.17 \%$ & 0.031 \\
\cline { 2 - 7 } & $40 \%$ & 10 & $\$ 7,132.00$ & $\$ 939.20$ & $13.17 \%$ & 0.047 \\
\cline { 2 - 7 } & $50 \%$ & 13 & $\$ 7,132.00$ & $\$ 1,928.00$ & $27.03 \%$ & 0.047 \\
\hline
\end{tabular}

Effects of Model A1 results to variations of loading and unloading times at the collaborator pick-up and delivery locations are shown in Table 3. The loading/unloading times for the base data sets utilizes times of 1 hour for loading and 1 hour for unloading, which is typical of the carrier of interest's existing schedule. The results in Table 3 are from model runs 
all using the $30 \%$ revenue level and the base $\$ 1.60 /$ mile transportation cost. For the example network, reducing the loading/unloading times to 0.5 hour and 0.75 hour did not reduce the number of matched pairs as compared to the 1 hour times. Extending the loading/unloading times to 1.25 hour and 1.5 hour reduced the number of matched pairs to 7 out of 15 . The percent cost savings is higher for the 1.25 hour case than the 1.5 hour case because the 7 matched pairs are not the same 7 collaborators.

\section{TABLE 3 Model A1 Results with Variations in Unloading and Loading Times}

\begin{tabular}{|c|c|c|c|c|}
\hline $\begin{array}{c}\text { Unloading and } \\
\text { loading time } \\
\text { parameters } \\
\text { (hours) }\end{array}$ & $\begin{array}{c}\text { Number of } \\
\text { backhaul } \\
\text { routes matched } \\
\text { to } \\
\text { collaborators }\end{array}$ & $\begin{array}{c}\text { Total cost of } \\
\text { backhauls } \\
\text { without } \\
\text { collaboration* }\end{array}$ & $\begin{array}{c}\text { Total cost } \\
\text { savings with } \\
\text { collaboration* }\end{array}$ & $\begin{array}{c}\text { Percent cost } \\
\text { savings of } \\
\text { backhauls with } \\
\text { collaboration }\end{array}$ \\
\hline 0.5 & 10 & $\$ 5,705.60$ & $\$ 751.36$ & $13.17 \%$ \\
\hline 0.75 & 10 & $\$ 5,705.60$ & $\$ 751.36$ & $13.17 \%$ \\
\hline 1 & 10 & $\$ 5,705.60$ & $\$ 751.36$ & $13.17 \%$ \\
\hline 1.25 & 7 & $\$ 5,705.60$ & $\$ 660.58$ & $11.58 \%$ \\
\hline 1.5 & 7 & $\$ 5,705.60$ & $\$ 649.28$ & $11.38 \%$ \\
\hline
\end{tabular}

*All trials use a transportation arc cost of $\$ 1.60 /$ mile and $30 \%$ revenue

The sensitivity of Model A1 results to reduction in the maximum backhaul time length parameter was analyzed and the results are shown in Table 4. Recall that the maximum backhaul time length, $T_{i}$, is based on the FMCSA hours-of-service rules (FMCSA, 2010). Results in Table 4 show the affects of reducing the original $T_{i}$ values by $10 \%$. At the $50 \%$ revenue level, the reduced $T_{i}$ results in only 9 of the 15 backhaul routes matching with a collaborative shipment while the original $T_{i}$ values have 13 of the 15 routes matched. 
TABLE 4 Model A1 Results with Reduction of the Maximum Backhaul Time Parameter

\begin{tabular}{|c|c|c|c|c|c|}
\hline $\begin{array}{c}\text { Maximum } \\
\text { backhaul trip } \\
\text { length }\end{array}$ & $\begin{array}{c}\text { Percentage } \\
\text { revenue } \\
\text { parameter }\end{array}$ & $\begin{array}{c}\text { Number of } \\
\text { backhaul } \\
\text { routes matched } \\
\text { to } \\
\text { collaborators }\end{array}$ & $\begin{array}{c}\text { Total cost of } \\
\text { backhauls } \\
\text { without } \\
\text { collaboration* }\end{array}$ & $\begin{array}{c}\text { Total cost } \\
\text { savings with } \\
\text { collaboration }\end{array}$ & $\begin{array}{c}\text { Percent cost } \\
\text { savings of } \\
\text { backhauls with } \\
\text { collaboration }\end{array}$ \\
\hline \multirow{2}{*}{ Original } & $30 \%$ & 10 & $\$ 5705.60$ & $\$ 751.36$ & $13.17 \%$ \\
\cline { 2 - 6 } & $40 \%$ & 10 & $\$ 5705.60$ & $\$ 1,130.88$ & $19.82 \%$ \\
\hline \multirow{2}{*}{$\begin{array}{c}10 \% \\
\text { Reduction }\end{array}$} & $30 \%$ & 13 & $\$ 5705.60$ & $\$ 1,542.40$ & $27.03 \%$ \\
\cline { 2 - 6 } & $40 \%$ & 7 & $\$ 5705.60$ & $\$ 660.48$ & $11.58 \%$ \\
\hline
\end{tabular}

*All trials use a transportation arc cost of $\$ 1.60 /$ mile

\subsubsection{Model A2- Analysis of Results}

Model A2 was solved using the tabu search heuristic. After sensitivity analysis, the parameters used in the tabu search were: (i) max number of iterations - 2000, (ii) size of tabu list - 7. Also the program is terminated if the incumbent solutions fail to improve over 100 iterations. The results of Model A2 are summarized in Tables 5 through 8 . Table 5 shows the results of Model A2 when the transportation arc costs and the percent revenue parameters are varied. Model A2 results show some similar trends to the Model A1 results. Model A2 results show that changing the transportation arc cost while keeping the percent revenue constant does not affect the number of backhaul routes matched to collaborators or affect the percent cost savings. The increasing of the percent revenue parameter does not have as much of an effect on the number of matched pairs as it does for Model A1. For the computational runs using \$1.20/mile transportation cost, only one additional backhaul route is matched when increasing the percent revenue from $30 \%$ to $50 \%$. For the other transportation cost trials, the number of matched backhaul routes does not increase with increased percent revenue. Model A2 has more matched backhaul routes than Model A1 at the 30\% and 40\% revenue levels, but Model A1 has more matched backhauls than Model A2 at the 50\% revenue level. However, all trials of Model A2 
experience more percent cost savings than Model A1. This is because some of the matched

backhaul routes are matched to more than 1 collaborator. Model A1 does not allow for a

backhaul route to fulfill more than 1 collaborator's demand. Table 6 shows how many

collaborators each backhaul route is matched with for varying transportation costs and revenues.

Some of the backhauls are matched with two collaborators, and the backhaul route from origin 9

is matched with up to 3 collaborators.

TABLE 5 Model A2 Results with Variations in Transportation Cost and Percent Revenue Parameters

\begin{tabular}{|c|c|c|c|c|c|c|}
\hline \multirow{2}{*}{$\begin{array}{c}\text { Transportation } \\
\text { arc cost } \\
\text { parameter }\end{array}$} & $\begin{array}{c}\text { Percentage } \\
\text { revenue } \\
\text { parameter }\end{array}$ & $\begin{array}{c}\text { Number of } \\
\text { backhaul } \\
\text { routes matched } \\
\text { to } \\
\text { collaborators }\end{array}$ & $\begin{array}{c}\text { Total cost of } \\
\text { backhauls } \\
\text { without } \\
\text { collaboration }\end{array}$ & $\begin{array}{c}\text { Total cost } \\
\text { savings with } \\
\text { collaboration }\end{array}$ & $\begin{array}{c}\text { Percent cost } \\
\text { savings of } \\
\text { backhauls with } \\
\text { collaboration }\end{array}$ & $\begin{array}{c}\text { Computation } \\
\text { time (sec) }\end{array}$ \\
\hline \multirow{2}{*}{$\begin{array}{c}\$ 1.20 / \\
\text { mile }\end{array}$} & $30 \%$ & 11 & $\$ 4,279.20$ & $\$ 706.32$ & $16.51 \%$ & 0.203 \\
\cline { 2 - 7 } & $40 \%$ & 11 & $\$ 4,279.20$ & $\$ 941.76$ & $22.01 \%$ & 0.203 \\
\hline \multirow{2}{*}{$\begin{array}{c}\$ 1.40 / \\
\text { mile }\end{array}$} & $30 \%$ & 12 & $\$ 4,279.20$ & $\$ 1,177.20$ & $27.51 \%$ & 0.218 \\
\cline { 2 - 7 } & $50 \%$ & 11 & $\$ 4,992.40$ & $\$ 824.04$ & $16.51 \%$ & 0.218 \\
\hline \multirow{2}{*}{$\begin{array}{c}\$ 1.60 / \\
\text { mile }\end{array}$} & $30 \%$ & 11 & $\$ 5,7992.40$ & $\$ 1,098.72$ & $22.01 \%$ & 0.203 \\
\cline { 2 - 7 } & $50 \%$ & 11 & $\$ 5,705.60$ & $\$ 1,255.68$ & $22.01 \%$ & 0.218 \\
\hline \multirow{2}{*}{$\begin{array}{c}\$ 1.80 / \\
\text { mile }\end{array}$} & $30 \%$ & 11 & $\$ 5,705.60$ & $\$ 1,569.60$ & $27.51 \%$ & 0.218 \\
\cline { 2 - 7 } & $40 \%$ & 11 & $\$ 6,418.80$ & $\$ 1,059.48$ & $16.51 \%$ & 0.234 \\
\hline \multirow{2}{*}{$\begin{array}{c}\$ 2.00 / \\
\text { mile }\end{array}$} & $30 \%$ & 11 & $\$ 6,418.80$ & $\$ 1,412.64$ & $22.01 \%$ & 0.218 \\
\cline { 2 - 7 } & $40 \%$ & 11 & $\$ 7,13.80$ & $\$ 1,765.80$ & $27.51 \%$ & 0.188 \\
\cline { 2 - 7 } & $50 \%$ & 11 & $\$ 7,132.00$ & $\$ 1,962.00$ & $27.51 \%$ & 0.218 \\
\hline
\end{tabular}


TABLE 6 Model 2 Results for Number of Collaborators Serviced on Each Route

\begin{tabular}{|c|c|c|c|c|c|c|c|c|c|c|c|c|c|c|c|}
\hline \multirow{3}{*}{ Route } & \multicolumn{3}{|c|}{$\$ 1.20 /$ mile } & \multicolumn{3}{|c|}{$\$ 1.40 /$ mile } & \multicolumn{3}{|c|}{$\$ 1.60 /$ mile } & \multicolumn{3}{|c|}{$\$ 1.80 /$ mile } & \multicolumn{3}{|c|}{$\$ 2.0 /$ mile } \\
\hline & 30 & 40 & 50 & 30 & 40 & 50 & 30 & 40 & 50 & 30 & 40 & 50 & 30 & 40 & 50 \\
\hline & $\%$ & $\%$ & $\%$ & $\%$ & $\%$ & $\%$ & $\%$ & $\%$ & $\%$ & $\%$ & $\%$ & $\%$ & $\%$ & $\%$ & $\%$ \\
\hline 1 & 2 & 2 & 2 & 2 & 2 & 2 & 2 & 2 & 2 & 2 & 2 & 2 & 2 & 2 & 2 \\
\hline 2 & 0 & 0 & 0 & 0 & 0 & 0 & 0 & 0 & 0 & 0 & 0 & 0 & 0 & 0 & 0 \\
\hline 3 & 0 & 0 & 0 & 0 & 0 & 0 & 0 & 0 & 0 & 0 & 0 & 0 & 0 & 0 & 0 \\
\hline 4 & 0 & 0 & 0 & 0 & 0 & 0 & 0 & 0 & 0 & 0 & 0 & 0 & 0 & 0 & 0 \\
\hline 5 & 1 & 1 & 1 & 1 & 1 & 1 & 1 & 1 & 1 & 1 & 1 & 1 & 1 & 1 & 1 \\
\hline 6 & 1 & 1 & 1 & 1 & 1 & 1 & 1 & 1 & 1 & 1 & 1 & 1 & 1 & 1 & 1 \\
\hline 7 & 1 & 1 & 1 & 1 & 1 & 1 & 1 & 1 & 1 & 1 & 1 & 1 & 1 & 1 & 1 \\
\hline 8 & 1 & 1 & 1 & 1 & 1 & 1 & 1 & 1 & 1 & 1 & 1 & 1 & 0 & 1 & 1 \\
\hline 9 & 3 & 3 & 3 & 3 & 3 & 3 & 3 & 3 & 3 & 2 & 3 & 3 & 2 & 3 & 3 \\
\hline 10 & 1 & 1 & 1 & 1 & 1 & 1 & 1 & 1 & 1 & 1 & 1 & 1 & 1 & 1 & 1 \\
\hline 11 & 1 & 1 & 1 & 1 & 1 & 1 & 1 & 1 & 1 & 1 & 1 & 1 & 1 & 1 & 1 \\
\hline 12 & 2 & 1 & 1 & 2 & 2 & 1 & 1 & 2 & 1 & 1 & 2 & 2 & 1 & 1 & 2 \\
\hline 13 & 0 & 1 & 1 & 0 & 0 & 1 & 0 & 0 & 1 & 0 & 0 & 0 & 1 & 0 & 0 \\
\hline 14 & 1 & 2 & 2 & 1 & 1 & 2 & 1 & 1 & 1 & 1 & 1 & 1 & 1 & 1 & 1 \\
\hline 15 & 2 & 2 & 2 & 2 & 2 & 2 & 1 & 2 & 2 & 1 & 2 & 2 & 1 & 2 & 2 \\
\hline
\end{tabular}

Table 7 summarizes how Model A2 is affected by variations to the loading and unloading time parameters. The results in Table 7 are from model runs all using the $30 \%$ revenue level and the base $\$ 1.60 /$ mile transportation cost. Similar to Model A1 results, Model A2 results show that increasing the loading and unloading times above 1 hour causes the number of matched backhauls to decrease by 3 backhauls.

TABLE 7 Model A2 Results with Variations in Unloading and Loading Times

\begin{tabular}{|c|c|c|c|c|}
\hline $\begin{array}{c}\text { Unloading and } \\
\text { loading time } \\
\text { parameters } \\
\text { (hours) }\end{array}$ & $\begin{array}{c}\text { Number of } \\
\text { backhaul } \\
\text { routes matched } \\
\text { to } \\
\text { collaborators }\end{array}$ & $\begin{array}{c}\text { Total cost of } \\
\text { backhauls } \\
\text { without } \\
\text { collaboration* }\end{array}$ & $\begin{array}{c}\text { Total cost } \\
\text { savings with } \\
\text { collaboration* }\end{array}$ & $\begin{array}{c}\text { Percent cost } \\
\text { savings of } \\
\text { backhauls with } \\
\text { collaboration }\end{array}$ \\
\hline 0.5 & 11 & $\$ 5,705.60$ & $\$ 941.76$ & $16.51 \%$ \\
\hline 0.75 & 11 & $\$ 5,705.60$ & $\$ 941.76$ & $16.51 \%$ \\
\hline 1 & 11 & $\$ 5,705.60$ & $\$ 930.48$ & $16.31 \%$ \\
\hline 1.25 & 8 & $\$ 5,705.60$ & $\$ 726.48$ & $12.73 \%$ \\
\hline 1.5 & 8 & $\$ 5,705.60$ & $\$ 726.48$ & $12.73 \%$ \\
\hline
\end{tabular}

*All trials use a transportation arc cost of $\$ 1.60 /$ mile and $30 \%$ revenue 
Model A2 results for reduction in the maximum backhaul length parameter, $T_{o}$, are summarized in Table 8 and reveal similarities with Model A1 results from Table 4. When the maximum backhaul time length is reduced by $10 \%$ from the original times, the number of matched backhaul routes decreases between 2 to 3 backhauls, depending on percent revenue.

TABLE 8 Model A2 Results with Reduction of the Maximum Backhaul Time Parameter

\begin{tabular}{|c|c|c|c|c|c|}
\hline $\begin{array}{c}\text { Maximum } \\
\text { backhaul trip } \\
\text { length }\end{array}$ & $\begin{array}{c}\text { Percentage } \\
\text { revenue } \\
\text { parameter }\end{array}$ & $\begin{array}{c}\text { Number of } \\
\text { backhaul } \\
\text { routes matched } \\
\text { to } \\
\text { collaborators }\end{array}$ & $\begin{array}{c}\text { Total cost of } \\
\text { backhauls } \\
\text { without } \\
\text { collaboration* }\end{array}$ & $\begin{array}{c}\text { Total cost } \\
\text { savings with } \\
\text { collaboration }\end{array}$ & $\begin{array}{c}\text { Percent cost } \\
\text { savings of } \\
\text { backhauls with } \\
\text { collaboration }\end{array}$ \\
\hline \multirow{2}{*}{ Original } & $30 \%$ & 11 & $\$ 5705.60$ & $\$ 941.76$ & $16.51 \%$ \\
\cline { 2 - 6 } & $40 \%$ & 11 & $\$ 5705.60$ & $\$ 1,255.68$ & $22.01 \%$ \\
\hline \multirow{2}{*}{$\begin{array}{c}10 \% \\
\text { Reduction }\end{array}$} & $30 \%$ & 11 & $\$ 5705.60$ & $\$ 1,569.60$ & $27.51 \%$ \\
\cline { 2 - 6 } & $40 \%$ & 8 & $\$ 5705.60$ & $\$ 755.52$ & $13.24 \%$ \\
\hline
\end{tabular}

*All trials use a transportation arc cost of $\$ 1.60 /$ mile

In this chapter the solution methodologies have been presented: a greedy algorithm to solve Model A1; a tabu search heuristic to solve Model A2. The example network was constructed using a real world freight network, with modified parameters. Assumptions were made where information was not provided. Numerical analysis was performed on the two models using the example network to reveal potential cost savings of the collaboration framework A. 


\section{CHAPTER 5. PROBLEM B MODEL FORMULATION}

\subsection{Problem B Description}

The second collaboration framework presented in the thesis demonstrates how full truckload shippers can collaborate their truck movements to attain lower rates from a common carrier. This problem, named Problem B, is particularly applicable to shippers who have long haul truckload shipments and have costly empty trips to return to their depot or origin. These deadhead miles cause increase in rates that carriers offer to shippers. Problem B matches shippers to form loops between their lanes, to reduce empty repositioning miles. The shippers can then provide bundled lanes to a common carrier and realize lower rates.

Figure 3 demonstrates a simple example of collaboration under problem B. Given four shippers with two of the shipping lanes' origins near the other two shipping lanes' destinations, the potential to form two loops with the four shipping lanes is great. As can be seen in Figure 3, the collaboration scenario involves much shorter reposition arcs, resulting in less costs for the four shippers.

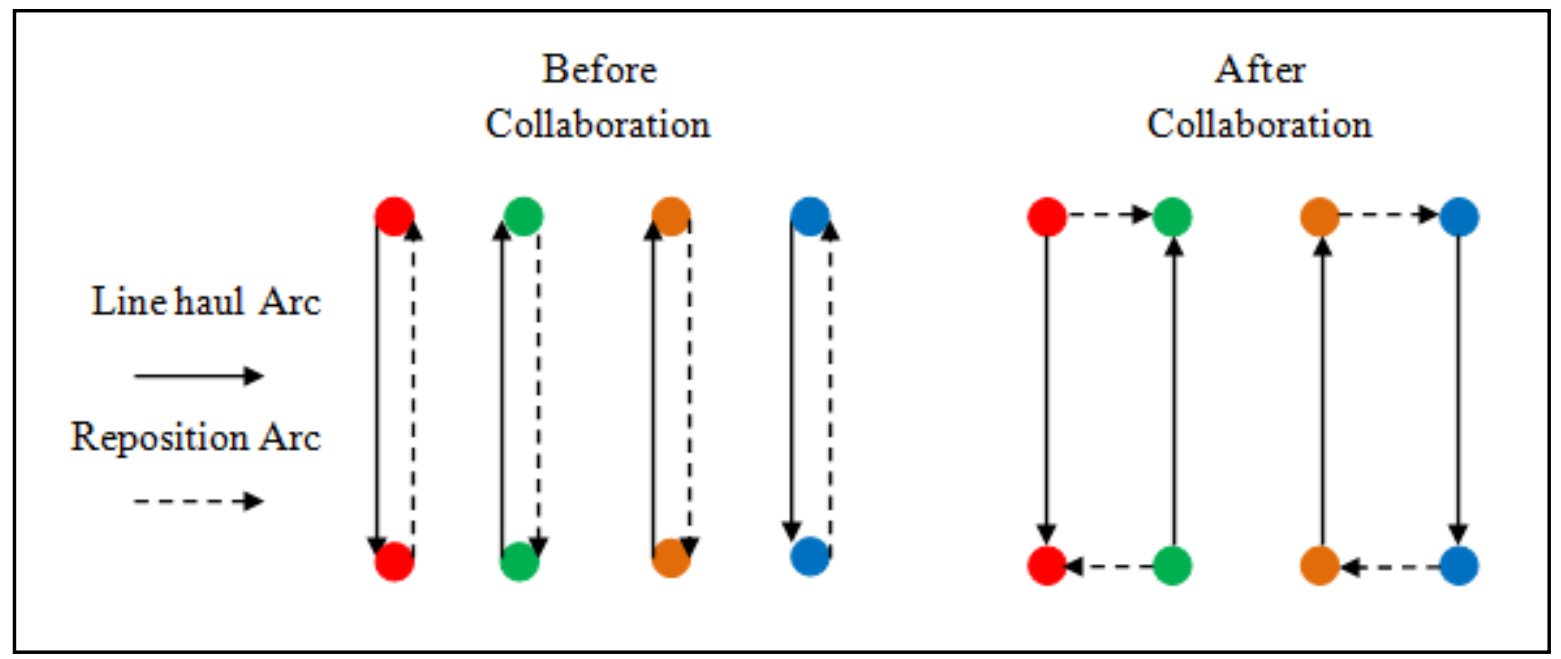

FIGURE 3 Simple Example for Model B 
Problem B is a capacitated loop model and is formulated as a mixed integer program. One significant difference between this framework and the framework of Problem A is that this is a "full" collaboration, where the all shipper's points of view are taken into consideration. The problem consists of a group of collaborative shippers whose shipping lanes and truck capacities are taken in common to route trucks such that all shipping lanes are covered and all the demand is met. This is accomplished through the creation of loops, or cycles. Each loop starts and ends at an origin node and covers a set of shipping lanes and reposition arcs. Reposition arcs connect O-D shipping lanes in order to form a loop. The model minimizes the transportation cost all of the loops while meeting the demand of all the shippers. More than one loop, or truck route, can cover a lane to ensure all of the demand is met, meaning an O-D shipment can be split up into more than one truck movement. The model assigns arcs to loops to accomplish the routing of trucks while minimizing the cost of the loops. The number of loops $l$ in the model is the maximum number of truck routes that can be formed by the network. The worst case scenario is that all shippers operate separately, and therefore, the set of all loops $l$ is equal to the number of truck routes to fulfill all of the shippers' demand. Depending on truck capacity, some shippers could require multiple truck routes to complete the demand of a shipping lane. Truck capacity is taken into consideration in the model and a homogenous fleet is assumed. Because this collaborative scenario is from the perspective of the whole collaborative network, it is of interest to examine an effective and fair method of allocating the costs to the shippers. The routing is accomplished first by solving Model B, followed by cost allocation to the shippers. The cost allocation methodologies used in the thesis are provided in Chapter 6. The following is the formulation of Model B: 


\subsection{Model B Parameters}

$N \quad$ set of all nodes $i$

A $\quad$ set of all $\operatorname{arcs}(i, j)$

$L \quad$ set of all loops $l$

$M \quad$ set of all O-D shipment lanes $m$

$u_{i}^{m} \quad$ demand at node $i$ for O-D shipment $m$

$K \quad$ maximum number of arcs for each loop

$c_{i j} \quad$ cost to traverse $\operatorname{arc}(i, j)$

C truck capacity

\subsection{Model B Variables}

$x_{i j l} \quad$ binary decision variable indicating whether arc $(i, j)$ is covered by loop $l$

$y_{i j l}{ }^{m} \quad$ product flow on arc $(i, j)$ for loop $l$ of O-D shipment $m$

\subsection{Model B Formulation}

$$
\begin{aligned}
& \text { Minimize } \sum_{(i, j) \in A} \sum_{l \in L} c_{i j} x_{i j l} \\
& \sum_{j \in N} x_{i j l}-\sum_{j \in N} x_{j i l}=0 \quad \forall i \in N, \forall l \in L \\
& \sum_{j \in N} \sum_{l \in L} y_{i j l}^{m}-\sum_{j \in N} \sum_{l \in L} y_{j i l}^{m}=u_{i}^{m} \sum_{j \in N} \sum_{l \in L} x_{i j l} \quad \forall m \in M, \forall i \in N \\
& \sum_{m \in M} y_{i j l}^{m} \leq C * x_{i j l} \quad \forall(i, j) \in A, \forall l \in L \\
& \sum_{(i, j) \in A} x_{i j l} \leq K \quad \forall l \in L
\end{aligned}
$$




$$
\begin{array}{ll}
y_{i j l}^{m} \geq 0 & \forall(i, j) \in A, \forall l \in L, \forall m \in M \\
x_{i j l}=\{0,1\} & \forall(i, j) \in A, \forall l \in L
\end{array}
$$

\subsection{Model B Constraints Descriptions}

The objection function of Model B (23) minimizes the total transportation cost of all the loops in the network. Constraint (24) is a flow balance constraint, ensuring that the number of arcs coming into a node equals the number of arcs coming out of the node for each loop. Constraint (25) is a product flow balance constraint ensuring that the demand at each node is met. This constraint allows O-D shipments to be split up into multiple loops. Constraint (26) ensures that the truck capacity is not exceeded on each arc of the loop. Constraint (27) provides a limit on the maximum number of arcs per loop. This provides the model with a length constraint on each loop, to restrict how many consecutive days a driver would work to complete a cycle. This is not as precise of a time constraint as the ones used in Models A1 and A2, but allows for some restriction on the length of a truck cycle. After Model B solves the routing, the loops can then be examined to determine loops that would cause the driver to exceed maximum driver hours set by the Federal Motor Carrier Safety Administration and reconfigure those select loops. Constraints (28) and (29) define the decision variables of Model B. The product flow variable $y_{i j l}{ }^{m}$ can take the value of any positive real number or zero. The variable $x_{i j l}$ can take the value of 0 or 1.

Note that Ergun et al. (2007b) prove that the cardinality constrained lane covering problem (CCLP) is NP - Hard. The above formulation can be viewed as a capacitated cardinality constrained lane covering problem (CCCLP). CCLP can be viewed as a special case of the CCCLP with sufficiently high capacities. If we had a polynomial time algorithm for CCCLP then 
the CCLP can also be solved in polynomial time. Therefore CCCLP is also an NP -Hard problem. The next chapter presents the solution methodology for solving Model B and cost allocation methodologies, followed by the numerical analysis. 


\section{CHAPTER 6. PROBLEM B SOLUTION METHODOLOGY AND NUMERICAL RESULTS}

\subsection{Tabu search solution methodology}

To solve the capacitated loop model, Model B, the tabu search methodology is used due to its efficiency in solving vehicle routing problems (Gendreau et al., 1991; Taillard et al., 1997; Cordeau et al., 1998). Because Model B has integer variables, it becomes difficult to solve for larger networks. Tabu search provides good results with reasonable computation time. The methodology to solve Model B is very similar to the methodology used to solve Model A2, as described in Section 4.2, with one notable difference. In this implementation of tabu search, neighborhood solutions are generated using a two step process. In the first step a random lane is linked with a random loop in the current solution. In the second step, a new loop is created by combining the linked loop and the random lane.

\subsection{Cost allocation methodology}

Cooperative game theory analyzes situations where a group of players, or members, may operate together either partially or fully to obtain benefits. It provides frameworks for profit/cost allocation when a set of members called coalitions agree to collaborate (Shoham et al., 2009). Model B forms least cost loops between shipping lanes but a framework for allocating the costs to the shippers needs to be specified. Since every shipper brings very different contributions to the collaboration, it is important that a cost allocation methodology provides a "fair" allocation and is desirable to every shipper. Three cost allocation schemes are selected to demonstrate how costs can be allocated to shippers involved in the collaboration framework of Model B: proportion allocation; proportion allocation by loop; and marginal contribution allocation. 


\subsubsection{Proportion Allocation}

One of the most commonly used allocation mechanism is proportion allocation, which distributes the cost among the players equally, weighted by each players stand-alone cost (Xu et al., 2009). In the context of Model B, the players of the cooperative game are the shippers. The stand-alone cost is the cost of a shipper operating on its own, without collaboration. The weight

of shipper $i$, represented as $r_{i}$, is computed as the ratio of its stand alone $\operatorname{cost} c(\{i\})$ to the sum of all shippers' stand alone costs. The weight of each shipper $i$ is expressed as

$$
r_{i}=\frac{c(\{i\})}{\sum_{i \in N} c(\{i\})}
$$

The cost allocation of each shipper $i$ is then computed as

$$
y_{i}=r_{i} * c(N)
$$

where $c(N)$ is the cost of the collaborative network, or the objective value of the Model B solution. Proportion allocation is a method that is easy to understand and compute. It also ensures that every shipper in the collaboration is allocated a cost that is no more than if it were to operate alone. In collaborative game theory this concept is known as individual rational (Xu et al., 2009). A disadvantage of proportion allocation is that it does not take into consideration the contribution of each shipper in the collaboration. For instance, if a shipper cannot easily form loops with other shippers in the collaborative network, its weight is computed in the same manner as a shipper who easily forms loops with many other shippers and contributes significantly to the cost savings of the collaboration.

\subsubsection{Proportion Allocation by Loop}

Additional analysis using proportion allocation is applied to the results of Model B by using proportion allocation to individual loops. In this analysis, the results of Model B are 
separated into individual loops and then proportion allocation is applied within each loop. Each shipper's weight is based on the proportion of its stand-alone cost to the sum of the stand-alone costs of the shippers in the same loop. The allocated cost is then computed as the shipper's weight multiplied by the collaborative loop cost.

\subsubsection{Marginal Contribution Allocation}

The second cost allocation scheme which is applied to Model B is a marginal contribution allocation. Its concept is rooted in the popular Shapley value allocation method but does not follow the Shapley value definition exactly. The Shapley value is described next, followed by the marginal contribution allocation used in this thesis.

Shapley value is a very popular cost allocation method, and is based on each players contribution to the collaboration. The grand coalition, $N$, is the set of all players in the collaboration and $S$ represents any subset of the grand coalition. The Shapley value, $\mathrm{Sh}_{\mathrm{i}}$ for each player $i$, is the average marginal contribution of each player if it were to join the grand coalition one member at a time. $c(N)$ represents the value/cost of the $\mathrm{N}$-player coalition. The marginal contribution of player $i$ to the subset $S$ is defined as $c(S)-c(S \backslash\{i\})$. The Shapley value is defined as the weighted average of the player's marginal contribution to each possible subset $S$ of the collaboration (Shapley, 1953).

The following definition is a popular definition for the Shapley value. $\mathrm{Sh}_{\mathrm{i}}$ represents the Shapley value for player $i$ in the collaboration.

$$
S h_{i}(c)=\sum_{S \subset N, i \in S} \frac{(N-S) !(S-1) !}{N !}[c(S)-c(S /\{i\})], \quad \forall i=1, \ldots, N
$$

where $N$ and $S$ are the number of shippers in the collaborative network and the number of shippers in the subset, respectively. 
Computing the Shapley value for larger sized coalitions becomes computationally hard to solve. Because this analysis uses a large sized example collaborative network, the concepts of the Shapley value are used to develop a marginal contribution cost allocation method which is more computationally easy to solve. For each loop that Model B forms, the costs of that loop are distributed to the shippers in the loop. Within loop $L$, a shipper's allocated cost, $M C_{i}(c)$, is computed as:

$$
M C_{i}(c)=\sum_{S \subset L, i \in S} \frac{(L-S) !(S-1) !}{L !}[c(S)-c(S /\{i\})], \quad \forall i=1, \ldots, L
$$

\subsection{Problem B Numerical Analysis}

Computational runs are conducted on Model B using a real freight network to determine the potential for cost savings under this collaboration scenario. The example network setup is described in this chapter, followed by an analysis of the results. Computational results for the proportion allocation, proportion allocation by loop, and marginal contribution allocation are then provided for select problem instances.

\subsubsection{Example Network Setup}

An example network was used to implement Model B and examine the cost savings of the collaborative network. The network consists of real truckload lanes across the United States. Fifty lanes were chosen from this network to comprise the example network used in this analysis. Lanes were chosen in a manner so that there was good potential for collaboration; one lane's line haul route is close to another lane's backhaul route. Lanes were selected to cover many regions of the U.S. Each lane is taken as an individual shipper, so that there are 50 shippers and 50 lanes in the network. Table 9 provides a list of the shipping lanes' origins and destinations and each 
lane's demand. Due to privacy concerns, information about the commodity type was not made available and the demand values were scaled in relation to the capacity. The set of loops $l$ is the maximum number of truck cycles to complete all of the shippers' demand. The truck capacity, $C$, was taken as 2000 units, then adjusted to 3000 units and 4000 units during the analysis. The transportation cost, $c_{i j}$, was determined by first calculating the distance between every node in the network. A base cost of $\$ 1.60$ per mile was used to compute $c_{i j}$ for every arc in the network. The cost per mile is adjusted from $\$ 1.20, \$ 1.40, \$ 1.80$ and $\$ 2.00$ per mile in the analysis of results section. The maximum number of arcs per loops, $K$, was set as 4 for a base level and was adjusted to 6 and 8 arcs per loop during the analysis. 
TABLE 9 Shipping Lanes in Model B Dataset

\begin{tabular}{|c|c|c|c|c|c|}
\hline Origin & Destination & Demand & Origin & Destination & Demand \\
\hline Franklin, $\mathrm{OH}$ & Portland, OR & 2758 & Florence, KY & Newnan, GA & 617 \\
\hline Columbus, $\mathrm{OH}$ & Clackamas, OR & 193 & Louisville, KY & Newnan, GA & 136 \\
\hline Portland, OR & Columbus, $\mathrm{OH}$ & 460 & Suwanee, GA & Louisville, $\mathrm{KY}$ & 755 \\
\hline Salem, OR & Columbus, $\mathrm{OH}$ & 728 & Villa Rica, GA & Fairborn, $\mathrm{OH}$ & 849 \\
\hline Boardman, OR & Columbus, $\mathrm{OH}$ & 272 & Bremen, GA & Ridgefield Park, NJ & 3478 \\
\hline Portland, OR & Danville, IL & 161 & Doraville, GA & Elizabeth, NJ & 1955 \\
\hline Portland, OR & Danville, IL & 198 & Duluth, GA & South Plainfield, NJ & 207 \\
\hline Monmouth, IL & Portland, OR & 1070 & Elizabeth, NJ & Newnan, GA & 1015 \\
\hline Belvidere, IL & Clackamas, OR & 2671 & Elizabeth, NJ & Atlanta, GA & 265 \\
\hline Shelbyville, IL & Portland, OR & 1528 & Haines City, FL & Harrisburg, PA & 2460 \\
\hline Franklin, $\mathrm{OH}$ & Los Alamitos, CA & 1968 & Sarasota, FL & Harrisburg, PA & 2821 \\
\hline Marion, $\mathrm{OH}$ & Los Alamitos, CA & 115 & Lake Wales, FL & Baltimore, MD & 291 \\
\hline Columbus, $\mathrm{OH}$ & Lancaster, CA & 325 & Philadelphia, PA & Orlando, FL & 243 \\
\hline Fullerton, CA & Columbus, $\mathrm{OH}$ & 507 & Chambersburg, PA & Orlando, FL & 133 \\
\hline Los Angeles, CA & Columbus, $\mathrm{OH}$ & 813 & San Antonio, TX & Charlotte, NC & 194 \\
\hline Vernon, CA & Danville, IL & 3465 & Houston, TX & Charlotte, NC & 100 \\
\hline Irvine, CA & Danville, IL & 2823 & Spartanburg, SC & Temple, TX & 675 \\
\hline Irvine, CA & Columbus, $\mathrm{OH}$ & 3853 & Mooresville, NC & San Antonio, TX & 244 \\
\hline Indianapolis, IN & Lancaster, CA & 2342 & Statesville, NC & Lafayette, LA & 1332 \\
\hline Monmouth, IL & Los Alamitos, CA & 378 & Concord, NC & Arlington, TX & 184 \\
\hline Monmouth, IL & Phoenix, AZ & 378 & Newton, NC & Arlington, TX & 187 \\
\hline Stuttgart, AR & Danville, IL & 966 & Euless, TX & Charlotte, NC & 291 \\
\hline Fort Smith, AR & Danville, IL & 2281 & McCook, IL & Phoenix, AZ & 3100 \\
\hline Osceola, AR & Hanover Park, IL & 248 & Wauconda, IL & Phoenix, AZ & 346 \\
\hline Louisville, KY & Winter Garden, FL & 2376 & Tolleson, AZ & University Park, IL & 255 \\
\hline
\end{tabular}

\subsubsection{Model B - Analysis of Results}

Table 10 shows the results of Model B using tabu search with the 50-lane network. The cost per mile was varied from $\$ 1.20$ per mile to $\$ 2.00$ per mile, in $\$ 0.20$ increments. The second column in Table 10 shows the total stand-alone cost for the network. This represents the total cost of all shippers if they operated separately, or the no-collaboration scenario. The stand-alone cost was computed by first determining the number of times a shipping lane would need to be traversed, based on truck capacity, in order to fulfill all of the demand. Then the cost of the 
loop/s for that shipper was computed based on the cost per mile of that test instance. The collaborative cost, shown in the third column, is the objective value solution of Model B. Table 10 also shows the number of loops formed in the solution and the percent network cost savings, computed as the cost savings of the collaborative cost divided by the stand-alone cost. Because the tabu search algorithm provides different results in each run, multiple runs for each problem instance are necessary to get the true performance of the model. The tabu search algorithm was run ten times for each instance, then average values were calculated for the collaborative cost, the number of loops formed in the results, and the network percent cost savings were calculated. When varying the cost per mile from $\$ 1.20$ to $\$ 2.00$, the number of loops that are formed range from 39 to 41 loops. The average network cost savings ranges from $6.65 \%$ to $9.79 \%$. If more iterations are performed on each instance, it is likely the average cost savings for each instance will converge.

TABLE 10 Results of Model B Analysis with Variations in Cost Per Mile

\begin{tabular}{|c|c|c|c|c|}
\hline Cost Per Mile & $\begin{array}{c}\text { Stand-Alone } \\
\text { Cost }\end{array}$ & $\begin{array}{c}\text { Collaborative } \\
\text { Cost }\end{array}$ & $\begin{array}{c}\text { Number of } \\
\text { Loops Formed }\end{array}$ & $\begin{array}{c}\text { Network } \\
\text { Cost Savings }\end{array}$ \\
\hline$\$ 1.20$ & $\$ 220,948.80$ & $\$ 206,259.24$ & 40 & $6.65 \%$ \\
\hline$\$ 1.40$ & $\$ 257,773.60$ & $\$ 232,548.54$ & 40 & $9.79 \%$ \\
\hline$\$ 1.60$ & $\$ 294,598.40$ & $\$ 267,763.84$ & 41 & $9.11 \%$ \\
\hline$\$ 1.80$ & $\$ 331,423.20$ & $\$ 301,229.37$ & 40 & $9.11 \%$ \\
\hline$\$ 2.00$ & $\$ 368,248.00$ & $\$ 333,372.70$ & 39 & $9.47 \%$ \\
\hline
\end{tabular}

$*$ All of these test instances used the following parameters: truck capacity $=2000$; maximum arcs per loop $=4$

Table 11 shows how the results of Model B respond to changes in the maximum number of arcs per loop allowed in the solution. The model was run using 4, 6, and 8 maximum arcs per loop. When the maximum arcs per loop parameter is set to 4 , the numerical analysis resulted in a maximum of 2 shippers collaborating in a loop. Two arcs are line haul arcs and two arcs are backhaul, or repositioning, arcs. When the maximum arcs per loop parameter is set to 6 and 8 , it 
resulted in a maximum of 3 and 4 shippers, respectively, collaborating in a loop. After running 10 iterations of each instance, the average number of loops formed and the average percent cost savings was computed. Using 4 to 8 maximum arcs per loop the resulting number of loops formed in the network is 41 to 30 loops, respectively. Using 4 arcs per loops, there is more of a restriction on the model and more loops are formed as a result. When the maximum arcs per loops is increased to 8 , fewer loops are formed to cover all of the lanes. Increasing the maximum arcs per loop results in a slight increase in the cost savings for the collaborative network.

TABLE 11 Results of Model B Analysis with Variations in the Maximum Arcs per Loop

\begin{tabular}{|c|c|c|c|c|}
\hline $\begin{array}{c}\text { Maximum Arcs } \\
\text { Per Loop }\end{array}$ & $\begin{array}{c}\text { Stand-Alone } \\
\text { Cost }\end{array}$ & $\begin{array}{c}\text { Collaborative } \\
\text { Cost }\end{array}$ & $\begin{array}{c}\text { Number of } \\
\text { Loops Formed }\end{array}$ & $\begin{array}{c}\text { Network Cost } \\
\text { Savings }\end{array}$ \\
\hline 4 & $\$ 294,598.40$ & $\$ 267,763.84$ & 41 & $9.11 \%$ \\
\hline 6 & $\$ 294,598.40$ & $\$ 262,355.92$ & 35 & $10.94 \%$ \\
\hline 8 & $\$ 294,598.40$ & $\$ 260,739.76$ & 33 & $11.94 \%$ \\
\hline
\end{tabular}

* All of these test instances used the following parameters: cost per mile $=\$ 1.60$; truck capacity $=2000$

The results in Table 12 show how Model B performs when altering the truck capacity parameter. For these tests instances, the capacity was changed from 2000, 3000 and 4000 units using the base cost level of $\$ 1.60$ per mile and using a maximum of 4 arcs per loop for each test instance. All of the shipping lanes' demands are under 4000 units so the 4000 capacity instance requires each shipping lane to be traversed only once in order to meet all of the demand. Increasing the capacity from 2000 units to 4000 units resulted in 41 and 38 loops formed, respectively. Increasing the demand relaxes the model and requires fewer shipments to be made, thus fewer loops to be formed. Changing the truck capacity did not result in much variation in the percent cost savings of the network; the cost savings ranged from $8.34 \%$ to $9.11 \%$. 
TABLE 12 Results of Model B Analysis with Variations in the Capacity

\begin{tabular}{|c|c|c|c|c|}
\hline Truck Capacity & $\begin{array}{c}\text { Stand-Alone } \\
\text { Cost }\end{array}$ & $\begin{array}{c}\text { Collaborative } \\
\text { Cost }\end{array}$ & $\begin{array}{c}\text { Number of } \\
\text { Loops Formed }\end{array}$ & $\begin{array}{c}\text { Network } \\
\text { Cost Savings }\end{array}$ \\
\hline 2000 & $\$ 294,598.40$ & $\$ 267,763.84$ & 41 & $9.11 \%$ \\
\hline 3000 & $\$ 255,996.80$ & $\$ 234,656.96$ & 38 & $8.34 \%$ \\
\hline 4000 & $\$ 233,731.20$ & $\$ 210,582.32$ & 38 & $9.90 \%$ \\
\hline
\end{tabular}

* All of these test instances used the following parameters: cost per mile $=\$ 1.60$; maximum arcs per loop $=4$

Additional runs of Model B were performed with modifications to the demand input data. Some of the shippers' demands are very small in comparison to the other shippers. Therefore, these demands were increased to be comparable to the other shippers' demands. For one set of runs, all of the demand which was less than 1000 units was increased to be greater than 1000 units. The original demand was increased by multiplying by the lowest integer which makes the demand greater than 1000. This is called case 1 and the results are summarized in Tables 13 and 14. As shown in Table 13, the network cost savings ranged from $7.71 \%$ to $9.64 \%$ when the cost per mile parameter was varied from $\$ 1.20$ per mile to $\$ 2.00$ per mile, not respectively. Table 14 shows the results of case 2 when the maximum number of arcs per loop was varied from 4 to 6 to 8 arcs; the cost savings increased from $9.09 \%$ to $11.68 \%$. For the second set of runs, called case 2, all demand less than 1500 units is increased to be greater than 1500 units using the same procedure as case 1 . The results of case 2 analysis is summarized in tables 15 and 16 . When varying the cost per mile parameter, the network cost savings ranged from $7.95 \%$ to $9.91 \%$. As shown in Table 16, the network cost savings increased from $9.12 \%$ to $10.59 \%$ using a maximum of 4 arcs per loop and 8 arcs per loop, respectively. 
TABLE 13 Case 1 Results of Model B with Variations in Cost per Mile

\begin{tabular}{|c|c|c|c|c|}
\hline Cost Per Mile & $\begin{array}{c}\text { Stand-Alone } \\
\text { Cost }\end{array}$ & $\begin{array}{c}\text { Collaborative } \\
\text { Cost }\end{array}$ & $\begin{array}{c}\text { Number of } \\
\text { Loops } \\
\text { Formed }\end{array}$ & $\begin{array}{c}\text { Network Cost } \\
\text { Savings }\end{array}$ \\
\hline$\$ 1.20$ & $\$ 220,948.80$ & $\$ 201,395.64$ & 41 & $8.85 \%$ \\
\hline$\$ 1.40$ & $\$ 257,773.60$ & $\$ 237,893.46$ & 40 & $7.71 \%$ \\
\hline$\$ 1.60$ & $\$ 294,598.40$ & $\$ 267,813.12$ & 39 & $9.09 \%$ \\
\hline$\$ 1.80$ & $\$ 331,423.20$ & $\$ 299,478.24$ & 40 & $9.64 \%$ \\
\hline$\$ 2.00$ & $\$ 368,248.00$ & $\$ 335,087.40$ & 40 & $9.00 \%$ \\
\hline
\end{tabular}

* All of these test instances used the following parameters: truck capacity $=2000$; maximum arcs per loop $=4$

TABLE 14 Case 1 Results of Model B with Variations in the Maximum Arcs Per Loop

\begin{tabular}{|c|c|c|c|c|}
\hline $\begin{array}{c}\text { Maximum } \\
\text { Arcs Per } \\
\text { Loop }\end{array}$ & $\begin{array}{c}\text { Stand-Alone } \\
\text { Cost }\end{array}$ & $\begin{array}{c}\text { Collaborative } \\
\text { Cost }\end{array}$ & $\begin{array}{c}\text { Number of } \\
\text { Loops } \\
\text { Formed }\end{array}$ & $\begin{array}{c}\text { Network Cost } \\
\text { Savings }\end{array}$ \\
\hline 4 & $\$ 294,598.40$ & $\$ 267,813.12$ & 39 & $9.09 \%$ \\
\hline 6 & $\$ 294,598.40$ & $\$ 261,070.08$ & 34 & $11.38 \%$ \\
\hline 8 & $\$ 294,598.40$ & $\$ 260,175.04$ & 32 & $11.68 \%$ \\
\hline
\end{tabular}

* All of these test instances used the following parameters: cost per mile $=\$ 1.6$; truck capacity $=2000$

TABLE 15 Case 2 Results of Model B with Variations in Cost per Mile

\begin{tabular}{|c|c|c|c|c|}
\hline $\begin{array}{c}\text { Cost Per } \\
\text { Mile }\end{array}$ & $\begin{array}{c}\text { Stand- } \\
\text { Alone Cost }\end{array}$ & $\begin{array}{c}\text { Collaborative } \\
\text { Cost }\end{array}$ & $\begin{array}{c}\text { Number of } \\
\text { Loops } \\
\text { Formed }\end{array}$ & $\begin{array}{c}\text { Network } \\
\text { Cost Savings }\end{array}$ \\
\hline$\$ 1.20$ & $\$ 238,286.40$ & $\$ 219,348.78$ & 43 & $7.95 \%$ \\
\hline$\$ 1.40$ & $\$ 278,000.80$ & $\$ 252,133.98$ & 40 & $9.30 \%$ \\
\hline$\$ 1.60$ & $\$ 317,715.20$ & $\$ 288,737.04$ & 41 & $9.12 \%$ \\
\hline$\$ 1.80$ & $\$ 357,429.60$ & $\$ 322,021.26$ & 43 & $9.91 \%$ \\
\hline$\$ 2.00$ & $\$ 397,144.00$ & $\$ 363,656.60$ & 41 & $8.43 \%$ \\
\hline
\end{tabular}

$*$ All of these test instances used the following parameters: truck capacity $=2000$; maximum arcs per loop $=4$ 
TABLE 16 Case 2 Results of Model B with Variations in the Maximum Arcs per Loop

\begin{tabular}{|c|c|c|c|c|}
\hline $\begin{array}{c}\text { Maximum } \\
\text { Arcs Per } \\
\text { Loop }\end{array}$ & $\begin{array}{c}\text { Stand- } \\
\text { Alone Cost }\end{array}$ & $\begin{array}{c}\text { Collaborative } \\
\text { Cost }\end{array}$ & $\begin{array}{c}\text { Number of } \\
\text { Loops } \\
\text { Formed }\end{array}$ & $\begin{array}{c}\text { Network } \\
\text { Cost Savings }\end{array}$ \\
\hline 4 & $\$ 317,715.20$ & $\$ 288,737.04$ & 41 & $9.12 \%$ \\
\hline 6 & $\$ 317,715.20$ & $\$ 287,495.76$ & 35 & $9.51 \%$ \\
\hline 8 & $\$ 317,715.20$ & $\$ 284,067.28$ & 34 & $10.59 \%$ \\
\hline
\end{tabular}

* All of these test instances used the following parameters: cost per mile $=$ $\$ 1.6$; truck capacity $=2000$

\subsubsection{Proportion Allocation - Analysis of Results}

Using the results of Model B, the costs are then allocated to the shippers in the collaborative network using the three previously mentioned methods- a proportion cost allocation, a proportion cost allocation by loop and a marginal contribution cost allocation. Three cases are used to apply the cost allocation methodologies. All cases are test instances using \$1.60 per mile, and a 2000 unit capacity. Case 1 uses 4 maximum arcs per loop, Case 2 uses 6 maximum arcs per loop and Case 3 uses 8 maximum arcs per loop.

The results of the proportion cost allocation methodology are shown in Tables 17 through 19. Each table represents the cost allocation for the specific test instances of Case 1, 2, and 3 . With proportion allocation the collaborative network cost is divided equally among the shippers weighted by each shipper's stand-alone cost. Therefore, the percent cost savings of each shipper in the 50-shipper network is the same for each test instance. For the test instance shown in Table 18 (Case 2) the percent cost savings of the collaborative network is $12.43 \%$. Therefore, each shipper is allocated a cost which is $12.43 \%$ lower than their stand-alone cost. This allocation method provides an incentive to every shipper to participate in the collaboration, but it does not take into consideration the contribution of each shipper to the collaboration. 
TABLE 17 Proportion Allocation Results for Case 1

\begin{tabular}{|c|c|c|c|c|c|}
\hline Shipper & $\begin{array}{c}\text { Stand- } \\
\text { Alone Cost }\end{array}$ & Allocated & Shipper & $\begin{array}{c}\text { Stand- } \\
\text { Alone Cost }\end{array}$ & $\begin{array}{c}\text { Allocated } \\
\text { Cost }\end{array}$ \\
\hline 1 & $\$ 15,040.00$ & $\$ 13,178.62$ & 26 & $\$ 1,548.80$ & $\$ 1,357.02$ \\
\hline 2 & $\$ 7,731.20$ & $\$ 6,774.26$ & 27 & $\$ 1,472.00$ & $\$ 1,289.91$ \\
\hline 3 & $\$ 7,724.80$ & $\$ 6,768.58$ & 28 & $\$ 1,398.40$ & $\$ 1,225.37$ \\
\hline 4 & $\$ 7,872.00$ & $\$ 6,897.65$ & 29 & $\$ 1,670.40$ & $\$ 1,463.63$ \\
\hline 5 & $\$ 7,206.40$ & $\$ 6,314.52$ & 30 & $\$ 5,875.20$ & $\$ 5,148.01$ \\
\hline 6 & $\$ 6,883.20$ & $\$ 6,031.35$ & 31 & $\$ 2,764.80$ & $\$ 2,422.61$ \\
\hline 7 & $\$ 6,886.40$ & $\$ 6,034.19$ & 32 & $\$ 2,704.00$ & $\$ 2,369.43$ \\
\hline 8 & $\$ 6,288.00$ & $\$ 5,509.65$ & 33 & $\$ 2,915.20$ & $\$ 2,554.51$ \\
\hline 9 & $\$ 13,228.80$ & $\$ 11,591.60$ & 34 & $\$ 2,790.40$ & $\$ 2,445.06$ \\
\hline 10 & $\$ 6,688.00$ & $\$ 5,860.20$ & 35 & $\$ 6,406.40$ & $\$ 5,613.43$ \\
\hline 11 & $\$ 7,008.00$ & $\$ 6,140.54$ & 36 & $\$ 6,848.00$ & $\$ 6,000.37$ \\
\hline 12 & $\$ 7,296.00$ & $\$ 6,393.00$ & 37 & $\$ 3,020.80$ & $\$ 2,646.93$ \\
\hline 13 & $\$ 7,123.20$ & $\$ 6,241.47$ & 38 & $\$ 3,145.60$ & $\$ 2,756.38$ \\
\hline 14 & $\$ 7,168.00$ & $\$ 6,280.71$ & 39 & $\$ 3,040.00$ & $\$ 2,663.71$ \\
\hline 15 & $\$ 7,200.00$ & $\$ 6,308.84$ & 40 & $\$ 3,942.40$ & $\$ 3,454.38$ \\
\hline 16 & $\$ 13,088.00$ & $\$ 11,468.21$ & 41 & $\$ 3,328.00$ & $\$ 2,916.16$ \\
\hline 17 & $\$ 13,056.00$ & $\$ 11,440.07$ & 42 & $\$ 3,296.00$ & $\$ 2,888.03$ \\
\hline 18 & $\$ 14,368.00$ & $\$ 12,589.55$ & 43 & $\$ 4,016.00$ & $\$ 3,518.91$ \\
\hline 19 & $\$ 13,152.00$ & $\$ 11,524.22$ & 44 & $\$ 2,745.60$ & $\$ 2,405.83$ \\
\hline 20 & $\$ 6,032.00$ & $\$ 5,285.33$ & 45 & $\$ 3,424.00$ & $\$ 3,000.31$ \\
\hline 21 & $\$ 4,966.40$ & $\$ 4,351.66$ & 46 & $\$ 3,392.00$ & $\$ 2,972.18$ \\
\hline 22 & $\$ 1,654.40$ & $\$ 1,449.69$ & 47 & $\$ 3,488.00$ & $\$ 3,056.33$ \\
\hline 23 & $\$ 4,032.00$ & $\$ 3,532.85$ & 48 & $\$ 11,200.00$ & $\$ 9,813.81$ \\
\hline 24 & $\$ 1,600.00$ & $\$ 1,401.94$ & 49 & $\$ 5,696.00$ & $\$ 4,991.06$ \\
\hline & $\$ 5,440.00$ & $\$ 4,766.74$ & 50 & $\$ 5,737.60$ & $\$ 5,027.46$ \\
\hline
\end{tabular}


TABLE 18 Proportion Allocation Results for Case 2

\begin{tabular}{|c|c|c|c|c|c|}
\hline Shipper & $\begin{array}{c}\text { Stand- } \\
\text { Alone Cost }\end{array}$ & $\begin{array}{c}\text { Allocated } \\
\text { Cost }\end{array}$ & Shipper & $\begin{array}{c}\text { Stand- } \\
\text { Alone Cost }\end{array}$ & $\begin{array}{c}\text { Allocated } \\
\text { Cost }\end{array}$ \\
\hline 1 & $\$ 15,040.00$ & $\$ 13,169.88$ & 26 & $\$ 1,548.80$ & $\$ 1,356.12$ \\
\hline 2 & $\$ 7,731.20$ & $\$ 6,769.77$ & 27 & $\$ 1,472.00$ & $\$ 1,289.05$ \\
\hline 3 & $\$ 7,724.80$ & $\$ 6,764.10$ & 28 & $\$ 1,398.40$ & $\$ 1,224.56$ \\
\hline 4 & $\$ 7,872.00$ & $\$ 6,893.08$ & 29 & $\$ 1,670.40$ & $\$ 1,462.66$ \\
\hline 5 & $\$ 7,206.40$ & $\$ 6,310.33$ & 30 & $\$ 5,875.20$ & $\$ 5,144.59$ \\
\hline 6 & $\$ 6,883.20$ & $\$ 6,027.35$ & 31 & $\$ 2,764.80$ & $\$ 2,421.00$ \\
\hline 7 & $\$ 6,886.40$ & $\$ 6,030.19$ & 32 & $\$ 2,704.00$ & $\$ 2,367.86$ \\
\hline 8 & $\$ 6,288.00$ & $\$ 5,506.00$ & 33 & $\$ 2,915.20$ & $\$ 2,552.82$ \\
\hline 9 & $\$ 13,228.80$ & $\$ 11,583.91$ & 34 & $\$ 2,790.40$ & $\$ 2,443.44$ \\
\hline 10 & $\$ 6,688.00$ & $\$ 5,856.32$ & 35 & $\$ 6,406.40$ & $\$ 5,609.70$ \\
\hline 11 & $\$ 7,008.00$ & $\$ 6,136.47$ & 36 & $\$ 6,848.00$ & $\$ 5,996.39$ \\
\hline 12 & $\$ 7,296.00$ & $\$ 6,388.76$ & 37 & $\$ 3,020.80$ & $\$ 2,645.17$ \\
\hline 13 & $\$ 7,123.20$ & $\$ 6,237.33$ & 38 & $\$ 3,145.60$ & $\$ 2,754.55$ \\
\hline 14 & $\$ 7,168.00$ & $\$ 6,276.54$ & 39 & $\$ 3,040.00$ & $\$ 2,661.94$ \\
\hline 15 & $\$ 7,200.00$ & $\$ 6,304.66$ & 40 & $\$ 3,942.40$ & $\$ 3,452.08$ \\
\hline 16 & $\$ 13,088.00$ & $\$ 11,460.60$ & 41 & $\$ 3,328.00$ & $\$ 2,914.23$ \\
\hline 17 & $\$ 13,056.00$ & $\$ 11,432.48$ & 42 & $\$ 3,296.00$ & $\$ 2,886.11$ \\
\hline 18 & $\$ 14,368.00$ & $\$ 12,581.20$ & 43 & $\$ 4,016.00$ & $\$ 3,516.58$ \\
\hline 19 & $\$ 13,152.00$ & $\$ 11,516.58$ & 44 & $\$ 2,745.60$ & $\$ 2,404.23$ \\
\hline 20 & $\$ 6,032.00$ & $\$ 5,281.83$ & 45 & $\$ 3,424.00$ & $\$ 2,998.32$ \\
\hline 21 & $\$ 4,966.40$ & $\$ 4,348.77$ & 46 & $\$ 3,392.00$ & $\$ 2,970.21$ \\
\hline 22 & $\$ 1,654.40$ & $\$ 1,448.73$ & 47 & $\$ 3,488.00$ & $\$ 3,054.30$ \\
\hline 23 & $\$ 4,032.00$ & $\$ 3,530.51$ & 48 & $\$ 11,200.00$ & $\$ 9,807.31$ \\
\hline 25 & $\$ 1,600.00$ & $\$ 1,401.01$ & 49 & $\$ 5,696.00$ & $\$ 4,987.75$ \\
\hline$\$ 5,440.00$ & $\$ 4,763.58$ & 50 & $\$ 5,737.60$ & $\$ 5,024.12$ \\
\hline
\end{tabular}


TABLE 19 Proportion Allocation Results for Case 3

\begin{tabular}{|c|c|c|c|c|c|}
\hline Shipper & $\begin{array}{c}\text { Stand- } \\
\text { Alone Cost }\end{array}$ & $\begin{array}{c}\text { Allocated } \\
\text { Cost }\end{array}$ & Shipper & $\begin{array}{c}\text { Stand- } \\
\text { Alone Cost }\end{array}$ & $\begin{array}{c}\text { Allocated } \\
\text { Cost }\end{array}$ \\
\hline 1 & $\$ 15,040.00$ & $\$ 13,323.77$ & 26 & $\$ 1,548.80$ & $\$ 1,371.97$ \\
\hline 2 & $\$ 7,731.20$ & $\$ 6,848.88$ & 27 & $\$ 1,472.00$ & $\$ 1,304.11$ \\
\hline 3 & $\$ 7,724.80$ & $\$ 6,843.14$ & 28 & $\$ 1,398.40$ & $\$ 1,238.87$ \\
\hline 4 & $\$ 7,872.00$ & $\$ 6,973.63$ & 29 & $\$ 1,670.40$ & $\$ 1,479.75$ \\
\hline 5 & $\$ 7,206.40$ & $\$ 6,384.07$ & 30 & $\$ 5,875.20$ & $\$ 5,204.71$ \\
\hline 6 & $\$ 6,883.20$ & $\$ 6,097.78$ & 31 & $\$ 2,764.80$ & $\$ 2,449.29$ \\
\hline 7 & $\$ 6,886.40$ & $\$ 6,100.65$ & 32 & $\$ 2,704.00$ & $\$ 2,395.53$ \\
\hline 8 & $\$ 6,288.00$ & $\$ 5,570.34$ & 33 & $\$ 2,915.20$ & $\$ 2,582.65$ \\
\hline 9 & $\$ 13,228.80$ & $\$ 11,719.27$ & 34 & $\$ 2,790.40$ & $\$ 2,471.99$ \\
\hline 10 & $\$ 6,688.00$ & $\$ 5,924.75$ & 35 & $\$ 6,406.40$ & $\$ 5,675.25$ \\
\hline 11 & $\$ 7,008.00$ & $\$ 6,208.17$ & 36 & $\$ 6,848.00$ & $\$ 6,066.46$ \\
\hline 12 & $\$ 7,296.00$ & $\$ 6,463.41$ & 37 & $\$ 3,020.80$ & $\$ 2,676.08$ \\
\hline 13 & $\$ 7,123.20$ & $\$ 6,310.22$ & 38 & $\$ 3,145.60$ & $\$ 2,786.74$ \\
\hline 14 & $\$ 7,168.00$ & $\$ 6,349.88$ & 39 & $\$ 3,040.00$ & $\$ 2,693.04$ \\
\hline 15 & $\$ 7,200.00$ & $\$ 6,378.33$ & 40 & $\$ 3,942.40$ & $\$ 3,492.42$ \\
\hline 16 & $\$ 13,088.00$ & $\$ 11,594.52$ & 41 & $\$ 3,328.00$ & $\$ 2,948.28$ \\
\hline 17 & $\$ 13,056.00$ & $\$ 11,566.08$ & 42 & $\$ 3,296.00$ & $\$ 2,919.84$ \\
\hline 18 & $\$ 14,368.00$ & $\$ 12,728.22$ & 43 & $\$ 4,016.00$ & $\$ 3,557.67$ \\
\hline 19 & $\$ 13,152.00$ & $\$ 11,651.16$ & 44 & $\$ 2,745.60$ & $\$ 2,432.33$ \\
\hline 20 & $\$ 6,032.00$ & $\$ 5,343.55$ & 45 & $\$ 3,424.00$ & $\$ 3,033.36$ \\
\hline 21 & $\$ 4,966.40$ & $\$ 4,399.59$ & 46 & $\$ 3,392.00$ & $\$ 3,004.91$ \\
\hline 22 & $\$ 1,654.40$ & $\$ 1,465.66$ & 47 & $\$ 3,488.00$ & $\$ 3,089.99$ \\
\hline 23 & $\$ 4,032.00$ & $\$ 3,571.76$ & 48 & $\$ 11,200.00$ & $\$ 9,921.91$ \\
\hline 24 & $\$ 1,600.00$ & $\$ 1,417.38$ & 49 & $\$ 5,696.00$ & $\$ 5,046.03$ \\
\hline 25 & $\$ 5,440.00$ & $\$ 4,819.24$ & 50 & $\$ 5,737.60$ & $\$ 5,082.83$ \\
\hline
\end{tabular}

\subsubsection{Proportion Allocation by Loop - Analysis of Results}

In this section, the results of Model B are separated into individual loops and then proportion allocation is applied within each loop. The numerical results of this methodology are provided in Tables 20 through 22, showing the allocated costs and percent cost savings of each shipper. Tables 28 through 31 in the appendix show more detail analysis for computing the cost allocations by showing the allocated costs for each loop. With this methodology, every shipper is 
allocated the same percent cost savings as each shipper that is involved in the same loop so a shipper's contribution to the savings of the network is not taken into consideration. It should be noted that shippers can be in multiple loops so the allocated costs in the Tables 20, 21 and 22 are aggregate values.

TABLE 20 - Results of Proportion Allocation by Loop for Case 1

\begin{tabular}{|c|c|c|c|c|c|c|c|}
\hline Shipper & $\begin{array}{c}\text { Stand } \\
\text { Alone- } \\
\text { Cost }\end{array}$ & $\begin{array}{c}\text { Allocated } \\
\text { Cost }\end{array}$ & $\begin{array}{c}\text { Cost } \\
\text { Savings }\end{array}$ & Shipper & $\begin{array}{c}\text { Stand } \\
\text { Alone- } \\
\text { Cost }\end{array}$ & $\begin{array}{c}\text { Allocated } \\
\text { Cost }\end{array}$ & $\begin{array}{c}\text { Cost } \\
\text { Savings }\end{array}$ \\
\hline 1 & $\$ 15,040.00$ & $\$ 14,740.50$ & $1.99 \%$ & 26 & $\$ 1,548.80$ & $\$ 1,418.80$ & $8.39 \%$ \\
\hline 2 & $\$ 7,731.20$ & $\$ 7,731.20$ & $0.00 \%$ & 27 & $\$ 1,472.00$ & $\$ 1,314.00$ & $10.73 \%$ \\
\hline 3 & $\$ 7,724.80$ & $\$ 7,652.52$ & $0.94 \%$ & 28 & $\$ 1,398.40$ & $\$ 1,398.40$ & $0.00 \%$ \\
\hline 4 & $\$ 7,872.00$ & $\$ 4,349.89$ & $44.74 \%$ & 29 & $\$ 1,670.40$ & $\$ 1,670.40$ & $0.00 \%$ \\
\hline 5 & $\$ 7,206.40$ & $\$ 6,693.19$ & $7.12 \%$ & 30 & $\$ 5,875.20$ & $\$ 5,875.20$ & $0.00 \%$ \\
\hline 6 & $\$ 6,883.20$ & $\$ 4,381.89$ & $36.34 \%$ & 31 & $\$ 2,764.80$ & $\$ 2,764.80$ & $0.00 \%$ \\
\hline 7 & $\$ 6,886.40$ & $\$ 6,312.85$ & $8.33 \%$ & 32 & $\$ 2,704.00$ & $\$ 1,412.83$ & $47.75 \%$ \\
\hline 8 & $\$ 6,288.00$ & $\$ 6,219.60$ & $1.09 \%$ & 33 & $\$ 2,915.20$ & $\$ 1,523.17$ & $47.75 \%$ \\
\hline 9 & $\$ 13,228.80$ & $\$ 10,269.31$ & $22.37 \%$ & 34 & $\$ 2,790.40$ & $\$ 2,790.40$ & $0.00 \%$ \\
\hline 10 & $\$ 6,688.00$ & $\$ 4,384.59$ & $34.44 \%$ & 35 & $\$ 6,406.40$ & $\$ 6,406.40$ & $0.00 \%$ \\
\hline 11 & $\$ 7,008.00$ & $\$ 4,461.31$ & $36.34 \%$ & 36 & $\$ 6,848.00$ & $\$ 6,123.03$ & $10.59 \%$ \\
\hline 12 & $\$ 7,296.00$ & $\$ 5,875.28$ & $19.47 \%$ & 37 & $\$ 3,020.80$ & $\$ 3,020.80$ & $0.00 \%$ \\
\hline 13 & $\$ 7,123.20$ & $\$ 3,625.26$ & $49.11 \%$ & 38 & $\$ 3,145.60$ & $\$ 2,776.35$ & $11.74 \%$ \\
\hline 14 & $\$ 7,168.00$ & $\$ 6,756.75$ & $5.74 \%$ & 39 & $\$ 3,040.00$ & $\$ 2,865.65$ & $5.74 \%$ \\
\hline 15 & $\$ 7,200.00$ & $\$ 3,664.34$ & $49.11 \%$ & 40 & $\$ 3,942.40$ & $\$ 3,479.65$ & $11.74 \%$ \\
\hline 16 & $\$ 13,088.00$ & $\$ 13,088.00$ & $0.00 \%$ & 41 & $\$ 3,328.00$ & $\$ 2,679.92$ & $19.47 \%$ \\
\hline 17 & $\$ 13,056.00$ & $\$ 13,056.00$ & $0.00 \%$ & 42 & $\$ 3,296.00$ & $\$ 3,021.55$ & $8.33 \%$ \\
\hline 18 & $\$ 14,368.00$ & $\$ 11,291.01$ & $21.42 \%$ & 43 & $\$ 4,016.00$ & $\$ 3,129.96$ & $22.06 \%$ \\
\hline 19 & $\$ 13,152.00$ & $\$ 13,152.00$ & $0.00 \%$ & 44 & $\$ 2,745.60$ & $\$ 2,550.01$ & $7.12 \%$ \\
\hline 20 & $\$ 6,032.00$ & $\$ 6,032.00$ & $0.00 \%$ & 45 & $\$ 3,424.00$ & $\$ 3,424.00$ & $0.00 \%$ \\
\hline 21 & $\$ 4,966.40$ & $\$ 4,889.34$ & $1.55 \%$ & 46 & $\$ 3,392.00$ & $\$ 2,673.77$ & $21.17 \%$ \\
\hline 22 & $\$ 1,654.40$ & $\$ 1,636.40$ & $1.09 \%$ & 47 & $\$ 3,488.00$ & $\$ 3,488.00$ & $0.00 \%$ \\
\hline 23 & $\$ 4,032.00$ & $\$ 3,796.68$ & $5.84 \%$ & 48 & $\$ 11,200.00$ & $\$ 11,200.00$ & $0.00 \%$ \\
\hline 24 & $\$ 1,600.00$ & $\$ 1,600.00$ & $0.00 \%$ & 49 & $\$ 5,696.00$ & $\$ 5,557.36$ & $2.43 \%$ \\
\hline 25 & $\$ 5,440.00$ & $\$ 5,440.00$ & $0.00 \%$ & 50 & $\$ 5,737.60$ & $\$ 4,471.64$ & $22.06 \%$ \\
\hline
\end{tabular}


TABLE 21 - Results of Proportion Allocation by Loop for Case 2

\begin{tabular}{|c|c|c|c|c|c|c|c|}
\hline Shipper & $\begin{array}{c}\text { Stand } \\
\text { Alone- } \\
\text { Cost }\end{array}$ & $\begin{array}{c}\text { Allocated } \\
\text { Cost }\end{array}$ & $\begin{array}{c}\text { Cost } \\
\text { Savings }\end{array}$ & Shipper & $\begin{array}{c}\text { Stand } \\
\text { Alone- } \\
\text { Cost }\end{array}$ & $\begin{array}{c}\text { Allocated } \\
\text { Cost }\end{array}$ & $\begin{array}{c}\text { Cost } \\
\text { Savings }\end{array}$ \\
\hline 1 & $\$ 15,040.00$ & $\$ 15,040.00$ & $0.00 \%$ & 26 & $\$ 1,548.80$ & $\$ 1,442.37$ & $6.87 \%$ \\
\hline 2 & $\$ 7,731.20$ & $\$ 5,048.77$ & $34.70 \%$ & 27 & $\$ 1,472.00$ & $\$ 1,429.84$ & $2.86 \%$ \\
\hline 3 & $\$ 7,724.80$ & $\$ 7,724.80$ & $0.00 \%$ & 28 & $\$ 1,398.40$ & $\$ 1,398.40$ & $0.00 \%$ \\
\hline 4 & $\$ 7,872.00$ & $\$ 5,140.61$ & $34.70 \%$ & 29 & $\$ 1,670.40$ & $\$ 1,670.40$ & $0.00 \%$ \\
\hline 5 & $\$ 7,206.40$ & $\$ 7,206.40$ & $0.00 \%$ & 30 & $\$ 5,875.20$ & $\$ 4,507.00$ & $23.29 \%$ \\
\hline 6 & $\$ 6,883.20$ & $\$ 6,883.20$ & $0.00 \%$ & 31 & $\$ 2,764.80$ & $\$ 2,520.34$ & $8.84 \%$ \\
\hline 7 & $\$ 6,886.40$ & $\$ 5,467.90$ & $20.60 \%$ & 32 & $\$ 2,704.00$ & $\$ 2,368.63$ & $12.40 \%$ \\
\hline 8 & $\$ 6,288.00$ & $\$ 6,288.00$ & $0.00 \%$ & 33 & $\$ 2,915.20$ & $\$ 2,300.34$ & $21.09 \%$ \\
\hline 9 & $\$ 13,228.80$ & $\$ 10,518.30$ & $20.49 \%$ & 34 & $\$ 2,790.40$ & $\$ 2,790.40$ & $0.00 \%$ \\
\hline 10 & $\$ 6,688.00$ & $\$ 5,310.38$ & $20.60 \%$ & 35 & $\$ 6,406.40$ & $\$ 6,406.40$ & $0.00 \%$ \\
\hline 11 & $\$ 7,008.00$ & $\$ 6,065.72$ & $13.45 \%$ & 36 & $\$ 6,848.00$ & $\$ 5,403.59$ & $21.09 \%$ \\
\hline 12 & $\$ 7,296.00$ & $\$ 4,994.77$ & $31.54 \%$ & 37 & $\$ 3,020.80$ & $\$ 3,020.80$ & $0.00 \%$ \\
\hline 13 & $\$ 7,123.20$ & $\$ 4,816.37$ & $32.38 \%$ & 38 & $\$ 3,145.60$ & $\$ 2,413.07$ & $23.29 \%$ \\
\hline 14 & $\$ 7,168.00$ & $\$ 6,803.26$ & $5.09 \%$ & 39 & $\$ 3,040.00$ & $\$ 2,627.61$ & $13.57 \%$ \\
\hline 15 & $\$ 7,200.00$ & $\$ 7,200.00$ & $0.00 \%$ & 40 & $\$ 3,942.40$ & $\$ 3,407.59$ & $13.57 \%$ \\
\hline 16 & $\$ 13,088.00$ & $\$ 12,849.80$ & $1.82 \%$ & 41 & $\$ 3,328.00$ & $\$ 3,328.00$ & $0.00 \%$ \\
\hline 17 & $\$ 13,056.00$ & $\$ 8,937.89$ & $31.54 \%$ & 42 & $\$ 3,296.00$ & $\$ 2,841.10$ & $13.80 \%$ \\
\hline 18 & $\$ 14,368.00$ & $\$ 9,714.98$ & $32.38 \%$ & 43 & $\$ 4,016.00$ & $\$ 3,740.03$ & $6.87 \%$ \\
\hline 19 & $\$ 13,152.00$ & $\$ 13,152.00$ & $0.00 \%$ & 44 & $\$ 2,745.60$ & $\$ 2,502.81$ & $8.84 \%$ \\
\hline 20 & $\$ 6,032.00$ & $\$ 5,220.97$ & $13.45 \%$ & 45 & $\$ 3,424.00$ & $\$ 2,999.37$ & $12.40 \%$ \\
\hline 21 & $\$ 4,966.40$ & $\$ 3,943.33$ & $20.60 \%$ & 46 & $\$ 3,392.00$ & $\$ 3,092.05$ & $8.84 \%$ \\
\hline 22 & $\$ 1,654.40$ & $\$ 1,426.10$ & $13.80 \%$ & 47 & $\$ 3,488.00$ & $\$ 3,019.05$ & $13.44 \%$ \\
\hline 23 & $\$ 4,032.00$ & $\$ 3,778.72$ & $6.28 \%$ & 48 & $\$ 11,200.00$ & $\$ 11,200.00$ & $0.00 \%$ \\
\hline 24 & $\$ 1,600.00$ & $\$ 1,570.86$ & $1.82 \%$ & 49 & $\$ 5,696.00$ & $\$ 5,696.00$ & $0.00 \%$ \\
\hline 25 & $\$ 5,440.00$ & $\$ 5,163.26$ & $5.09 \%$ & 50 & $\$ 5,737.60$ & $\$ 5,573.36$ & $2.86 \%$ \\
\hline & & & & & & \\
\hline
\end{tabular}


TABLE 22 - Results of Proportion Allocation by Loop for Case 3

\begin{tabular}{|c|c|c|c|c|c|c|c|}
\hline Shipper & $\begin{array}{c}\text { Stand } \\
\text { Alone- } \\
\text { Cost }\end{array}$ & $\begin{array}{c}\text { Allocated } \\
\text { Cost }\end{array}$ & $\begin{array}{c}\text { Cost } \\
\text { Savings }\end{array}$ & Shipper & $\begin{array}{c}\text { Stand } \\
\text { Alone- } \\
\text { Cost }\end{array}$ & $\begin{array}{c}\text { Allocated } \\
\text { Cost }\end{array}$ & $\begin{array}{c}\text { Cost } \\
\text { Savings }\end{array}$ \\
\hline 1 & $\$ 15,040.00$ & $\$ 14,653.78$ & $2.57 \%$ & 26 & $\$ 1,548.80$ & $\$ 1,286.72$ & $16.92 \%$ \\
\hline 2 & $\$ 7,731.20$ & $\$ 7,731.20$ & $0.00 \%$ & 27 & $\$ 1,472.00$ & $\$ 1,118.40$ & $24.02 \%$ \\
\hline 3 & $\$ 7,724.80$ & $\$ 7,724.80$ & $0.00 \%$ & 28 & $\$ 1,398.40$ & $\$ 1,280.92$ & $8.40 \%$ \\
\hline 4 & $\$ 7,872.00$ & $\$ 7,872.00$ & $0.00 \%$ & 29 & $\$ 1,670.40$ & $\$ 1,387.70$ & $16.92 \%$ \\
\hline 5 & $\$ 7,206.40$ & $\$ 5,475.10$ & $24.02 \%$ & 30 & $\$ 5,875.20$ & $\$ 5,823.40$ & $0.88 \%$ \\
\hline 6 & $\$ 6,883.20$ & $\$ 5,229.54$ & $24.02 \%$ & 31 & $\$ 2,764.80$ & $\$ 2,584.94$ & $6.51 \%$ \\
\hline 7 & $\$ 6,886.40$ & $\$ 6,886.40$ & $0.00 \%$ & 32 & $\$ 2,704.00$ & $\$ 2,704.00$ & $0.00 \%$ \\
\hline 8 & $\$ 6,288.00$ & $\$ 6,288.00$ & $0.00 \%$ & 33 & $\$ 2,915.20$ & $\$ 2,861.84$ & $1.83 \%$ \\
\hline 9 & $\$ 13,228.80$ & $\$ 10,923.19$ & $17.43 \%$ & 34 & $\$ 2,790.40$ & $\$ 2,739.32$ & $1.83 \%$ \\
\hline 10 & $\$ 6,688.00$ & $\$ 6,688.00$ & $0.00 \%$ & 35 & $\$ 6,406.40$ & $\$ 6,378.20$ & $0.44 \%$ \\
\hline 11 & $\$ 7,008.00$ & $\$ 7,008.00$ & $0.00 \%$ & 36 & $\$ 6,848.00$ & $\$ 6,848.00$ & $0.00 \%$ \\
\hline 12 & $\$ 7,296.00$ & $\$ 5,543.18$ & $24.02 \%$ & 37 & $\$ 3,020.80$ & $\$ 2,509.57$ & $16.92 \%$ \\
\hline 13 & $\$ 7,123.20$ & $\$ 6,659.86$ & $6.50 \%$ & 38 & $\$ 3,145.60$ & $\$ 3,145.60$ & $0.00 \%$ \\
\hline 14 & $\$ 7,168.00$ & $\$ 6,565.84$ & $8.40 \%$ & 39 & $\$ 3,040.00$ & $\$ 2,984.35$ & $1.83 \%$ \\
\hline 15 & $\$ 7,200.00$ & $\$ 6,595.18$ & $8.40 \%$ & 40 & $\$ 3,942.40$ & $\$ 3,130.88$ & $20.58 \%$ \\
\hline 16 & $\$ 13,088.00$ & $\$ 8,239.01$ & $37.05 \%$ & 41 & $\$ 3,328.00$ & $\$ 1,903.31$ & $42.81 \%$ \\
\hline 17 & $\$ 13,056.00$ & $\$ 10,780.81$ & $17.43 \%$ & 42 & $\$ 3,296.00$ & $\$ 2,297.47$ & $30.30 \%$ \\
\hline 18 & $\$ 14,368.00$ & $\$ 14,368.00$ & $0.00 \%$ & 43 & $\$ 4,016.00$ & $\$ 2,799.29$ & $30.30 \%$ \\
\hline 19 & $\$ 13,152.00$ & $\$ 8,947.72$ & $31.97 \%$ & 44 & $\$ 2,745.60$ & $\$ 2,514.86$ & $8.40 \%$ \\
\hline 20 & $\$ 6,032.00$ & $\$ 6,032.00$ & $0.00 \%$ & 45 & $\$ 3,424.00$ & $\$ 3,424.00$ & $0.00 \%$ \\
\hline 21 & $\$ 4,966.40$ & $\$ 2,873.94$ & $42.13 \%$ & 46 & $\$ 3,392.00$ & $\$ 1,939.89$ & $42.81 \%$ \\
\hline 22 & $\$ 1,654.40$ & $\$ 1,654.40$ & $0.00 \%$ & 47 & $\$ 3,488.00$ & $\$ 2,431.24$ & $30.30 \%$ \\
\hline 23 & $\$ 4,032.00$ & $\$ 3,884.24$ & $3.66 \%$ & 48 & $\$ 11,200.00$ & $\$ 11,200.00$ & $0.00 \%$ \\
\hline 24 & $\$ 1,600.00$ & $\$ 1,558.86$ & $2.57 \%$ & 49 & $\$ 5,696.00$ & $\$ 4,523.52$ & $20.58 \%$ \\
\hline 25 & $\$ 5,440.00$ & $\$ 5,240.56$ & $3.67 \%$ & 50 & $\$ 5,737.60$ & $\$ 5,737.60$ & $0.00 \%$ \\
\hline
\end{tabular}

\subsubsection{Marginal Contribution Allocation - Analysis of Results}

Using the results from Model B analysis, the costs are allocated to the shippers in the collaborative network using the marginal contribution allocation method. This allocation mechanism distributes the costs of each loop to the shippers in the loop based on their marginal contributions. Some numerical results of this allocation mechanism are shown in Tables 23, 24 and 25 for Cases 1, 2, and 3, respectively. Tables 23 through 25 show the percent cost savings 
for each shipper in the three test scenarios. For the Case 1 (Table 23), the cost savings ranges from about $0 \%$ to $49.6 \%$. The more a shipper contributes to the cost savings of a loop, the less cost it is allocated and the more cost savings it realizes. The shippers that have $0 \%$ cost savings are not matched up in a loop with other shippers and therefore are allocated their stand-alone cost. As shown in Table 24, the cost allocation of Case 2 reveals individual cost savings ranging from $-6.4 \%$ to $65.14 \%$ with one shipper experiencing negative cost savings. Case 3 marginal contribution allocation is shown in Table 25 and the cost savings ranges from $-38.7 \%$ to $61.2 \%$ with three shippers allocated negative cost savings. The reasoning behind the negative cost savings of some shippers in Case 2 and 3 is explained in section 6.3.6. Tables 32 through 34 in the appendix provide the marginal cost allocation computations for each loop. 
TABLE 23 Results of Marginal Contribution Allocation for Case 1

\begin{tabular}{|c|c|c|c|c|c|c|c|}
\hline Shipper & $\begin{array}{c}\text { Stand- } \\
\text { Alone } \\
\text { Cost }\end{array}$ & $\begin{array}{c}\text { Allocated } \\
\text { Cost }\end{array}$ & $\begin{array}{c}\text { Percent } \\
\text { Savings }\end{array}$ & Shipper & $\begin{array}{c}\text { Stand - } \\
\text { Alone } \\
\text { Cost }\end{array}$ & $\begin{array}{c}\text { Allocated } \\
\text { Cost }\end{array}$ & $\begin{array}{c}\text { Percent } \\
\text { Savings }\end{array}$ \\
\hline 1 & $\$ 15,040.00$ & $\$ 14,782.40$ & $1.71 \%$ & 26 & $\$ 1,548.80$ & $\$ 1,182.40$ & $23.66 \%$ \\
\hline 2 & $\$ 7,731.20$ & $\$ 7,731.20$ & $0.00 \%$ & 27 & $\$ 1,472.00$ & $\$ 1,284.80$ & $12.72 \%$ \\
\hline 3 & $\$ 7,724.80$ & $\$ 7,679.20$ & $0.59 \%$ & 28 & $\$ 1,398.40$ & $\$ 1,398.40$ & $0.00 \%$ \\
\hline 4 & $\$ 7,872.00$ & $\$ 4,631.20$ & $41.17 \%$ & 29 & $\$ 1,670.40$ & $\$ 1,670.40$ & $0.00 \%$ \\
\hline 5 & $\$ 7,206.40$ & $\$ 6,852.00$ & $4.92 \%$ & 30 & $\$ 5,875.20$ & $\$ 5,875.20$ & $0.00 \%$ \\
\hline 6 & $\$ 6,883.20$ & $\$ 4,359.20$ & $36.67 \%$ & 31 & $\$ 2,764.80$ & $\$ 2,764.80$ & $0.00 \%$ \\
\hline 7 & $\$ 6,886.40$ & $\$ 6,462.40$ & $6.16 \%$ & 32 & $\$ 2,704.00$ & $\$ 1,362.40$ & $49.62 \%$ \\
\hline 8 & $\$ 6,288.00$ & $\$ 6,244.80$ & $0.69 \%$ & 33 & $\$ 2,915.20$ & $\$ 1,573.60$ & $46.02 \%$ \\
\hline 9 & $\$ 13,228.80$ & $\$ 9,988.00$ & $24.50 \%$ & 34 & $\$ 2,790.40$ & $\$ 2,790.40$ & $0.00 \%$ \\
\hline 10 & $\$ 6,688.00$ & $\$ 4,299.20$ & $35.72 \%$ & 35 & $\$ 6,406.40$ & $\$ 6,406.40$ & $0.00 \%$ \\
\hline 11 & $\$ 7,008.00$ & $\$ 4,484.00$ & $36.02 \%$ & 36 & $\$ 6,848.00$ & $\$ 6,126.40$ & $10.54 \%$ \\
\hline 12 & $\$ 7,296.00$ & $\$ 6,261.60$ & $14.18 \%$ & 37 & $\$ 3,020.80$ & $\$ 3,020.80$ & $0.00 \%$ \\
\hline 13 & $\$ 7,123.20$ & $\$ 3,606.40$ & $49.37 \%$ & 38 & $\$ 3,145.60$ & $\$ 2,729.60$ & $13.22 \%$ \\
\hline 14 & $\$ 7,168.00$ & $\$ 6,875.20$ & $4.08 \%$ & 39 & $\$ 3,040.00$ & $\$ 2,747.20$ & $9.63 \%$ \\
\hline 15 & $\$ 7,200.00$ & $\$ 3,683.20$ & $48.84 \%$ & 40 & $\$ 3,942.40$ & $\$ 3,526.40$ & $10.55 \%$ \\
\hline 16 & $\$ 13,088.00$ & $\$ 13,088.00$ & $0.00 \%$ & 41 & $\$ 3,328.00$ & $\$ 2,293.60$ & $31.08 \%$ \\
\hline 17 & $\$ 13,056.00$ & $\$ 13,056.00$ & $0.00 \%$ & 42 & $\$ 3,296.00$ & $\$ 2,872.00$ & $12.86 \%$ \\
\hline 18 & $\$ 14,368.00$ & $\$ 11,612.80$ & $19.18 \%$ & 43 & $\$ 4,016.00$ & $\$ 2,940.00$ & $26.79 \%$ \\
\hline 19 & $\$ 13,152.00$ & $\$ 13,152.00$ & $0.00 \%$ & 44 & $\$ 2,745.60$ & $\$ 2,391.20$ & $12.91 \%$ \\
\hline 20 & $\$ 6,032.00$ & $\$ 6,032.00$ & $0.00 \%$ & 45 & $\$ 3,424.00$ & $\$ 3,424.00$ & $0.00 \%$ \\
\hline 21 & $\$ 4,966.40$ & $\$ 4,869.60$ & $1.95 \%$ & 46 & $\$ 3,392.00$ & $\$ 2,670.40$ & $21.27 \%$ \\
\hline 22 & $\$ 1,654.40$ & $\$ 1,611.20$ & $2.61 \%$ & 47 & $\$ 3,488.00$ & $\$ 3,488.00$ & $0.00 \%$ \\
\hline 23 & $\$ 4,032.00$ & $\$ 3,799.20$ & $5.77 \%$ & 48 & $\$ 11,200.00$ & $\$ 11,200.00$ & $0.00 \%$ \\
\hline 24 & $\$ 1,600.00$ & $\$ 1,600.00$ & $0.00 \%$ & 49 & $\$ 5,696.00$ & $\$ 5,535.20$ & $2.82 \%$ \\
\hline 25 & $\$ 5,440.00$ & $\$ 5,440.00$ & $0.00 \%$ & 50 & $\$ 5,737.60$ & $\$ 4,661.60$ & $18.75 \%$ \\
\hline
\end{tabular}


TABLE 24 Results of Marginal Contribution Allocation for Case 2

\begin{tabular}{|c|c|c|c|c|c|c|c|}
\hline Shipper & $\begin{array}{c}\text { Stand- } \\
\text { Alone } \\
\text { Cost }\end{array}$ & $\begin{array}{c}\text { Allocated } \\
\text { Cost }\end{array}$ & $\begin{array}{c}\text { Percent } \\
\text { Savings }\end{array}$ & Shipper & $\begin{array}{c}\text { Stand - } \\
\text { Alone } \\
\text { Cost }\end{array}$ & $\begin{array}{c}\text { Allocated } \\
\text { Cost }\end{array}$ & $\begin{array}{c}\text { Percent } \\
\text { Savings }\end{array}$ \\
\hline 1 & $\$ 15,040.00$ & $\$ 15,040.00$ & $0.00 \%$ & 26 & $\$ 1,548.80$ & $\$ 1,357.60$ & $12.35 \%$ \\
\hline 2 & $\$ 7,731.20$ & $\$ 6,037.33$ & $21.91 \%$ & 27 & $\$ 1,472.00$ & $\$ 1,368.80$ & $7.01 \%$ \\
\hline 3 & $\$ 7,724.80$ & $\$ 7,724.80$ & $0.00 \%$ & 28 & $\$ 1,398.40$ & $\$ 1,398.40$ & $0.00 \%$ \\
\hline 4 & $\$ 7,872.00$ & $\$ 2,937.33$ & $62.69 \%$ & 29 & $\$ 1,670.40$ & $\$ 1,670.40$ & $0.00 \%$ \\
\hline 5 & $\$ 7,206.40$ & $\$ 7,206.40$ & $0.00 \%$ & 30 & $\$ 5,875.20$ & $\$ 5,174.93$ & $11.92 \%$ \\
\hline 6 & $\$ 6,883.20$ & $\$ 6,883.20$ & $0.00 \%$ & 31 & $\$ 2,764.80$ & $\$ 2,236.27$ & $19.12 \%$ \\
\hline 7 & $\$ 6,886.40$ & $\$ 3,984.53$ & $42.14 \%$ & 32 & $\$ 2,704.00$ & $\$ 2,324.00$ & $14.05 \%$ \\
\hline 8 & $\$ 6,288.00$ & $\$ 6,288.00$ & $0.00 \%$ & 33 & $\$ 2,915.20$ & $\$ 1,542.40$ & $47.09 \%$ \\
\hline 9 & $\$ 13,228.80$ & $\$ 11,702.66$ & $11.54 \%$ & 34 & $\$ 2,790.40$ & $\$ 2,790.40$ & $0.00 \%$ \\
\hline 10 & $\$ 6,688.00$ & $\$ 5,451.73$ & $18.48 \%$ & 35 & $\$ 6,406.40$ & $\$ 6,406.40$ & $0.00 \%$ \\
\hline 11 & $\$ 7,008.00$ & $\$ 6,274.93$ & $10.46 \%$ & 36 & $\$ 6,848.00$ & $\$ 6,161.60$ & $10.02 \%$ \\
\hline 12 & $\$ 7,296.00$ & $\$ 3,016.53$ & $58.65 \%$ & 37 & $\$ 3,020.80$ & $\$ 3,020.80$ & $0.00 \%$ \\
\hline 13 & $\$ 7,123.20$ & $\$ 2,483.20$ & $65.14 \%$ & 38 & $\$ 3,145.60$ & $\$ 1,745.07$ & $44.52 \%$ \\
\hline 14 & $\$ 7,168.00$ & $\$ 6,740.27$ & $5.97 \%$ & 39 & $\$ 3,040.00$ & $\$ 2,566.40$ & $15.58 \%$ \\
\hline 15 & $\$ 7,200.00$ & $\$ 7,200.00$ & $0.00 \%$ & 40 & $\$ 3,942.40$ & $\$ 3,468.80$ & $12.01 \%$ \\
\hline 16 & $\$ 13,088.00$ & $\$ 12,998.93$ & $0.68 \%$ & 41 & $\$ 3,328.00$ & $\$ 3,328.00$ & $0.00 \%$ \\
\hline 17 & $\$ 13,056.00$ & $\$ 10,916.27$ & $16.39 \%$ & 42 & $\$ 3,296.00$ & $\$ 2,954.40$ & $10.36 \%$ \\
\hline 18 & $\$ 14,368.00$ & $\$ 12,048.00$ & $16.15 \%$ & 43 & $\$ 4,016.00$ & $\$ 3,824.80$ & $4.76 \%$ \\
\hline 19 & $\$ 13,152.00$ & $\$ 13,152.00$ & $0.00 \%$ & 44 & $\$ 2,745.60$ & $\$ 2,599.47$ & $5.32 \%$ \\
\hline 20 & $\$ 6,032.00$ & $\$ 5,842.93$ & $3.13 \%$ & 45 & $\$ 3,424.00$ & $\$ 3,044.00$ & $11.10 \%$ \\
\hline 21 & $\$ 4,966.40$ & $\$ 5,285.30$ & $-6.42 \%$ & 46 & $\$ 3,392.00$ & $\$ 3,279.47$ & $3.32 \%$ \\
\hline 22 & $\$ 1,654.40$ & $\$ 1,312.80$ & $20.65 \%$ & 47 & $\$ 3,488.00$ & $\$ 2,187.73$ & $37.28 \%$ \\
\hline 23 & $\$ 4,032.00$ & $\$ 3,809.06$ & $5.53 \%$ & 48 & $\$ 11,200.00$ & $\$ 11,200.00$ & $0.00 \%$ \\
\hline 24 & $\$ 1,600.00$ & $\$ 1,421.87$ & $11.13 \%$ & 49 & $\$ 5,696.00$ & $\$ 5,696.00$ & $0.00 \%$ \\
\hline 25 & $\$ 5,440.00$ & $\$ 5,226.14$ & $3.93 \%$ & 50 & $\$ 5,737.60$ & $\$ 5,634.40$ & $1.80 \%$ \\
\hline
\end{tabular}


TABLE 25 Results of Marginal Contribution Allocation for Case 3

\begin{tabular}{|c|c|c|c|c|c|c|c|}
\hline Shipper & $\begin{array}{c}\text { Stand- } \\
\text { Alone } \\
\text { Cost }\end{array}$ & $\begin{array}{c}\text { Allocated } \\
\text { Cost }\end{array}$ & $\begin{array}{c}\text { Percent } \\
\text { Savings }\end{array}$ & Shipper & $\begin{array}{c}\text { Stand - } \\
\text { Alone } \\
\text { Cost }\end{array}$ & $\begin{array}{c}\text { Allocated } \\
\text { Cost }\end{array}$ & $\begin{array}{c}\text { Percent } \\
\text { Savings }\end{array}$ \\
\hline 1 & $\$ 15,040.00$ & $\$ 14,897.60$ & $0.95 \%$ & 26 & $\$ 1,548.80$ & $\$ 715.20$ & $53.82 \%$ \\
\hline 2 & $\$ 7,731.20$ & $\$ 7,731.20$ & $0.00 \%$ & 27 & $\$ 1,472.00$ & $\$ 2,042.13$ & $-38.73 \%$ \\
\hline 3 & $\$ 7,724.80$ & $\$ 7,724.80$ & $0.00 \%$ & 28 & $\$ 1,398.40$ & $\$ 1,454.67$ & $-4.02 \%$ \\
\hline 4 & $\$ 7,872.00$ & $\$ 7,872.00$ & $0.00 \%$ & 29 & $\$ 1,670.40$ & $\$ 1,367.20$ & $18.15 \%$ \\
\hline 5 & $\$ 7,206.40$ & $\$ 6,478.13$ & $10.11 \%$ & 30 & $\$ 5,875.20$ & $\$ 5,848.53$ & $0.45 \%$ \\
\hline 6 & $\$ 6,883.20$ & $\$ 4,864.80$ & $29.32 \%$ & 31 & $\$ 2,764.80$ & $\$ 2,443.20$ & $11.63 \%$ \\
\hline 7 & $\$ 6,886.40$ & $\$ 6,886.40$ & $0.00 \%$ & 32 & $\$ 2,704.00$ & $\$ 2,704.00$ & $0.00 \%$ \\
\hline 8 & $\$ 6,288.00$ & $\$ 6,288.00$ & $0.00 \%$ & 33 & $\$ 2,915.20$ & $\$ 2,888.80$ & $0.91 \%$ \\
\hline 9 & $\$ 13,228.80$ & $\$ 10,938.40$ & $17.31 \%$ & 34 & $\$ 2,790.40$ & $\$ 2,763.20$ & $0.97 \%$ \\
\hline 10 & $\$ 6,688.00$ & $\$ 6,688.00$ & $0.00 \%$ & 35 & $\$ 6,406.40$ & $\$ 6,353.07$ & $0.83 \%$ \\
\hline 11 & $\$ 7,008.00$ & $\$ 7,008.00$ & $0.00 \%$ & 36 & $\$ 6,848.00$ & $\$ 6,848.00$ & $0.00 \%$ \\
\hline 12 & $\$ 7,296.00$ & $\$ 3,981.33$ & $45.43 \%$ & 37 & $\$ 3,020.80$ & $\$ 3,101.60$ & $-2.67 \%$ \\
\hline 13 & $\$ 7,123.20$ & $\$ 6,801.60$ & $4.51 \%$ & 38 & $\$ 3,145.60$ & $\$ 3,145.60$ & $0.00 \%$ \\
\hline 14 & $\$ 7,168.00$ & $\$ 6,764.00$ & $5.64 \%$ & 39 & $\$ 3,040.00$ & $\$ 2,933.60$ & $3.50 \%$ \\
\hline 15 & $\$ 7,200.00$ & $\$ 6,945.87$ & $3.53 \%$ & 40 & $\$ 3,942.40$ & $\$ 2,950.40$ & $25.16 \%$ \\
\hline 16 & $\$ 13,088.00$ & $\$ 6,465.87$ & $50.60 \%$ & 41 & $\$ 3,328.00$ & $\$ 1,889.60$ & $43.22 \%$ \\
\hline 17 & $\$ 13,056.00$ & $\$ 10,765.60$ & $17.54 \%$ & 42 & $\$ 3,296.00$ & $\$ 2,776.53$ & $15.76 \%$ \\
\hline 18 & $\$ 14,368.00$ & $\$ 14,368.00$ & $0.00 \%$ & 43 & $\$ 4,016.00$ & $\$ 3,399.73$ & $15.35 \%$ \\
\hline 19 & $\$ 13,152.00$ & $\$ 11,053.33$ & $15.96 \%$ & 44 & $\$ 2,745.60$ & $\$ 1,792.27$ & $34.72 \%$ \\
\hline 20 & $\$ 6,032.00$ & $\$ 6,032.00$ & $0.00 \%$ & 45 & $\$ 3,424.00$ & $\$ 3,424.00$ & $0.00 \%$ \\
\hline 21 & $\$ 4,966.40$ & $\$ 2,541.60$ & $48.82 \%$ & 46 & $\$ 3,392.00$ & $\$ 1,953.60$ & $42.41 \%$ \\
\hline 22 & $\$ 1,654.40$ & $\$ 1,654.40$ & $0.00 \%$ & 47 & $\$ 3,488.00$ & $\$ 1,351.73$ & $61.25 \%$ \\
\hline 23 & $\$ 4,032.00$ & $\$ 3,858.40$ & $4.31 \%$ & 48 & $\$ 11,200.00$ & $\$ 11,200.00$ & $0.00 \%$ \\
\hline 24 & $\$ 1,600.00$ & $\$ 1,315.20$ & $17.80 \%$ & 49 & $\$ 5,696.00$ & $\$ 4,704.00$ & $17.42 \%$ \\
\hline 25 & $\$ 5,440.00$ & $\$ 5,266.40$ & $3.19 \%$ & 50 & $\$ 5,737.60$ & $\$ 5,737.60$ & $0.00 \%$ \\
\hline
\end{tabular}

\subsubsection{Stability of Model B}

As mentioned in the previous section, the marginal contribution cost allocations resulted in some shippers being allocated costs which are higher than their stand-alone costs. Shipper 21 has negative cost savings in Case 2 and shippers 27, 28 and 37 have negative cost savings in Case 3. A shipper can be allocated a higher cost than its stand-alone cost, and have negative cost savings, when it is contributes insignificantly to the collaborative cost savings of the loop it's 
involved. Because some shippers are allocated costs which are higher than their stand-alone costs, it can be concluded that marginal contribution allocation is not a stable allocation for Model B when using more than 4 arcs per loop. In cooperative game theory, a stable allocation means that no subset of the coalition can operate separately and experience lower costs than the costs when operating with the grand coalition. Model B does will not form loops that increase the objective value of the problem and, therefore, each loop has positive cost savings. In the 4 arcs per loop case, this means no shipper will be allocated a negative cost savings using marginal contribution allocation. This is not the situation, however, with cases involving more than $4 \operatorname{arcs}$ per loop.

To provide more insight into why some shippers are allocated higher costs than their stand-alone costs, a detailed cost analysis is provided for shipper 21 of Case 2. In loop 23 of Case 2, shippers 7, 10, and 21 are matched up together. Using the marginal contribution allocation, shipper 21 is allocated negative cost savings because shippers 7 and 10 will experience more savings if they operate separately from shipper 21 . Table 26 shows every possible combination of loop formation between these three shippers and the resulting allocated cost using marginal contribution allocation. They can form loops separately, two shippers can form a loop together, or all three shippers can form a single loop. When shippers 7 and 10 form a loop, their allocated costs are lower than if they would form a loop with shipper 21. Therefore, shippers 7 and 10 would prefer to operate without shipper 21, making the original 3-shipper loop unstable. Additional incentives will have to be developed to ensure the stability of this collaboration (Agarwal et al., 2010). 
TABLE 26 - Cost Analysis of Loop 23 for Case 2

\begin{tabular}{|c|c|c|c|c|}
\hline \multirow{2}{*}{$\begin{array}{c}\text { Potential } \\
\text { Loop } \\
\text { Formations }\end{array}$} & Loop Cost & \multicolumn{3}{|c|}{ Allocated Cost } \\
\cline { 3 - 5 } & & $\begin{array}{c}\text { Shipper } \\
\mathbf{7}\end{array}$ & $\begin{array}{c}\text { Shipper } \\
\mathbf{1 0}\end{array}$ & $\begin{array}{c}\text { Shipper } \\
\mathbf{2 1}\end{array}$ \\
\hline 7 & $\$ 6,886.40$ & $\$ 6,886.40$ & - & - \\
\hline 10 & $\$ 6,688.00$ & - & $\$ 6,688.00$ & \\
\hline 21 & $\$ 4,966.40$ & - & - & $\$ 4,966.40$ \\
\hline 7,10 & $\$ 6,976.00$ & $\$ 3,587.20$ & $\$ 3,388.80$ & - \\
\hline 10,21 & $\$ 11,497.60$ & - & $\$ 6,609.60$ & $\$ 4,888.00$ \\
\hline 7,21 & $\$ 8,364.80$ & $\$ 5,142.40$ & - & $\$ 3,222.40$ \\
\hline $7,10,21$ & $\$ 14,721.60$ & $\$ 3,984.53$ & $\$ 5,451.73$ & $\$ 5,285.33$ \\
\hline
\end{tabular}

\subsubsection{Cost Allocation Summary}

Table 27 summarizes the cost allocation mechanism applied to three cases of Model B results. Proportion allocation allocates the same percent cost savings to every shipper in the network. Marginal cost allocation allocates costs in each loop depending on each shipper's contribution to the overall loop cost savings. Proportional allocation by loop allocates the same percent cost savings to the shipper in the same loop. Marginal cost allocation is the only unstable allocation mechanism investigated in this report, as indicated by the negative cost savings. However, it is a more fair allocation methodology than proportion allocation. 
TABLE 27 Summary of Cost Allocations

\begin{tabular}{|l|c|c|c|c|c|c|c|}
\hline \multirow{2}{*}{$\begin{array}{c}\text { Allocation } \\
\text { Type }\end{array}$} & \multirow{2}{*}{ Case } & \multicolumn{3}{|c|}{ Allocated Cost } & \multicolumn{3}{c|}{ Allocated Percent Cost Savings } \\
\cline { 3 - 8 } & & Minimum & Maximum & Average & Minimum & Maximum & Average \\
\hline PA & 1 & $\$ 1,225.37$ & $\$ 13,178.62$ & $\$ 5,162.73$ & $12.4 \%$ & $12.4 \%$ & $12.4 \%$ \\
\hline PA & 2 & $\$ 1,224.56$ & $\$ 13,169.88$ & $\$ 5,159.30$ & $12.4 \%$ & $12.4 \%$ & $12.4 \%$ \\
\hline PA & 3 & $\$ 1,238.87$ & $\$ 260,979.46$ & $\$ 10,234.49$ & $11.4 \%$ & $11.4 \%$ & $11.4 \%$ \\
\hline PA by Loop & 1 & $\$ 1,314.00$ & $\$ 14,740.50$ & $\$ 5,162.72$ & $0.0 \%$ & $49.1 \%$ & $12.1 \%$ \\
\hline PA by Loop & 2 & $\$ 1,398.40$ & $\$ 15,040.00$ & $\$ 5,159.30$ & $0.0 \%$ & $34.7 \%$ & $11.1 \%$ \\
\hline PA by Loop & 3 & $\$ 1,118.40$ & $\$ 14,653.78$ & $\$ 5,219.57$ & $0.0 \%$ & $42.8 \%$ & $11.5 \%$ \\
\hline MC & 1 & $\$ 1,182.40$ & $\$ 14,782.40$ & $\$ 5,162.72$ & $0.0 \%$ & $49.6 \%$ & $12.7 \%$ \\
\hline MC & 2 & $\$ 1,312.80$ & $\$ 15,040.00$ & $\$ 5,159.30$ & $-6.4 \%$ & $65.1 \%$ & $12.7 \%$ \\
\hline MC & 3 & $\$ 715.20$ & $\$ 14,897.60$ & $\$ 5,219.58$ & $-38.7 \%$ & $61.2 \%$ & $11.5 \%$ \\
\hline
\end{tabular}

PA: Proportion allocation, PA by loop: Proportion allocation by loop, MC: Marginal contribution allocation

In this chapter the tabu search was presented to solve Model B. The example network was constructed using a real world freight network, with modified parameters. Assumptions were made where information was not provided. Numerical analysis was performed on the model using the example network to reveal potential cost savings of the collaboration framework B. Then computations were performed on the results to demonstrate proportion allocation, proportion allocation by loop and marginal contribution allocation mechanisms for Model B. 


\section{CHAPTER 7. CONCLUSIONS}

With expected increase in freight movement, a competitive trucking environment, and businesses' demand for timely delivery of products, there is a great need for more innovative solutions to improve efficiency and lower operation costs in truck transportation. There are increasing concerns to reduce the air pollutants that heavy trucks emit. Collaboration among trucking firms is a great way for the trucking industry to help accomplish these goals. Collaboration can improve truck operations by increasing efficiency and reducing empty truck movements. Reducing deadhead miles reduces the amount of pollutants that trucks emit and can greatly reduce costs of freight companies. When carriers or shippers form alliances they can collaborate their truck operations and change non-profitable empty hauls into profitable backhauls. Other benefits of collaboration include increased asset utilization, decreased lead times and improved service levels to customers.

In this thesis, collaboration scenarios are investigated to demonstrate how shippers or carriers can collaborate their operations to realize cost savings. Two frameworks are investigated. The first problem focuses on a carrier of interest wanting to collaborate with other carriers and/or shippers to reduce operating costs along its backhaul routes. The second problem's focus is how shippers can collaborate to form loops with their truckload lanes and submit their loops to a common carrier for better rates. The backhaul problem or Problem A, shows how a carrier can introduce collaboration into their operations without modification of its line haul routing. Only the backhaul route includes collaboration with other shippers and/or carriers. The loop model, or Problem B, is a full collaboration where all demand and capacities of the shipper network are taken into consideration and optimal routing is found. 
For Problem A, two formulations are presented to solve the backhaul routing under collaboration. Model A1 is formulated as an integer program and matches the carrier of interest's backhaul origins to either collaborator nodes or the depot node, while maximizing cost savings for the carrier of interests. Model A2 is formulated as a mixed integer program, minimizes the carrier of interest's transportation costs and routes the backhaul trucks to collaborator pick-up and delivery nodes where profitable, and then routes back to the depot node. One distinguishable difference between the models is that Model A1 allows each backhaul truck to fulfill at most one collaborator's shipping requests, while Model A2 allows more than one to be fulfilled.

The numerical analysis of the models using our example network reveal backhaul cost savings between $13 \%$ and $28 \%$. The original empty hauls to the depot are non-profitable trips and any savings for the carrier of interest is significant. Through computational runs, it was found that the arc transportation cost does not affect the percent cost savings of the solutions. The revenue percentage level, the percent transportation cost that the carrier of interest charges for delivering a collaborator's shipment, affects the results of the models. The higher the percent revenue, the more likely backhaul routes are matched with collaborators. Model A2 results show that the percent cost savings is greater than the Model A1 results. This is because Model A2 allows for each backhaul truck to fulfill more than one delivery task.

Problem B is a capacitated loop model and is formulated as a mixed integer program. One significant difference between this framework and the framework of Problem A is that this is a "full" collaboration, where the all shipper's points of view are taken into consideration. The problem consists of a group of collaborative shippers whose shipping lanes and truck capacities are taken in common to route trucks such that all shipping lanes are covered and all the demand 
is met. This is accomplished through the creation of loops, or cycles. The model assigns arcs to loops to accomplish the routing of trucks while minimizing the cost of the loops. Model B is solved by the tabu search heuristic because of its similarity to a VRP formulation. Tabu search does not provide optimal solutions to Model B, but provides good solutions in a reasonable amount of time. The results of the model showed between $7 \%$ and $12 \%$ network cost savings.

To allocate costs to the shippers involved in the collaboration of problem B, three allocation mechanisms were used. Proportion allocation distributes costs to the shippers evenly, weighted by each shipper's stand alone cost. This mechanism is easy to understand and easy to compute, but does not incorporate the contribution of each shipper to the collaboration. The results show that each shipper is allocated a cost which is less than the cost of that shipper operating separately. Also, proportion allocation was used to allocate costs by individual loops, depending on the collaborative cost of each loop. This resulted in each shipper being allocated a cost which is less than or equal to its stand-alone cost. The third allocation mechanism used was a marginal contribution cost allocation and uses the concepts of the Shapley value to allocate costs to shippers involved in a loop. The marginal contribution mechanism is more computationally difficult than the proportion allocation, but it considers the contribution of each shipper to a loop it participates.

\subsection{Future Research}

Areas of possible future research for the backhaul problem, Problem A, lie in developing a profit-sharing mechanism for the carrier of interest and the collaborative carriers/shippers. This could allow more insight on the collaborator's incentives to form partnerships with the carrier of interest. 
A potential area for development of Model B is a Shapley value allocation that incorporates the whole collaborative network. For larger sized networks, this is very computationally difficult but an approximation method that is less time consuming could possibly provide good results. In general, incentive mechanisms which ensure that everybody participating in the collaboration experience adequate cost savings have to be developed. This will ensure stability of the collaboration.

In this thesis also it was assumed that all the parameters such as demand, travel time and travel costs are time invariant and are known with certainty. In reality, such parameters are timedependent and are uncertain. Truck routes passing through urban areas are more likely to be affected by recurrent and non-recurrent congestion. Demand for goods may exhibit significant variations and uncertainties across seasons. More robust collaboration models should be developed which account for the time varying and stochastic travel time, travel costs and demands.

Another potential area for development is to develop models for evaluating potential for collaboration in more complex freight systems. The models developed in this thesis focus on relatively simple point to point pick-up and delivery systems. There is significant scope for extending the above models to more complex freight delivery systems including cross-docking and intermodal transportation. 


\section{REFERENCES}

Agarwal, R. and Ö. Ergun. Collaborative logistics in sea cargo industry. Informs Tomorrow, 2005. http://ormstomorrow.informs.org/archive/summerfall05/seacargo.pdf

Agarwal, R. and Ö. Ergun. Mechanism Design for a Multicommodity Flow Game in Service Network Alliances. Operational Research Letters, Vol. 36, No. 5, 2008, pp. 520-524.

Agarwal, R. and Ö. Ergun. Network Design and Allocation Mechanisms for Carrier Alliances in Liner Shipping. Operations Research, Vol. 58, No. 6, Nov-Dec 2010, pp. 1726-1742.

Arcelus, F.J., H.A. Eiselt and E.Y.H. Lin. Minimizing Empty Hauls in Multi-day, Multi-depot Trucking. International Transactions Operational Research, Vol. 5, No. 3, 1998, pp. 201-210.

ATA. American Trucking Activity Report, 2008. American Trucking Association. Accessed from http://www.truckline.com June 2011.

ATA. American Trucking Trends 2010. American Trucking Association, Inc, 2010. Accessed from http://www.atri-online.org/index.php?option=com_content\&view=article\&id=65 \&Itemid $=76$ on June 2011 .

Baita, F., W. Ukovich, R. Presenti, and D. Favaretto. Dynamic Routing and Inventory Problems: A Review. Transportation Research Part A, Vol 32, 1998, pp 585-598. 
Baldacci, R., Christodes, N., Mingozzi, A. An Exact Algorithm for the Vehicle Routing Problem based on the Set Partitioning Formulation with Additional Cuts. Mathematical Programming, Vol 115 (2), 2008, pp. 351-385.

Balinski, M., Quandt, R.. On an Integer Program for a Delivery Problem. Operations Research, Vol 12 (2), 1964, pp. 300-304.

Ball, M.O., B.L. Golden, A.A. Assad, and L.D. Bodin. Planning for Truck Fleet Size in the Presence of a Common-Carrier Option. Decision Sciences, Vol. 14, No.1, 1983, pp. 103120.

Brotcorne, L., M. Labbe, and G. Savard. A Bilevel Model and Solution Algorithm for a Freight Tariff Setting Problem. Transportation Science, Vol. 34 (3), August 2000, pp. 289-302.

Barbarosoglu, G. and D. Ozgur. A Tabu Search Algorithm for the Vehicle Routing Problem. Computers and Operations Research, Vol 26 (3), 1999, pp. 255-270.

Berger, S. and C. Bierwirth. Solutions to the Request Reassignment Problem in Collaborative Carrier Networks. Transportation Research Part E, Vol. 46, No. 5, 2010, pp. 627-638.

Bruenckner, J.K. The Benefits of Codesharing and Antitrust Immunity for International Passengers, with an Application to the Star Alliance. Journal of Air Transport Management, Vol. 9, 2003, pp. 83-89. 
Castro, J., D. Gómez, and J. Tejada. A Polynomial Rule for the Problem of Sharing Delay Costs in PERT Networks. Computers and Operations Research, Vol 35, 2008, pp. 2376-2387.

Castro, J., D. Gómez, and J. Tejada. Polynomial Calculation of the Shapley Value Based on Sampling. Computers and Operations Research, Vol. 36, 2009, pp. 1726-1730.

Christofides, N., Mingozzi, A., Toth, P.,. Exact Algorithms for the VehicleRouting Problem, based on Spanning Tree and Shortest Path Relaxations.Mathematical Programming, Vol $20(1), 1981,255-282$.

Chu, C.W. A Heuristic Algorithm for the Truckload and Less-than-Truckload Problem. European Journal of Operational Research, Vol. 165, 2005, pp. 657-667.

Clarke, C., Wright, J. Q. Scheduling of Vehicle from a Central Depot to a Number of Delivery Points. Operations Research Vol. 12 (4), 1964, pp. 568-581.

Cordeau, J.F.,M.Gendreau, and G. Laporte. A Tabu Search Heuristic for Periodic and Multidepot Vehicle Routing Problems. Networks, Vol 30(2), 1998, pp. 105-119

Crainic, T.G. Service Network Design in Freight Transportation. European Journal of Operations Research, Vol. 122, 2000, pp 272-288.

Dai, B. and H. Chen. Mathematical Model and Solution Approach for Collaborative Logistics in Less Than Truckload (LTL) Transportation. Computers and Industrial Engineering, 2009, pp. 767-772. 
Dantzig, G. and Ramser, J. The Truck Dispatching Problem. Management Science, Vol 6 (1), 1959, pp 80-91.

Dumas, Y., J. Desrosiers, F. Soumis. The Pick-up and Delivery Problem with Time Windows. European Journal of Operational Research, Vol. 54, 1991, pp. 7-22.

Eilon, S., Watson-Gandy, C., Christodes, N., de Neufville, R.,. Distribution Management Mathematical Modelling and Practical Analysis. Systems, Man and Cybernetics, IEEE Transactions on Vol. 4 (6), 1974, p. 589.

Engevall, S., M. Göthe-Lundgren, and P. Värbrand. The Traveling Salesman Game: An Application of Cost Allocation in a Gas and Oil Company. Annals of Operations Research, Vol 82, 1998, pp. 453-471.

EPA. Pollutants. U.S. Environmental Protection Agency, 2007. Accessed from http://www.epa.gov/otaq/invntory/overview/pollutants/index.htm on 27 May 2011

EPA. 2011 U.S. Greenhouse Gas Inventory Report. U.S. Environmental Protection Agency, \#430-R-11-005, 2011. Accessed from http://www.epa.gov/climatechange/emissions/usinventoryreport.html on 27 May 2011.

EPA. EPA and NHTSA Propose First-Ever Program to Reduce Greenhouse Gas Emissions and Improve Fuel Efficiency of Medium- and Heavy-Duty Vehicles: Regulatory Announcement. US Environmental Protection Agency, EPA-420-F-10-901, October 
2010. Accessed at http://www.epa.gov/oms/climate/regulations/420f10901.htm 27 May 2011.

Ergun, Ö., G. Kuyzu, and M. Savelsbergh. Reducing Truckload Transportation Costs Through Collaboration. Transportation Science, Vol. 41, No. 2, May 2007a, pp. 206-221.

Ergun, Ö., G. Kuyzu, and M. Savelsbergh. Shipper Collaboration. Computers and Operation Research, Vol. 34, No. 6, 2007b, pp. 1551-1560.

Fatima, S.S., M. Wooldridge, N. R. Jennings. A Linear Approximation Method for the Shapley Value. Artificial Intelligence Journal, Vol. 172 (14), 2008, pp. 1673-1699.

FHWA. Freight Facts and Figures 2010. Federal Highway Administration, U.S. Department of Transportation. Accessed May 2011 http://ops.fhwa.dot.gov/freight/freight_analysis/ nat_freight_stats/docs/10factsfigures/index.htm

Figliozzi, M.A. Analysis and Evaluation of Incentive Compatible Dynamic Mechanism for Carrier Collaboration. Transportation Research Record: Journal of the Transportation Research Board, No. 1996, Transportation Research Board of the National Academies, Washington, D.C., 2006, pp. 34-40.

Fisher, M. A Polynomial Algorithm for the Degree-Constrained Minimum k-tree Problem. Operations Research, Vol. 42 (4), 1994a, pp. 775-779. 
Fisher, M., Jaikumar, R., A Generalized Assignment Heuristic for Vehicle Routing. Networks, Vol 11 (2), 1981, pp. 109-124.

Fisher, M.. Optimal Solution of Vehicle Routing Problems using Minimum k-trees. Operations Research, Vol. 42 (4), 1994b, pp. 626-642.

Florian, M. and M. Los. A New Look at Static Spatial Price Equilibrium Models. Regional Science and Urban Economics, Vol 12. (4), 1982, pp. 579-597.

FMCSA. Hours-of-Service Regulations. Federal Motor Carrier Safety Administration, U.S Department of Transportation. Accessed from http://www.fmcsa.dot.gov/rulesregulations/topics/hos/index.htm on May 2010.

Friesz, T.L. and P.T. Harker. Prediction of Intercity Freight Flows, ii: Mathematical formulations. Transportation Research Part B, Vol 20B, 1986, pp 155-174.

Friesz, T.L., R.L. Tobin, T.E. Smith, and P.T. Harker. A Nonlinear Complementarity Formulation and Solution Procedure for the General Derived Demand Network Equilibrium Problem. Journal of Regional Science, Vol. 23 (3), 1983a, pp. 337-359.

Friesz, T.L., R.L. Tobin, and P.T. Harker. Predictive Intercity Freight Network Models. Transportation Research, Vol. 17 (6), 1983b, pp. 409-417.

Gendreau, M., A. Hertz and G. Laporte. A Tabu Search Heuristic for the Vehicle Routing Problem. Management Science, Vol 40(10), 1991, pp 1276-1290. 
Glover, F. Heuristic for Integer Programming Using Surrogate Constraints. Decision Sciences, Vol. 8, 1977, pp 156-166.

Glover, F. Tabu Search: A Tutorial. Interfaces, Vol. 20, Issue 4, 1990, pp. 74-94.

Goetschalckx , M., C. Jacon-Blecha. The Vehicle Routing Problem with Backhauls. European Journal of Operations Research, Vol. 42, 1989, pp. 39-51.

Gottfried, J.A. A Predictive Network Equilibrium Model for Application to Regional and National Freight Transportation Systems. Department of Civil Engineering, University of Pennsylvania, 1983.

Harker, P.T. and T.L. Friesz. Prediction of Intercity Freight Flows, i: Theory. Transportation Research Part B, Vol 20, 1986, pp 80-91.

Hernández, S. and S. Peeta. A Centralized Time-Dependent Multiple-Carrier Collaboration Problem for Less-than-Truckload Carriers. Transportation Research Board Annual Meeting 2011 Paper \#11-1045. CD-ROM. Transportation Research Board of the National Academies, Washington, D.C., 2011a

Hernández, S. and S. Peeta. A Less-Than-Truckload Carrier Collaboration Planning Problem under Dynamic Capacities. Article in press, corrected proof for Transportation Research Part E: Logistics and Transportation Review, $2011 \mathrm{~b}$. 
Hernández, S. and S. Peeta. Less-than-Truckload Static Single-Carrier Collaboration Problem. Transportation Research Board Annual Meeting 2010 Paper \#10-2574. CD-ROM. Transportation Research Board of the National Academies, Washington, D.C., 2010.

Houghtalen, L., Ö. Ergun, and J. Sokol. Designing Mechanisms for the Management of Carrier Alliances. Submitted to Management Science. Available at: http://www2.isye.gatech.edu/ oergun/publications/AirAlliance_MS.pdf , accessed in July 2010.

Ito, H. and D. Lee. Domestic Code Sharing, Alliances, and Airfares in the U.S. Airline Industry. The Journal of Law and Economics, The University of Chicago, Vol. 50, May 2007, pp. $355-380$.

Jordan, W. Truck Backhauling on Networks with Many Terminals. Transportation Research Part B, Vol. 21B, No. 3, 1987, pp. 183-193.

Krajewska, M.A., H. Kopfer, G. Laporte, S. Ropke, G. Zaccour. Horizontal Cooperation Among Freight Carriers: Request Allocation and Profit Sharing. Journal of the Operational Research Society, Vol. 59, 2008, pp. 1483-1491.

Laporte, G., Mercure, H., Nobert, Y. An Exact Algorithm for the Asymmetrical Capacitated Vehicle Routing Problem. Networks, Vol. 16 (1), 1986, pp. 33-46. 
Laporte, G., Semet, F. Classical Heuristics for the Capacitated VRP. In The Vehicle Routing Problem, Chapter 5, editors P. Toth and D. Vigo., 2002, pp. 109-128.

Lysgaard, J., Letchford, A., Eglese, R.. A New Branch-and-Cut Algorithm for the Capacitated Vehicle Routing Problem. Mathematical Programming, Vol. 100 (2), 2004, pp. 423-445.

Mingozzi, A. Giorgi, S., and Baldacci, R. An Exact Method for the Vehicle Routing Problem with Backhauls. Transportation Science, Vol. 33 (3), 1999, pp. 315-329.

Montane, F.A.T., R.D. Galvao. A tabu search algorithm for the vehicle routing problem with simultaneous pick-up and delivery service . Computers and Operations Research, Vol 33(3), 2006, pp 595-69.

Nagy, G. and S. Salhi. Heuristic algorithms for single and multiple depot vehicle routing problems with pickups and deliveries. European Journal of Operational Research, Vol. 162, 2005, pp. 126-141.

Osman, I. H. Metastrategy Simulated Annealing and Tabu Search Algorithms for the Vehicle Routing Problem. Annals of Operations Research, Vol 41 (4), 1993, pp 421-451.

Özener, O. Ö. and Ö. Ergun. Allocating Costs in a Collaborative Transportation Procurement Network. Transportation Science, Vol. 42, No. 2, May 2008, pp. 146-165.

Rodrigue, J.P., C. Comtois, and B. Slack. The Geography of Transport Systems. Routledge, New York, NY, 2009. 
SCAQMD. Multiple Air Toxics Exposure Study. South Coast Air Quality Management District, Diamond Bar, CA, 2000.

Semet, F. and E. Taillard. Solving Real-Life Vehicle Routing Problems Efficiently Using Tabu Search. Annals of Operations Research, Vol 41 (4), 1993, pp. 469-488.

Shapley, L.S. A Value for N-Persons Games. In Contributions to the Theory of Games, II, Annals of Mathematical Studies, Vol. 28, 1953, pp. 307-317.

Shoham, Y., and K. Leyton-Brown. Multiagent Systems: Algorithmic, Game-theoretic, and Logical Foundations. Cambridge University Press, New York, 2009.

Song, J. and A. Regan. An Auction Based Collaborative Carrier Network, CD-ROM, Transportation Research Board of the National Academies, Washington, D.C., 2004.

Taillard, É., P. Badeau, M. Gendreau, F. Guertin, J.-Y. Potvin. A tabu search heuristic for the vehicle routing problem with soft time windows. Transportation Science, Vol. 31, 1997 $170-186$.

Thompson, M., A. Conway, C. M. Walton, and A. Unnikrishnan. Reducing Heavy Truck Emissions: Survey of Regulations and Policies. Transportation Research Board Annual Meeting 2010 Paper \#10-2875. CD-ROM. Transportation Research Board of the National Academies, Washington, D.C., 2010. 
Toth, P. and D. Vigo. A heuristic algorithm for the symmetric and asymmetric vehicle routing problems with backhauls. European Journal of Operational Research, Vol. 113, 1999, pp. 528-543.

Toth, P. and D. Vigo. An Exact Algorithm for the Vehicle Routing Problem with Backhauls. Transportation Science, Vol. 31, 1997, pp. 372-385.

Toth, P. and D. Vigo, editors. The Vehicle Routing Problem. Vol. 9, SIAM Monographs on Discrete Mathematics and Applications, SIAM, Philadelphia, PA, 2001.

Unnikrishnan, A., V. Valsaraj, and S. T. Waller. Stochastic Shipper Carrier Network Design Problem. Networks and Spatial Economics, Volume 9(4), pp. 525-550, 2009.

US DOT. Freight Analysis Framework, 2010 Office of Freight Management and Operations, U.S. Department of Transportation. Access from http://ops.fhwa.dot.gov/freight/ freight_analysis/faf/index.htm on May 2011.

Voruganti, A., A. Unnikrishnan, and S.T.Waller. Modeling carrier collaboration in freight networks. Transportation Letters, Volume 3(1), pp. 51-61, 2011

Willard, J. Vehicle Routing Using r-Optimal Tabu Search. Dissertation. The Management School, Imperial College, London, 1989. 
Wren, A., Holliday, A. Computer Scheduling of Vehicles from One or More Depots to a Number of Delivery Points. Operational Research Quarterly, Vol 23 (3), 1972, pp 333-344.

Xu, N., C. Yu, L. Zhang, and P. Liu. Profit Allocation in Collaborative Less-Than-Truckload Carrier Alliance. Proceedings of the IEEE, International Conference on Automation and Logistics, Shenyang, China, August 2009.

Zhang, A., C. Lang, Y.V. Hui, and L. Leung. Intermodal Alliance and Rivalry of Transport Chains: The Air Cargo Market. Transportation Research Part E: Logistics and Transportation Review. Vol 43 (3), May 2007, pp. 234-246. 


\section{APPENDIX}

TABLE 28 Proportion Allocation by Loop for Case 1

\begin{tabular}{|c|c|c|c|c|c|c|}
\hline \multirow{2}{*}{$\begin{array}{l}\text { Loop } \\
\text { Number }\end{array}$} & \multicolumn{3}{|c|}{ Stand-Alone Cost } & \multirow{2}{*}{$\begin{array}{c}\text { Collaborative } \\
\text { Loop Cost }\end{array}$} & \multicolumn{2}{|c|}{ Allocated Cost } \\
\hline & Shipper A & Shipper B & Total & & Shipper A & Shipper B \\
\hline Loop 1 & $\$ 6,614.40$ & - & $\$ 6,614.40$ & $\$ 6,614.40$ & $\$ 6,614.40$ & - \\
\hline Loop 2 & $\$ 7,731.20$ & - & $\$ 7,731.20$ & $\$ 7,731.20$ & $\$ 7,731.20$ & - \\
\hline Loop 3 & $\$ 3,328.00$ & $\$ 7,296.00$ & $\$ 10,624.00$ & $\$ 8,555.20$ & $\$ 2,679.92$ & $\$ 5,875.28$ \\
\hline Loop 4 & $\$ 7,872.00$ & $\$ 6,614.40$ & $\$ 14,486.40$ & $\$ 8,004.80$ & $\$ 4,349.89$ & $\$ 3,654.91$ \\
\hline Loop 5 & $\$ 7,168.00$ & $\$ 3,040.00$ & $\$ 10,208.00$ & $\$ 9,622.40$ & $\$ 6,756.75$ & $\$ 2,865.65$ \\
\hline Loop 6 & $\$ 1,600.00$ & - & $\$ 1,600.00$ & $\$ 1,600.00$ & $\$ 1,600.00$ & - \\
\hline Loop 7 & $\$ 1,398.40$ & - & $\$ 1,398.40$ & $\$ 1,398.40$ & $\$ 1,398.40$ & - \\
\hline Loop 8 & $\$ 5,696.00$ & $\$ 7,520.00$ & $\$ 13,216.00$ & $\$ 12,894.40$ & $\$ 5,557.36$ & $\$ 7,337.04$ \\
\hline Loop 9 & $\$ 6,688.00$ & $\$ 7,184.00$ & $\$ 13,872.00$ & $\$ 9,094.40$ & $\$ 4,384.59$ & $\$ 4,709.81$ \\
\hline Loop 10 & $\$ 7,008.00$ & $\$ 6,883.20$ & $\$ 13,891.20$ & $\$ 8,843.20$ & $\$ 4,461.31$ & $\$ 4,381.89$ \\
\hline Loop 11 & $\$ 7,123.20$ & $\$ 7,200.00$ & $\$ 14,323.20$ & $\$ 7,289.60$ & $\$ 3,625.26$ & $\$ 3,664.34$ \\
\hline Loop 12 & $\$ 2,016.00$ & $\$ 1,472.00$ & $\$ 3,488.00$ & $\$ 3,113.60$ & $\$ 1,799.60$ & $\$ 1,314.00$ \\
\hline Loop 13 & $\$ 7,184.00$ & $\$ 1,548.80$ & $\$ 8,732.80$ & $\$ 8,000.00$ & $\$ 6,581.20$ & $\$ 1,418.80$ \\
\hline Loop 14 & $\$ 6,528.00$ & $\$ 6,528.00$ & $\$ 13,056.00$ & $\$ 13,056.00$ & $\$ 6,528.00$ & $\$ 6,528.00$ \\
\hline Loop 15 & $\$ 3,424.00$ & - & $\$ 3,424.00$ & $\$ 3,424.00$ & $\$ 3,424.00$ & - \\
\hline Loop 16 & $\$ 6,576.00$ & $\$ 6,576.00$ & $\$ 13,152.00$ & $\$ 13,152.00$ & $\$ 6,576.00$ & $\$ 6,576.00$ \\
\hline Loop 17 & $\$ 6,032.00$ & - & $\$ 6,032.00$ & $\$ 6,032.00$ & $\$ 6,032.00$ & - \\
\hline Loop 18 & $\$ 1,654.40$ & $\$ 6,288.00$ & $\$ 7,942.40$ & $\$ 7,856.00$ & $\$ 1,636.40$ & $\$ 6,219.60$ \\
\hline Loop 19 & $\$ 3,392.00$ & $\$ 3,424.00$ & $\$ 6,816.00$ & $\$ 5,372.80$ & $\$ 2,673.77$ & $\$ 2,699.03$ \\
\hline Loop 20 & $\$ 2,720.00$ & $\$ 2,720.00$ & $\$ 5,440.00$ & $\$ 5,440.00$ & $\$ 2,720.00$ & $\$ 2,720.00$ \\
\hline Loop 21 & $\$ 2,745.60$ & $\$ 7,206.40$ & $\$ 9,952.00$ & $\$ 9,243.20$ & $\$ 2,550.01$ & $\$ 6,693.19$ \\
\hline Loop 22 & $\$ 1,670.40$ & - & $\$ 1,670.40$ & $\$ 1,670.40$ & $\$ 1,670.40$ & - \\
\hline Loop 23 & $\$ 2,937.60$ & - & $\$ 2,937.60$ & $\$ 2,937.60$ & $\$ 2,937.60$ & - \\
\hline Loop 24 & $\$ 2,764.80$ & - & $\$ 2,764.80$ & $\$ 2,764.80$ & $\$ 2,764.80$ & - \\
\hline Loop 25 & $\$ 7,520.00$ & $\$ 4,966.40$ & $\$ 12,486.40$ & $\$ 12,292.80$ & $\$ 7,403.46$ & $\$ 4,889.34$ \\
\hline Loop 26 & $\$ 2,915.20$ & $\$ 2,704.00$ & $\$ 5,619.20$ & $\$ 2,936.00$ & $\$ 1,523.17$ & $\$ 1,412.83$ \\
\hline Loop 27 & $\$ 3,203.20$ & $\$ 3,203.20$ & $\$ 6,406.40$ & $\$ 6,406.40$ & $\$ 3,203.20$ & $\$ 3,203.20$ \\
\hline Loop 28 & $\$ 3,020.80$ & - & $\$ 3,020.80$ & $\$ 3,020.80$ & $\$ 3,020.80$ & - \\
\hline Loop 29 & $\$ 3,296.00$ & $\$ 6,886.40$ & $\$ 10,182.40$ & $\$ 9,334.40$ & $\$ 3,021.55$ & $\$ 6,312.85$ \\
\hline Loop 30 & $\$ 7,724.80$ & $\$ 2,016.00$ & $\$ 9,740.80$ & $\$ 9,649.60$ & $\$ 7,652.52$ & $\$ 1,997.08$ \\
\hline Loop 31 & $\$ 3,942.40$ & $\$ 3,145.60$ & $\$ 7,088.00$ & $\$ 6,256.00$ & $\$ 3,479.65$ & $\$ 2,776.35$ \\
\hline Loop 32 & $\$ 2,937.60$ & - & $\$ 2,937.60$ & $\$ 2,937.60$ & $\$ 2,937.60$ & - \\
\hline Loop 33 & $\$ 6,544.00$ & $\$ 6,544.00$ & $\$ 13,088.00$ & $\$ 13,088.00$ & $\$ 6,544.00$ & $\$ 6,544.00$ \\
\hline Loop 34 & $\$ 3,424.00$ & - & $\$ 3,424.00$ & $\$ 3,424.00$ & $\$ 3,424.00$ & - \\
\hline Loop 35 & $\$ 2,790.40$ & - & $\$ 2,790.40$ & $\$ 2,790.40$ & $\$ 2,790.40$ & - \\
\hline Loop 36 & $\$ 3,488.00$ & - & $\$ 3,488.00$ & $\$ 3,488.00$ & $\$ 3,488.00$ & - \\
\hline Loop 37 & $\$ 5,600.00$ & $\$ 5,600.00$ & $\$ 11,200.00$ & $\$ 11,200.00$ & $\$ 5,600.00$ & $\$ 5,600.00$ \\
\hline Loop 38 & $\$ 5,737.60$ & $\$ 4,016.00$ & $\$ 9,753.60$ & $\$ 7,601.60$ & $\$ 4,471.64$ & $\$ 3,129.96$ \\
\hline
\end{tabular}


TABLE 29 Proportion Allocation by Loop for Case 2

\begin{tabular}{|c|c|c|c|c|c|c|c|}
\hline \multirow[b]{2}{*}{ Loop } & \multicolumn{3}{|c|}{ Stand-Alone Cost } & \multirow{2}{*}{$\begin{array}{l}\text { Collaborative } \\
\text { Loop Cost }\end{array}$} & \multicolumn{3}{|c|}{ Allocated Cost } \\
\hline & $\begin{array}{c}\text { Shipper } \\
\text { A }\end{array}$ & $\begin{array}{c}\text { Shipper } \\
\text { B }\end{array}$ & $\begin{array}{c}\text { Shipper } \\
\text { C }\end{array}$ & & $\begin{array}{c}\text { Shipper } \\
\text { A }\end{array}$ & $\begin{array}{c}\text { Shipper } \\
\text { B }\end{array}$ & $\begin{array}{c}\text { Shipper } \\
\mathrm{C}\end{array}$ \\
\hline 1 & $7,520.00$ & $7,520.00$ & - & $\$ 15,040.00$ & $\$ 7,520.00$ & $\$ 7,520.00$ & - \\
\hline 2 & $7,724.80$ & - & - & $\$ 7,724.80$ & $\$ 7,724.80$ & - & - \\
\hline 3 & $7,206.40$ & - & - & $\$ 7,206.40$ & $\$ 7,206.40$ & - & - \\
\hline 4 & $6,883.20$ & - & - & $\$ 6,883.20$ & $\$ 6,883.20$ & - & - \\
\hline 5 & $6,614.40$ & $7,872.00$ & $7,731.20$ & $\$ 14,508.80$ & $\$ 4,319.41$ & $\$ 5,140.61$ & $\$ 5,048.77$ \\
\hline 6 & $7,200.00$ & - & - & $\$ 7,200.00$ & $\$ 7,200.00$ & - & - \\
\hline 7 & $4,016.00$ & $1,548.80$ & - & $\$ 5,182.40$ & $\$ 3,740.03$ & $\$ 1,442.37$ & - \\
\hline 8 & $7,123.20$ & $7,184.00$ & $7,184.00$ & $\$ 14,531.20$ & $\$ 4,816.37$ & $\$ 4,857.49$ & $\$ 4,857.49$ \\
\hline 9 & $3,040.00$ & $3,942.40$ & - & $\$ 6,035.20$ & $\$ 2,627.61$ & $\$ 3,407.59$ & - \\
\hline 10 & $1,654.40$ & $3,296.00$ & - & $\$ 4,267.20$ & $\$ 1,426.10$ & $\$ 2,841.10$ & - \\
\hline 11 & $6,528.00$ & $6,528.00$ & $7,296.00$ & $\$ 13,932.80$ & $\$ 4,468.95$ & $\$ 4,468.95$ & $\$ 4,994.77$ \\
\hline 12 & $6,288.00$ & - & - & $\$ 6,288.00$ & $\$ 6,288.00$ & - & - \\
\hline 13 & $6,576.00$ & $6,576.00$ & - & $\$ 13,152.00$ & $\$ 6,576.00$ & $\$ 6,576.00$ & - \\
\hline 14 & $2,016.00$ & $2,016.00$ & $6,614.40$ & $\$ 9,977.60$ & $\$ 1,889.36$ & $\$ 1,889.36$ & $\$ 6,198.88$ \\
\hline 15 & $1,600.00$ & $6,544.00$ & $6,544.00$ & $\$ 14,420.80$ & $\$ 1,570.86$ & $\$ 6,424.90$ & $\$ 6,424.90$ \\
\hline 16 & $5,600.00$ & $5,600.00$ & - & $\$ 11,200.00$ & $\$ 5,600.00$ & $\$ 5,600.00$ & - \\
\hline 17 & $1,398.40$ & - & - & $\$ 1,398.40$ & $\$ 1,398.40$ & - & - \\
\hline 18 & $2,937.60$ & $2,937.60$ & $3,145.60$ & $\$ 6,920.00$ & $\$ 2,253.50$ & $\$ 2,253.50$ & $\$ 2,413.07$ \\
\hline 19 & $2,704.00$ & $3,424.00$ & - & $\$ 5,368.00$ & $\$ 2,368.63$ & $\$ 2,999.37$ & - \\
\hline 20 & $2,915.20$ & $3,424.00$ & $3,424.00$ & $\$ 7,704.00$ & $\$ 2,300.34$ & $\$ 2,701.79$ & $\$ 2,701.79$ \\
\hline 21 & $2,790.40$ & - & - & $\$ 2,790.40$ & $\$ 2,790.40$ & - & - \\
\hline 22 & $3,203.20$ & $3,203.20$ & - & $\$ 6,406.40$ & $\$ 3,203.20$ & $\$ 3,203.20$ & - \\
\hline 23 & $6,688.00$ & $4,966.40$ & $6,886.40$ & $\$ 14,721.60$ & $\$ 5,310.38$ & $\$ 3,943.33$ & $\$ 5,467.90$ \\
\hline 24 & $3,020.80$ & - & - & $\$ 3,020.80$ & $\$ 3,020.80$ & - & - \\
\hline 25 & $7,168.00$ & $2,720.00$ & $2,720.00$ & $\$ 11,966.40$ & $\$ 6,803.26$ & $\$ 2,581.63$ & $\$ 2,581.63$ \\
\hline 26 & $1,670.40$ & - & - & $\$ 1,670.40$ & $\$ 1,670.40$ & - & - \\
\hline 27 & $3,328.00$ & - & - & $\$ 3,328.00$ & $\$ 3,328.00$ & - & - \\
\hline 28 & $7,008.00$ & $6,032.00$ & $3,488.00$ & $\$ 14,305.60$ & $\$ 6,065.72$ & $\$ 5,220.97$ & $\$ 3,019.05$ \\
\hline 29 & $3,392.00$ & $2,745.60$ & $2,764.80$ & $\$ 8,115.20$ & $\$ 3,092.05$ & $\$ 2,502.81$ & $\$ 2,520.34$ \\
\hline 30 & $5,696.00$ & - & - & $\$ 5,696.00$ & $\$ 5,696.00$ & - & - \\
\hline 31 & $5,737.60$ & $1,472.00$ & - & $\$ 7,003.20$ & $\$ 5,573.36$ & $\$ 1,429.84$ & - \\
\hline
\end{tabular}


TABLE 30 Proportion Allocation by Loop for Case 3 (Part 1)

\begin{tabular}{|c|c|c|c|c|}
\hline \multirow{2}{*}{ Loop } & \multicolumn{5}{|c|}{ Stand-Alone Cost } \\
\cline { 2 - 5 } & $\begin{array}{c}\text { Shipper } \\
\text { A }\end{array}$ & $\begin{array}{c}\text { Shipper } \\
\text { B }\end{array}$ & $\begin{array}{c}\text { Shipper } \\
\text { C }\end{array}$ & $\begin{array}{c}\text { Shipper } \\
\text { D }\end{array}$ \\
\hline 1 & $\$ 7,520.00$ & $\$ 7,520.00$ & $\$ 1,600.00$ & - \\
\hline 2 & $\$ 7,731.20$ & - & - & - \\
\hline 3 & $\$ 7,724.80$ & - & - & - \\
\hline 4 & $\$ 6,576.00$ & $\$ 6,576.00$ & $\$ 6,544.00$ & - \\
\hline 5 & $\$ 6,886.40$ & - & - & - \\
\hline 6 & $\$ 6,288.00$ & - & - & - \\
\hline 7 & $\$ 6,614.40$ & $\$ 6,614.40$ & $\$ 6,528.00$ & $\$ 6,528.00$ \\
\hline 8 & $\$ 6,688.00$ & - & - & - \\
\hline 9 & $\$ 7,008.00$ & - & - & - \\
\hline 10 & $\$ 1,472.00$ & $\$ 7,206.40$ & $\$ 7,296.00$ & $\$ 6,883.20$ \\
\hline 11 & $\$ 7,184.00$ & $\$ 7,184.00$ & - & - \\
\hline 12 & $\$ 7,200.00$ & $\$ 2,745.60$ & $\$ 7,168.00$ & $\$ 1,398.40$ \\
\hline 13 & $\$ 6,032.00$ & - & - & - \\
\hline 14 & $\$ 1,654.40$ & - & - & - \\
\hline 15 & $\$ 7,872.00$ & - & - & - \\
\hline 16 & $\$ 2,720.00$ & $\$ 2,720.00$ & $\$ 2,016.00$ & $\$ 2,016.00$ \\
\hline 17 & $\$ 1,548.80$ & $\$ 3,020.80$ & $\$ 1,670.40$ & - \\
\hline 18 & $\$ 4,966.40$ & $\$ 6,544.00$ & - & - \\
\hline 19 & $\$ 2,937.60$ & $\$ 2,937.60$ & $\$ 3,203.20$ & - \\
\hline 20 & $\$ 2,704.00$ & - & - & - \\
\hline 21 & $\$ 2,915.20$ & $\$ 2,790.40$ & $\$ 3,040.00$ & - \\
\hline 22 & $\$ 3,203.20$ & - & - & - \\
\hline 23 & $\$ 3,424.00$ & $\$ 3,424.00$ & - & - \\
\hline 24 & $\$ 3,145.60$ & - & - & - \\
\hline 25 & $\$ 7,123.20$ & $\$ 2,764.80$ & - & - \\
\hline 26 & $\$ 3,296.00$ & $\$ 3,488.00$ & $\$ 4,016.00$ & - \\
\hline 27 & $\$ 3,424.00$ & - & - & - \\
\hline 28 & $\$ 3,392.00$ & $\$ 3,328.00$ & - & - \\
\hline 29 & $\$ 5,600.00$ & $\$ 5,600.00$ & - & - \\
\hline 30 & $\$ 5,696.00$ & $\$ 3,942.40$ & - & - \\
\hline 31 & $\$ 5,737.60$ & - & - & - \\
\hline & & & & \\
\hline
\end{tabular}


TABLE 31 Proportion Allocation by Loop for Case 3 (Part 2)

\begin{tabular}{|c|c|c|c|c|c|}
\hline \multirow[b]{2}{*}{ Loop } & \multirow{2}{*}{$\begin{array}{l}\text { Collaborative } \\
\text { Loop Cost }\end{array}$} & \multicolumn{4}{|c|}{ Allocated Cost } \\
\hline & & $\begin{array}{c}\text { Shipper } \\
\text { A }\end{array}$ & $\begin{array}{c}\text { Shipper } \\
\text { B }\end{array}$ & $\begin{array}{c}\text { Shipper } \\
\text { C }\end{array}$ & $\begin{array}{c}\text { Shipper } \\
\text { D }\end{array}$ \\
\hline 1 & $\$ 16,212.80$ & $\$ 7,326.89$ & $\$ 7,326.89$ & $\$ 1,558.86$ & - \\
\hline 2 & $\$ 7,731.20$ & $\$ 7,731.20$ & - & - & - \\
\hline 3 & $\$ 7,724.80$ & $\$ 7,724.80$ & - & - & - \\
\hline 4 & $\$ 13,400.00$ & $\$ 4,473.86$ & $\$ 4,473.86$ & $\$ 4,452.15$ & - \\
\hline 5 & $\$ 6,886.40$ & $\$ 6,886.40$ & - & - & - \\
\hline 6 & $\$ 6,288.00$ & $\$ 6,288.00$ & - & - & - \\
\hline 7 & $\$ 21,704.00$ & $\$ 5,461.59$ & $\$ 5,461.59$ & $\$ 5,390.41$ & $\$ 5,390.41$ \\
\hline 8 & $\$ 6,688.00$ & $\$ 6,688.00$ & - & - & - \\
\hline 9 & $\$ 7,008.00$ & $\$ 7,008.00$ & - & - & - \\
\hline 10 & $\$ 17,366.40$ & $\$ 1,118.40$ & $\$ 5,475.10$ & $\$ 5,543.18$ & $\$ 5,229.54$ \\
\hline 11 & $\$ 14,368.00$ & $\$ 7,184.00$ & $\$ 7,184.00$ & - & - \\
\hline 12 & $\$ 16,956.80$ & $\$ 6,595.18$ & $\$ 2,514.86$ & $\$ 6,565.84$ & $\$ 1,280.92$ \\
\hline 13 & $\$ 6,032.00$ & $\$ 6,032.00$ & - & - & - \\
\hline 14 & $\$ 1,654.40$ & $\$ 1,654.40$ & - & - & - \\
\hline 15 & $\$ 7,872.00$ & $\$ 7,872.00$ & - & - & - \\
\hline 16 & $\$ 9,124.80$ & $\$ 2,620.28$ & $\$ 2,620.28$ & $\$ 1,942.12$ & $\$ 1,942.12$ \\
\hline 17 & $\$ 5,184.00$ & $\$ 1,286.72$ & $\$ 2,509.57$ & $\$ 1,387.70$ & - \\
\hline 18 & $\$ 6,660.80$ & $\$ 2,873.94$ & $\$ 3,786.86$ & - & - \\
\hline 19 & $\$ 8,998.40$ & $\$ 2,911.70$ & $\$ 2,911.70$ & $\$ 3,175.00$ & - \\
\hline 20 & $\$ 2,704.00$ & $\$ 2,704.00$ & & - & - \\
\hline 21 & $\$ 8,585.60$ & $\$ 2,861.84$ & $\$ 2,739.32$ & $\$ 2,984.35$ & - \\
\hline 22 & $\$ 3,203.20$ & $\$ 3,203.20$ & - & - & - \\
\hline 23 & $\$ 6,848.00$ & $\$ 3,424.00$ & $\$ 3,424.00$ & - & - \\
\hline 24 & $\$ 3,145.60$ & $\$ 3,145.60$ & - & - & - \\
\hline 25 & $\$ 9,244.80$ & $\$ 6,659.86$ & $\$ 2,584.94$ & - & - \\
\hline 26 & $\$ 7,528.00$ & $\$ 2,297.47$ & $\$ 2,431.24$ & $\$ 2,799.29$ & - \\
\hline 27 & $\$ 3,424.00$ & $\$ 3,424.00$ & - & - & - \\
\hline 28 & $\$ 3,843.20$ & $\$ 1,939.89$ & $\$ 1,903.31$ & - & - \\
\hline 29 & $\$ 11,200.00$ & $\$ 5,600.00$ & $\$ 5,600.00$ & - & - \\
\hline 30 & $\$ 7,654.40$ & $\$ 4,523.52$ & $\$ 3,130.88$ & - & - \\
\hline 31 & $\$ 5,737.60$ & $\$ 5,737.60$ & - & - & - \\
\hline
\end{tabular}


TABLE 32 Marginal Contribution Cost Allocation Results for Case 1

\begin{tabular}{|c|c|c|c|c|}
\hline \multirow{2}{*}{ Loop } & \multirow{2}{*}{$\begin{array}{c}\text { Number of Shippers } \\
\text { in Loop }\end{array}$} & \multirow{2}{*}{$\begin{array}{l}\text { Collaborative } \\
\text { Cost Of Loop }\end{array}$} & \multicolumn{2}{|c|}{ Allocated Cost } \\
\hline & & & Shipper A & Shipper B \\
\hline 1 & 1 & $\$ 6,614.40$ & $\$ 6,614.40$ & - \\
\hline 2 & 1 & $\$ 7,731.20$ & $\$ 7,731.20$ & - \\
\hline 3 & 2 & $\$ 8,555.20$ & $\$ 2,293.60$ & $\$ 6,261.60$ \\
\hline 4 & 2 & $\$ 8,004.80$ & $\$ 4,631.20$ & $\$ 3,373.60$ \\
\hline 5 & 2 & $\$ 9,622.40$ & $\$ 6,875.20$ & $\$ 2,747.20$ \\
\hline 6 & 1 & $\$ 1,600.00$ & $\$ 1,600.00$ & - \\
\hline 7 & 1 & $\$ 1,398.40$ & $\$ 1,398.40$ & - \\
\hline 8 & 2 & $\$ 12,894.40$ & $\$ 5,535.20$ & $\$ 7,359.20$ \\
\hline 9 & 2 & $\$ 9,094.40$ & $\$ 4,299.20$ & $\$ 4,795.20$ \\
\hline 10 & 2 & $\$ 8,843.20$ & $\$ 4,484.00$ & $\$ 4,359.20$ \\
\hline 11 & 2 & $\$ 7,289.60$ & $\$ 3,606.40$ & $\$ 3,683.20$ \\
\hline 12 & 2 & $\$ 3,113.60$ & $\$ 1,828.80$ & $\$ 1,284.80$ \\
\hline 13 & 2 & $\$ 8,000.00$ & $\$ 6,817.60$ & $\$ 1,182.40$ \\
\hline 14 & 2 & $\$ 13,056.00$ & $\$ 6,528.00$ & $\$ 6,528.00$ \\
\hline 15 & 1 & $\$ 3,424.00$ & $\$ 3,424.00$ & - \\
\hline 16 & 2 & $\$ 13,152.00$ & $\$ 6,576.00$ & $\$ 6,576.00$ \\
\hline 17 & 1 & $\$ 6,032.00$ & $\$ 6,032.00$ & - \\
\hline 18 & 2 & $\$ 7,856.00$ & $\$ 1,611.20$ & $\$ 6,244.80$ \\
\hline 19 & 2 & $\$ 5,372.80$ & $\$ 2,670.40$ & $\$ 2,702.40$ \\
\hline 20 & 2 & $\$ 5,440.00$ & $\$ 2,720.00$ & $\$ 2,720.00$ \\
\hline 21 & 2 & $\$ 9,243.20$ & $\$ 2,391.20$ & $\$ 6,852.00$ \\
\hline 22 & 1 & $\$ 1,670.40$ & $\$ 1,670.40$ & - \\
\hline 23 & 1 & $\$ 2,937.60$ & $\$ 2,937.60$ & - \\
\hline 24 & 1 & $\$ 2,764.80$ & $\$ 2,764.80$ & - \\
\hline 25 & 2 & $\$ 12,292.80$ & $\$ 7,423.20$ & $\$ 4,869.60$ \\
\hline 26 & 2 & $\$ 2,936.00$ & $\$ 1,573.60$ & $\$ 1,362.40$ \\
\hline 27 & 2 & $\$ 6,406.40$ & $\$ 3,203.20$ & $\$ 3,203.20$ \\
\hline 28 & 1 & $\$ 3,020.80$ & $\$ 3,020.80$ & - \\
\hline 29 & 2 & $\$ 9,334.40$ & $\$ 2,872.00$ & $\$ 6,462.40$ \\
\hline 30 & 2 & $\$ 9,649.60$ & $\$ 7,679.20$ & $\$ 1,970.40$ \\
\hline 31 & 2 & $\$ 6,256.00$ & $\$ 3,526.40$ & $\$ 2,729.60$ \\
\hline 32 & 1 & $\$ 2,937.60$ & $\$ 2,937.60$ & - \\
\hline 33 & 2 & $\$ 13,088.00$ & $\$ 6,544.00$ & $\$ 6,544.00$ \\
\hline 34 & 1 & $\$ 3,424.00$ & $\$ 3,424.00$ & - \\
\hline 35 & 1 & $\$ 2,790.40$ & $\$ 2,790.40$ & - \\
\hline 36 & 1 & $\$ 3,488.00$ & $\$ 3,488.00$ & - \\
\hline 37 & 2 & $\$ 11,200.00$ & $\$ 5,600.00$ & $\$ 5,600.00$ \\
\hline 38 & 2 & $\$ 7,601.60$ & $\$ 4,661.60$ & $\$ 2,940.00$ \\
\hline
\end{tabular}


TABLE 33 Marginal Contribution Cost Allocation Results for Case 2

\begin{tabular}{|c|c|c|c|c|c|}
\hline \multirow{2}{*}{ Loop } & \multirow{2}{*}{$\begin{array}{l}\text { Number of } \\
\text { Shippers } \\
\text { in Loop }\end{array}$} & \multirow{2}{*}{$\begin{array}{l}\text { Collaborative } \\
\text { Cost Of Loop }\end{array}$} & \multicolumn{3}{|c|}{ Allocated Cost } \\
\hline & & & Shipper A & Shipper B & Shipper C \\
\hline 1 & 2 & $\$ 15,040.00$ & $\$ 7,520.00$ & $\$ 7,520.00$ & - \\
\hline 2 & 1 & $\$ 7,724.80$ & $\$ 7,724.80$ & - & - \\
\hline 3 & 1 & $\$ 7,206.40$ & $\$ 7,206.40$ & - & - \\
\hline 4 & 1 & $\$ 6,883.20$ & $\$ 6,883.20$ & - & - \\
\hline 5 & 3 & $\$ 14,508.80$ & $\$ 5,534.13$ & $\$ 2,937.33$ & $\$ 6,037.33$ \\
\hline 6 & 1 & $\$ 7,200.00$ & $\$ 7,200.00$ & - & - \\
\hline 7 & 2 & $\$ 5,182.40$ & $\$ 3,824.80$ & $\$ 1,357.60$ & - \\
\hline 8 & 3 & $\$ 14,531.20$ & $\$ 2,483.20$ & $\$ 6,024.00$ & $\$ 6,024.00$ \\
\hline 9 & 2 & $\$ 6,035.20$ & $\$ 2,566.40$ & $\$ 3,468.80$ & - \\
\hline 10 & 2 & $\$ 4,267.20$ & $\$ 1,312.80$ & $\$ 2,954.40$ & - \\
\hline 11 & 3 & $\$ 13,932.80$ & $\$ 5,458.13$ & $\$ 5,458.13$ & $\$ 3,016.53$ \\
\hline 12 & 1 & $\$ 6,288.00$ & $\$ 6,288.00$ & - & - \\
\hline 13 & 2 & $\$ 13,152.00$ & $\$ 6,576.00$ & $\$ 6,576.00$ & - \\
\hline 14 & 3 & $\$ 9,977.60$ & $\$ 1,904.53$ & $\$ 1,904.53$ & $\$ 6,168.53$ \\
\hline 15 & 3 & $\$ 14,420.80$ & $\$ 1,421.87$ & $\$ 6,499.47$ & $\$ 6,499.47$ \\
\hline 16 & 2 & $\$ 11,200.00$ & $\$ 5,600.00$ & $\$ 5,600.00$ & - \\
\hline 17 & 1 & $\$ 1,398.40$ & $\$ 1,398.40$ & - & - \\
\hline 18 & 3 & $\$ 6,920.00$ & $\$ 2,587.47$ & $\$ 2,587.47$ & $\$ 1,745.07$ \\
\hline 19 & 2 & $\$ 5,368.00$ & $\$ 2,324.00$ & $\$ 2,324.00$ & - \\
\hline 20 & 3 & $\$ 7,704.00$ & $\$ 1,542.40$ & $\$ 3,080.80$ & $\$ 3,080.80$ \\
\hline 21 & 1 & $\$ 2,790.40$ & $\$ 2,790.40$ & - & - \\
\hline 22 & 2 & $\$ 6,406.40$ & $\$ 3,203.20$ & $\$ 3,203.20$ & - \\
\hline 23 & 3 & $\$ 14,721.60$ & $\$ 5,451.73$ & $\$ 5,285.30$ & $\$ 3,984.53$ \\
\hline 24 & 1 & $\$ 3,020.80$ & $\$ 3,020.80$ & - & - \\
\hline 25 & 3 & $\$ 11,966.40$ & $\$ 6,740.27$ & $\$ 2,613.07$ & $\$ 2,613.07$ \\
\hline 26 & 1 & $\$ 1,670.40$ & $\$ 1,670.40$ & - & - \\
\hline 27 & 1 & $\$ 3,328.00$ & $\$ 3,328.00$ & - & - \\
\hline 28 & 3 & $\$ 14,305.60$ & $\$ 6,274.93$ & $\$ 5,842.93$ & $\$ 2,187.73$ \\
\hline 29 & 3 & $\$ 8,115.20$ & $\$ 3,279.47$ & $\$ 2,599.47$ & $\$ 2,236.27$ \\
\hline 30 & 1 & $\$ 5,696.00$ & $\$ 5,696.00$ & - & - \\
\hline 31 & 2 & $\$ 7,003.20$ & $\$ 5,634.40$ & $\$ 1,368.80$ & - \\
\hline
\end{tabular}


TABLE 34 Marginal Contribution Cost Allocation Results for Case 3

\begin{tabular}{|c|c|c|c|c|c|c|}
\hline \multirow{2}{*}{ Loop } & \multirow{2}{*}{$\begin{array}{c}\text { Number } \\
\text { of } \\
\text { Shippers } \\
\text { in Loop }\end{array}$} & \multirow{2}{*}{$\begin{array}{c}\text { Cost Of } \\
\text { Loop }\end{array}$} & \multicolumn{4}{|c|}{ Allocated Cost } \\
\hline & & & Shipper A & Shipper B & Shipper C & Shipper D \\
\hline 1 & 3 & $\$ 16,212.80$ & $\$ 7,448.80$ & $\$ 7,448.80$ & $\$ 1,315.20$ & - \\
\hline 2 & 1 & $\$ 7,731.20$ & $\$ 7,731.20$ & - & - & - \\
\hline 3 & 1 & $\$ 7,724.80$ & $\$ 7,724.80$ & - & - & - \\
\hline 4 & 3 & $\$ 13,400.00$ & $\$ 5,526.67$ & $\$ 5,526.67$ & $\$ 2,346.67$ & - \\
\hline 5 & 1 & $\$ 6,886.40$ & $\$ 6,886.40$ & - & - & - \\
\hline 6 & 1 & $\$ 6,288.00$ & $\$ 6,288.00$ & - & - & - \\
\hline 7 & 4 & $\$ 21,704.00$ & $\$ 5,469.20$ & $\$ 5,469.20$ & $\$ 5,382.80$ & $\$ 5,382.80$ \\
\hline 8 & 1 & $\$ 6,688.00$ & $\$ 6,688.00$ & - & - & - \\
\hline 9 & 1 & $\$ 7,008.00$ & $\$ 7,008.00$ & - & - & - \\
\hline 10 & 4 & $\$ 17,366.40$ & $\$ 2,042.13$ & $\$ 6,478.13$ & $\$ 3,981.33$ & $\$ 4,864.80$ \\
\hline 11 & 2 & $\$ 14,368.00$ & $\$ 7,184.00$ & $\$ 7,184.00$ & - & - \\
\hline 12 & 4 & $\$ 16,956.80$ & $\$ 6,945.87$ & $\$ 1,792.27$ & $\$ 6,764.00$ & $\$ 1,454.67$ \\
\hline 13 & 1 & $\$ 6,032.00$ & $\$ 6,032.00$ & - & - & - \\
\hline 14 & 1 & $\$ 1,654.40$ & $\$ 1,654.40$ & - & - & - \\
\hline 15 & 1 & $\$ 7,872.00$ & $\$ 7,872.00$ & - & - & - \\
\hline 16 & 4 & $\$ 9,124.80$ & $\$ 2,633.20$ & $\$ 2,633.20$ & $\$ 1,929.20$ & $\$ 1,929.20$ \\
\hline 17 & 3 & $\$ 5,184.00$ & $\$ 715.20$ & $\$ 3,101.60$ & $\$ 1,367.20$ & - \\
\hline 18 & 2 & $\$ 6,660.80$ & $\$ 2,541.60$ & $\$ 4,119.20$ & - & - \\
\hline 19 & 3 & $\$ 8,998.40$ & $\$ 2,924.27$ & $\$ 2,924.27$ & $\$ 3,149.87$ & - \\
\hline 20 & 1 & $\$ 2,704.00$ & $\$ 2,704.00$ & - & - & - \\
\hline 21 & 3 & $\$ 8,585.60$ & $\$ 2,888.80$ & $\$ 2,763.20$ & $\$ 2,933.60$ & - \\
\hline 22 & 1 & $\$ 3,203.20$ & $\$ 3,203.20$ & - & - & - \\
\hline 23 & 2 & $\$ 6,848.00$ & $\$ 3,424.00$ & $\$ 3,424.00$ & - & - \\
\hline 24 & 1 & $\$ 3,145.60$ & $\$ 3,145.60$ & - & - & - \\
\hline 25 & 2 & $\$ 9,244.80$ & $\$ 6,801.60$ & $\$ 2,443.20$ & - & - \\
\hline 26 & 3 & $\$ 7,528.00$ & $\$ 2,776.53$ & $\$ 1,351.73$ & $\$ 3,399.73$ & - \\
\hline 27 & 1 & $\$ 3,424.00$ & $\$ 3,424.00$ & - & - & - \\
\hline 28 & 2 & $\$ 3,843.20$ & $\$ 1,953.60$ & $\$ 1,889.60$ & - & - \\
\hline 29 & 2 & $\$ 11,200.00$ & $\$ 5,600.00$ & $\$ 5,600.00$ & - & - \\
\hline 30 & 2 & $\$ 7,654.40$ & $\$ 4,704.00$ & $\$ 2,950.40$ & - & - \\
\hline 31 & 1 & $\$ 5,737.60$ & $\$ 5,737.60$ & - & - & - \\
\hline
\end{tabular}

